\title{
MASTER
}

\section{GEOSCIENCES PROGRAM}

\author{
ANNUAL REPORT 1978
}




\section{DISCLAIMER}

This report was prepared as an account of work sponsored by an agency of the United States Government. Neither the United States Government nor any agency Thereof, nor any of their employees, makes any warranty, express or implied, or assumes any legal liability or responsibility for the accuracy, completeness, or usefulness of any information, apparatus, product, or process disclosed, or represents that its use would not infringe privately owned rights. Reference herein to any specific commercial product, process, or service by trade name, trademark, manufacturer, or otherwise does not necessarily constitute or imply its endorsement, recommendation, or favoring by the United States Government or any agency thereof. The views and opinions of authors expressed herein do not necessarily state or reflect those of the United States Government or any agency thereof. 


\section{DISCLAIMER}

Portions of this document may be illegible in electronic image products. Images are produced from the best available original document. 


\section{GEOSCIENCES PROGRAM ANNUAL REPORT 1978}

This book was prepared as an account of work sponsored by an mency of the Unitect States Government. Neither the United States Government nor any agency thereot, nor any of their employees, maxes any

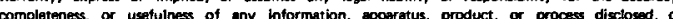
resresents that its use would not Infringe privetely owned rights Reforence herein to anv soecific commercial product, process or arvice by trade name, itrodemark, manufactures, or otherwise, toes not necossarly constitute or imply its endorsement, recommendation, of fworing by the Unired States Government or any agency thereot. The viows and opinions of wuthors expressed herein do not necesssarly state or reflect those of the United States Government or any mencey thereof.

. 


\section{CONTENTS}

\section{INTRODUCTION 1}

A NOTE ON THE MEANING OF STORAGE COEFFICIENT 2

T. N. Narasimhan and B. Y. Kanehiro

SIGNIFICANCE OF THE STORAGE PARAMETER IN SATURATED-UNSATURATED

GROUNDWATER FLOW 4

T. N. Narasimhan

USE OF AQUIFER RESPONSE TO EARTH TIDES AS A MEANS OF

DETERMINING AQUIFER CHARACTERISTICS 7

T. N. Narasimhan and B. Y. Kanehiro

PRELIMINARY ANALYSIS OF TIDAL DATA 9

B. Y. Kanehiro, T. N. Narasimhan, and C. F. Tsang

BEHAVIOR OF ROCK-FLUID SYSTEMS AT ELEVATED PRESSURES

AND TEMPERATURES 10

W. H. Somerton, A. Ghaffari, R. Greenwald, V. Hoang, F. Martínez-Baez, H. J. Su, and L. Wong

THERMODYNAMICS OF HIGH-TEMPERATURE BRINES 14

K. S. Pitzer, D. J. Bradley, P. Z. Rogers, and J. C. Peiper

SOLUBILITY OF ALBITE IN THE AQUEOUS PHASE AT ELEVATED TEMPERATURES 16

J. M. Neil and J. A. Apps

THERMODYNAMIC PROPERTIES OF SILICATE MATERIALS 21

I. S. E. Carmichael, M. S. Ghiorso, L. Moret, and S. A. Nelson

DEVELOPMENT OF A DATA BASE FOR AQUEOUS SOLUTIONS 24

R. J. Otto, H. Ozbek, and S. L. Phillips

KINETICS OF PRECIPITATION OF AMORPHOUS SILICA FROM AQUEOUS SOLUTION 25

$O$. Weres, A. Yee, and L. Tsao

ENHANCED OIL RECOVERY WITH MOBILITY AND REACTIVE TENSION AGENTS

C. J. Radke and W. H. Somerton

URANIUM IN ALKALINE ROCKS 36

B. Strisower, H. A. Wollenberg, M. Murphy, H. R. Bowman, S. Flexser, and I. S. E. Carmichael

GEODOSE PROJECT 41

H. A. Wollenberg and B. Strisower

THERMAL EFFECTS IN OVERLYING SEDIMENTARY ROCK FROM IN-SITU

COMBUSTION OF A COAL SEAM 43

D. C. Mangold, H. A. Wollenberg, and C. F. Tsang

FOUR-CHANNEL. SIMULTANEOUS COLLECTION SYSTEM FOR HIGH-PRECISION

MASS SPECTROMETRY 45

M. C. Michel, D. F. Mosier, and W. R. Keyes

DETERMINATION OF THE PROPERTIES OF SOILS BY IN-SITU MEASUREMENTS

W. C. B. Villet and J. K. Mitchell

STATISTICAL ANALYSIS OF THE CORRELATION OF EARTHQUAKES WITH RADON

CONCENTRATION IN WATER FROM SHALLOW WELLS NEAR OROVILLE, CALIFORNIA 49

B. Berlin 
$\bullet$ 
This report is a reprint of the Geosciences section of the Lawrence Berkeley taboratory's Earth Sciences Division Annual Report 1978 (LBL

8648). The organization of the Geosciences Program, its funding sources, and the papers submitted by each group are shown in the table below.

Project title/Principal investigator

Report title/Author

FUNDING BY DIVISION OF BASIC ENERGY SCIENCES (DOE)

Geosciences Applied Energy Technologies

P. A. WITHERSPOON

Reservoir dynamics. C. F. TSANG

Properties and behavior of rock-fluid systems at high temperatures and pressures. W. H. SOMERTON

Thermodynamics of high temperature brines, K. S. PITZER

Geochemistry and mass transfer in geothermal systems. J. A. APPS

Thermodynamic properties of silicate materials. I. S. E. CARMICHAEL

National geothermal information resource (GRID). S. L. PHILLIPS

A note on the meaning of storage coefficient. T. N. NARASIMHAN and $B$. Y. KANEHIRO

Significance of the storage parameter in saturated-unsaturated groundwater flow. T. N. NARASIMHAN

Use of aquifer response to earth tides as a means of determining aquifer characteristics. T. N. NARASIMHAN and B. Y. KANEHIRO

Preliminary analysis of tidal data. B. Y. KANEHIRO, T. N. NARASIMHAN, and C. F. TSANG

Behavior of rock-fluid systems at elevated pressures and temperatures. W. H. SOMERTON, A. GHAFFARI , R. GREENWALD, V. HOANG, F. MART INEZBAEZ, H. J. SU, and L. WONG

Thermodynamics of high-temperature brines. K. S. PITZER, D. J. BRADLEY, P. Z. ROGERS, and J. C. PEIPER

Solubility of albite in the aqueous phase at elevated temperatures. J. M. NEIL and J. A. APPS

Thermodynamic properties of silicate materials. I. S. E. CARMICHAEL, M. S. GHIORSO, L. MORET, and S. A. NELSON

Development of a data base for aqueous solutions. R. J. OTTO, H. OZBEK, and S. L. PHILLIPS 


\section{(contịnued)}

FUNDING BY DIVISION OF GEOTHERMAL ENERGY (DOE)

Geochemical Engineering
J. A. APPS
Kinetics of precipitation of amorphous silica from aqueous solution. 0 . WERES, A. YEE, and L. TSAO

\section{GEOSCIENCES FUNDING BY DIVISION OF FOSSIL FUEL EXTRACTION (DOE)}

Enhanced 0 il Recovery with Mobility and Reactive Tension Agents.
Enhanced oil recovery with mobility and reactive tension agents.

C. J. RADKE and W. H. SOMERTON

FUNDING BY BENDIX FIELD ENGINEERING CORP.

Uranium in Alkaline Rocks

Uranium in alkaline rocks.

B. STRISOWER, H. A. WOLLENBERG, M. MURPHY, H. R. BOWMAN, S. FLEXSER, and I. S. E. CARMICHAEL

FUNDING BY E. G. AND G. INC.

Support of the Aerial Measurements

System Program.
Geodose project. H. A. WOLLENBERG and $B$. STRISOWER

Thermal effects in overlying sedimentary rock from in-situ combustion of a coal seam. D. C. MANGOLD, H. A. WOLLENBERG, and C. F. TSANG

\section{GEOSCIENCES - FUNDING BY DIRECTOR'S DEVELOPMENT FUNDS}

High resolution mass spectrometry. M. C. MICHEL

In situ properties of soils and soft rocks and their stability. J. K. MITCHELL

Statistical analysis of radon data. J. A. APPS
Four-channel simultaneous collection system for high-precision mass spectrometry. M. C. MICHEL, D. F. MOSIER, and W. R. KEYES

Determination of the properties of soils by in-situ measurements. W. C. B. VILLET and J. K. MITCHELL

Statistical analysis of the correlation of earthquakes with radon concentration in water from shallow wells near Oroville, California. B. BERLIN 


\section{INTRODUCTION}

The summary papers which follow describe fundamental studies addressing variety of earth science problems in support of the U.S. Department of Energy' missions. They have applications in such diverse areas as geothermal energy, oil recovery, in-situ coal gasification, uranium resource evaluation and recovery, and exrthquake prediction.

Funding for studies described by approximately half of the papers comes from the $U . S$. Department of Energy Office of Basic Energy Sciences (OBES). The U.S. Department of Energy's Division of Fossil Fuel Extraction (DFFE) and Division of Geothermal Energy (DGE); Bendix Field Engineering Corp. E. G. G., Inc, and Lawrence Berkeley Laboratory's Director's Development Fund provide support for the remainder. Most of the studies are conducted under ongoing projects. For descriptions of earlier work, the reader is referred to the 1977 Annual Report of the Earth Sciences Division (LBL-7028) and the 1976 and 1975 Annual Reports of the Energy and Environment Division of Lawrence Berkeley Laboratory (LBL-5982 and 5299, respective1y).

In the following paragraphs, a brief discussion of the papers is given in order that the reader may appreciate the diversity of the work being accomplished and find his way to the subjects that interest him most.

The most promising geothermal energy resources are found in so-called "liquid dominated" reservoirs, where the energy is produced through the recovery and use of underground hot.water. Two major problems associated with this process are (a) the uncertainty of the properties and behavior of the fluid recovered, and $(b)$ the productive capacity and duration of the supply of hot water from the reservoir. In papers by Otto et al., Pitzer et al., and weres et al., various aspects of geothermal fluids are discussed including, respectively, the compositional characteristics, thermodynamic properties, and tendency of the fluid to precipitate amorphous silica. All of these aspects have an important bearing on the choice of design for and configuration of a geothermal plant, whether for power generation or for heating alone. Questions relating to subsurface factors controlling the chemical composition of geothermal fluids are considered in an ongoing study of rock-water interactions. In the paper by Neil and Apps, the oolubility of albite, an important rock-forming mineral in the aqueous phase at geothermal reservoir temperatures, is discussed.

Geothermal reservoir problems are investigated in a series of four fundamental papers by Narasimhan and his coworkers, Kanehiro and
Tsang. These papers are primarily concerned with the aquifer response to earth tides and the meaning of an important reservoir parameter, the storage coefficient. The physical properties of reservoir rocks when saturated with brine are considered by Somerton et 81 . in the paper on rock-fluid systems.

Mention should also be made of a potential source of geothermal energy: molten magmas. The thermodynamic and transport properties of oynthetic melts representative of natural magmas and the properties of the solid phases that crystallize from nelts are being studied by Carmichael et al.

Two papers concern the exploitation of fossil fuels. One by Radke and Somerton covers the subject of increasing oil recovery through the use of reactive tension agents. The other, by Mangold et al., makes predictions of the thermal effects on the surface after in-situ combustion of shallow coal seams.

Uranium resources are evaluated in a paper by Strisower et al. Specifically addressed are disseminated low-grade deposits found associated with peralkaline intrusive rocks in the United States. Another paper by Wollenbers and Strisower on the Geodose Project sumarizes the results of a literature search for data on uranium, thorium, and potassium contents of major rock types. This was done in order to characterize rock types by their natural gamaray exposure rates.

A paper by Villet and Mitchell, with broad implications in several energy fields, covers the subject of determining the properties of soils and soft rocks by in-situ measurements. Reliable Information on these geotechnical parameters is required for the design of structure foundations, stable slopes, and underground excavations, including those required for energy storage.

The ability to correlate earthquakes with the radon content of well waters was investigated by Berlin. His conclusions with regard to data collected from two wells near Oroville, California, are sumarized in his paper.

Finally, the results of efforts to increase the precision of messurements of the ratios of the heavy isotopes, using a 5-ft-radius mass spectrometer are presented by Michel. This work has important implications in the precise age determination of geological materials, and in the interpretation of the early history of the earth. 
A NOTE ON THE MEANING OF STORAGE COEFFICIENT T. N. Narasimhan and B. Y. Kanehiro

INTRODUCTION

The term storage coefficient $(S)$ and the synonymous terms coefficient of storage and storativity, have been used extensively in the groundwater literature. It has been defined (Ferris et al.; 1962) as "the volume of water which an aquifer releases from or takes into storage per unit surface area of aquifer per unit change in the component of head normal to the surface." Historically, this somewhat restricted definition appears to have been introduced to satisfy the need for a coefficient occurring in the differential equation describing nonsteady groundwater flow.

\section{ACTIVITIES IN FISCAL YEAR 1978}

The definition and applicability of the storage coefficient was examined by the authors. The impetus for this came from our observation of the response of aquifers to earth tides. The result of this study was some clarification of the assumptions made in defining storage coefficients and $a$ useful comparison of different storage coefficients employed by various fields involved in the study of porous media. A brief sumary of the results is presented below.

Although the aforementioned definition of storage coefficient is convenient and adequate for applications related to well testing, it is not adequate for the consideration of all nonsteady flow in arbitrary, heterogeneous, threedimensional systems. A more concisely defined and more general coefficient is specific storage $\left(s_{s}\right)$ also referred to as specific storativity. It can be defined directly in terms of the compressibility of the skeleton of the aquifer and the compressibility of water.

In examining the nature of the coefficients used to describe change in storage, the applicability of and expressions for the various coefficients used by different fields were considered. The specific storage coefficient is strictly applicable only to situations where the total stress on the porous medium is constant. This corresponds to a drainage problem where there is addition or removal of fluid from the system, as in the case of pumping tests. The seemingly different expressions for the coefficients used to describe change in storage arise from different choices of normalizing volumes.

The mass of fluid stored in a given volume of a porous medium may be expressed as (Harasimhan and witherspoon, 1977):

$$
M_{f}=v_{v} p_{f} S_{f}
$$

where

$$
\begin{aligned}
& u_{f}=\text { the mass of fluid, } \\
& v_{v}=\text { the volume of the voids, } \\
& p_{f}=\text { the density of the fluid, and } \\
& s_{f} \text { - the saturation of the fluid. }
\end{aligned}
$$

It is known empirically that $v_{v}, \rho_{f}$, and $S_{f}$ are all functions of the average fluid pressure in a given volume of the porous medium. Hence, it is possible to define a fluid mass capacity, $M_{c}^{*}$, which expresses the rate of change of mass of fluid with respect to the change in average fluid pressure within the volume.

$$
\begin{aligned}
M_{c}^{*} & =\frac{d v_{f}}{d p_{f}} \\
& =v_{v} s_{f} \frac{d p_{f}}{d p_{f}}+p_{f} s_{f} \frac{d v_{v}}{d p_{f}}+v_{v} p_{f} \frac{d s_{f}}{d p_{f}}
\end{aligned}
$$

The first term on the right-hand side of equation (2) represents the change in volume of the pore fluid. The second term represents the deformation of the skeleton of the porous medium, and the third term represents the desaturation of the medium.

At least in the fields of hydrology and petroleum engineering, the medium is generally assumed to be completely saturated. The expression for fluid mass capacity then simplifies to

$$
u_{c}^{*}=v_{v} \frac{d p_{f}}{d p_{f}}+p_{f} \frac{d v_{v}}{d p_{f}}
$$

The first term is evaluated by assuming a slightly compressible fluid of compressibility $c_{w}$. The fluid mass capacity may then be written as

$$
u_{c}^{*}=\rho v_{v} c_{w}+\rho_{f} \frac{d v_{v}}{d p_{f}}
$$

The second term is generally evalusted by sssuning that the total stress on the porous medium is constant. Because the effective stress ( $\left.\sigma^{\prime}\right)$ of the skeleton is generally related to the fluid pressure ( $p_{f}$ ) and total stress $(\sigma) a \sigma^{\circ}=\sigma-p_{f}$ for a saturated system, the magnitude of the change in fluid pressure is equal to the magnitude of change in effective stress. This makes it possible to write the fluid mass capacity as

$$
u_{c}^{*}=\rho_{f} v_{v} c_{w}-\frac{d v_{v}}{d \sigma^{T}} \text {. }
$$

Note, however, that the expression now refers directly only to situations where fluid is either being removed from or added to the system. 
This formulation of fluid mass capacity is related to an arbitrary volume element. For convenience it is generally necessary to have a volume normalized coefficient. Actually two normalization volumes are necessary. First, the second term of the expression for $M_{c}^{*}$ must be normalized so that it can be expressed in terms of some compressibility related to the skeleton of the porous medium. Then the entire expression for the fluid mass capacity is volumenormalized to give a specific fluid mass capacity. To conform with the more common practice of using specific fluid volume capacity with respect to hydraulic head, fluid pressure is converted to hydraulic head assuming constant fluid density.

It is in choosing various normalizing volumes that much of the confusion between the different coefficients arises. In general, there are three choices available. These are (a) the bulk volume; $v_{b}$; (b) the solid volume, $v_{s}$; and $(c)$ the pore volume, $v_{v}$.

The results of choosing various combinations of normalizing volumes may be summarized as the following four cases (Narasimhan and Kanehiro, 1978).

1. Bulk volume, $\nabla_{b}$, used in both cases,

$$
s_{s}=\rho_{f} g\left[n c_{w}+m_{v}\right]
$$

2. Solld volume, $v_{s}$, used in both cases,

$$
s_{s}=p_{f}\left[e c a_{w}\right]
$$

3. Pore volume, $v_{p}$, used for deformation, and $v_{b}$ used for volume over which specific storage is defined,

$$
\begin{aligned}
& s_{s}=\rho_{f} g n\left[c_{w}+c_{p}\right], \text { and } \\
& n c_{t}=n\left[c_{w}+c_{p}\right]
\end{aligned}
$$

4. $V_{s}$ used for deformation and $V_{b}$ used for volume over which specific storage is defined

$$
s_{s}=\rho_{f} g\left[\mathrm{nc}_{w}+(I-n) a_{v}\right]
$$

Here, $m_{v}$ is the volumetric coefficient of compressibility defined as

$$
m_{\mathbf{v}}=-\frac{1}{\Delta \sigma} \frac{\Delta v_{v}}{v_{b}}
$$

where $a_{v}$ is the coefficient of compressibllity defined as

$$
a_{v}=-\frac{1}{\Delta \sigma} \frac{\Delta V_{v}}{v_{s}},
$$

and $c_{p}$ is the pore volume compressibility defined as

$$
c_{p}=-\frac{1}{\Delta \sigma} \frac{\Delta v_{v}}{V_{v}}
$$

Finally, in view of the definition of the storage coefficient (s) specific storage is simply the storage coefficient normalized with respect to the thickness of the aquifer. That is,

$$
S=s_{8} b
$$

where $b$ is the thickness of the aquifer. Also, because $n_{t}$ is change in storage with respect to fluid pressure,

$$
s_{s}=\rho_{f} g^{n} c_{t},
$$

and the commonly used petroleum engineering term, $\phi c h\left(=n c_{t} b\right.$ in the present notation) can be written as :

$$
\phi c h=n c_{t} b=\frac{s_{g}}{R_{f} g} b=\frac{s}{\rho_{f} g} .
$$

\section{REFERENCES CITED}

Ferris, J. G., Rnowles, D. B., Brown, R. H., and Stallman, R. W., 1962. Theory of aquifer tests. Geological Survey Water Supply Paper 1536-E.

Narasimhan, T.N., and Kanehiro, B. Y,, 1978. $A$ note on the meaning of storage coefficient. Berkeley, Lawrence Berkeley Laboratory, LBL-8295.

Narasimhan, T. N., and Witherspoon, P. A., 1977. Numerical model for saturated-unsaturated flow in deformable porous media: Part I, Theory. Water Resources Res., v. 13, no. 3 , pp. $657-666$. 
SIGNIFICANCE OF THE STORAGE PARAMETER IN SATURATED-UNSATURATED GROUNDWATER FLOW

T. N. Narasimhan

\section{INTRODUCTION}

The primary phenomenon that distinguishes transient from steady groundwater flow is change in storage. The quantity of water stored in a groundwater system may change due to expansion of water (usually very small), change in void volume of the skeleton, or change in water saturation. These independent phenomena of ten occur simultaneously. In particular, change in storage in fully saturated media is usually dominated by soil deformation, while the phenomenon of desaturation usually dominates change in storage in the unsaturated zone. The customary assumption that the skeleton is rigid in a desaturating soil is realistic only under those conditions when saturation is relatively low. The assumption is particularly unrealistic in the transition regime between saturated and unsaturated flow. The importance of soil deformation in this transition regime cannot be overlooked. In fact, soil deformation at high saturations provides the key bond between saturated and unsaturated regimes of transient groundwater flow (Narasimhan and Witherspoon, 1977; Naresimhan and Holzer, 1978; Narasimhan, 1978).

\section{STORAGE AND CHANGE IN STORAGE}

The quantity of water stored in a small elemental volume of a soil is given by:

$$
M_{w}=\rho_{w} v_{v} s
$$

where $Y_{w}$ is mass of water, $P_{w}$ is water density, $V_{v}$ is void volume, and $S$ is saturation. It is known empirically that $\rho_{w}, V_{v}$, and $s$ are functions of the fluid pressure head $\psi$. Therefore, the quantity can be defined as fluid mass capacity, $\mathrm{K}_{c}$, which is the derivative $\mathrm{dM}_{w} / \mathrm{d} \psi$. $\mathrm{M}_{c}$ represents the quantity of water released from the volume element as the average pressure head is dropped by unity. If, for convenience, the compressibility of water is neglected, then $M_{c}$ can be obtained, using the chain rule of differentiation:

$$
M_{c}=p_{w}\left[s \frac{d V v}{d \psi}+v_{v} \frac{d S}{d \psi}\right] .
$$

The term $d V_{v} / d \psi$ on the right-hand side of equation (2) denotes void volume change as a function of $\psi$. However, soil deformation is properly a function of the effective skeletal stress $\left(\sigma^{\prime}\right)$ rather than pore pressure $\left(\rho_{w} g\right)$. Therefore an explicit constitutive law between $\Psi$ and $\sigma^{\prime}$ is required. From the soil mechanics literature, this relation is assumed to be

$$
\sigma^{\prime}=\sigma-x \rho_{w} \psi
$$

where $\sigma$ is the total external stress, $X<1$ in partially saturated soils and $x=1$ in fully saturated soils, and $g$ is acceleration due to gravity. In most groundwater problems, $\sigma$ can be treated as constant and hence,

$$
\frac{d \sigma^{\prime}}{d \psi}=-\left[x+\psi \frac{d x}{d \psi}\right] \rho_{w g}=-x^{*} \rho_{w g} .
$$

In view of equation (4), equation (2) can be written as

$$
M_{c}=\rho_{w}\left[-s X^{*} \rho_{w g} \frac{d v_{v}}{d \psi}+v_{v} \cdot \frac{d S}{d \psi}\right]
$$

If we stipulate that the volume element has constant volume of solids and normalize equation (5) with reference to the solid volume $\left(V_{g}\right)$ of the elemental volume, then

$$
u_{c}=v_{g} \rho_{w}\left[S x^{*} \rho_{w} g a_{v}+e \frac{d S}{d \psi}\right]
$$

where $a_{v}$ is the coefficient of compressibility defined by $a_{\mathbf{v}}=-\mathrm{de} / \mathrm{d} \sigma^{\prime}$.

In dealing with unsaturated soils, it is customary to treat the soil skeleton as rigid (that is, $a_{v}=0$ ), and attribute $M_{c}$ in equation (6) entirely to the desaturation phenomenon. Conceptually, however, it is more rational to consider that in unsaturated soils, $X^{*}$ is extremely small, rather than stating that a $=0$. If we recall that for a fully saturated soil, $X^{*}=1$, then it is obvious that $X^{*}$ has to decrease from 1 when the soil is saturated to nearly zero or when saturation is significantly small. This implies that when the soil has high saturations, $x^{*}>0$, and hence there will always be some deformation accompanying desaturation as pore pressure changes. This perspective is extremely important in unifying saturated-unsaturated flows. To understand this, suppose for a moment that the soil is rigid whenever pore pressure is less than atmospheric. As progressive suction is applied to a saturated soil, the soil will not begin to desaturate unless suction exceeds a critical air-entry value, $\mathrm{K}_{\mathrm{A}}$. In the pressure range, $\psi_{A}<\psi_{A}<0$, it is obvious that $\mathrm{dS} / \mathrm{d} \psi=0$. If in this range $A_{v}$ is also assumed to be zero (rigid soil), then $H_{c}=0$ in equation (6) means that the soil has no capacity to release water from storage and it cannot participate in transient flow. Of course this anomaly would not exist if $x^{*}>0$ when $\psi_{A}<\psi<0$, and the soil skeleton has nonzero $a_{v}$ corresponding to its existing stress leve1.

\section{An Example}

The fact that $x^{*}$ may not be zero except in extremely dry soils implies that soil deformation may occur simultaneousiy with desaturation in unsaturated soils. Although normally one considers deformation only in fully saturated soils (e.g., 
land subsidence), there is some evidence to suggest that deformation of partially saturated soils may be responsible for field problems of considerable. interest. One such problem is that of large earth fissures observed in areas of heavy groundwater withdrawal and large water-level declines in the arid tracts of Arizona and elsewhere (Davis, 1978). To investigate whether or not sufficient effective stresses could be mobilized in the zone of partial saturation, to cause contractions leading to earth fissuring, numerical simulations were carried out on a hypothetical soil column as described below.

Consider an 85-m-tall column of soil, barely saturated at the initial timme, with a hydraulic potential of $85 \mathrm{~m}$ of water everywhere in the flow region (Figure 1). For $t>0$, water is. allowed to drain at the bottom at a constant rate of $2.746 \times 10^{-5} \mathrm{~m}^{3} / \mathrm{sec}$. With the onset of drainage, desaturation is initiated at the top of the column. The purpose of simulation is to investigate if significant volume deformations can accompany desaturation.

Two hypothetical soils with different soil moisture characteristics were considered but with essentislly the same X-vs-saturation relationships (Figure 2 ). Both soils were

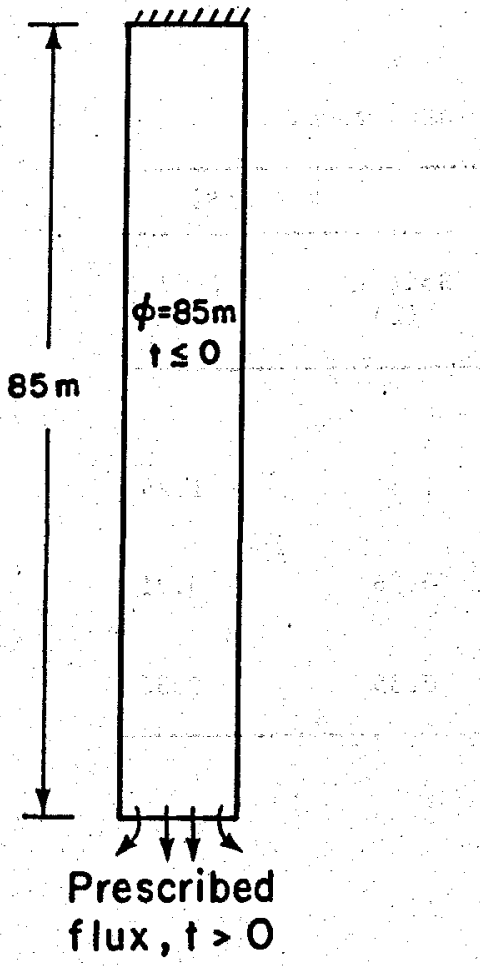

XBL785-936

Figure 1. Earth fissure problem: initial and boundary conditions. assumed to have the same nonlinear deformation coefficient, $c_{c}=0.1$, and to have absolute permeability, $k$, given by

$$
k=\left(\frac{4.628}{4.628+|\psi|^{1.645}}\right)\left(5.67 \times 10^{-14} \mathrm{~m}^{2}\right)
$$

The effective stress to pore-pressure relationship for the two soils is given in Figure 2 .

The colum was subjected to a drainage simulation equal to 10 years, with simultaneous compaction. The profiles of variation of some of the Important parameters for Soll 2 at the end of 10 years are given In Figure 3.

The computed deformations in the unsaturated zone are summarized in Table 1.

- As can be seen from the table, for both soils deformation in the unsaturated regime is over $25 \%$ of the total volume strain. This leads to the inference that, under certain conditions of heavy groundwater withdrawal from unconfined aquifers, one could expect significant column strains to accompany the desaturation process. Such strains may, if conditions are favorable, cause contractions leading to earth fissures.

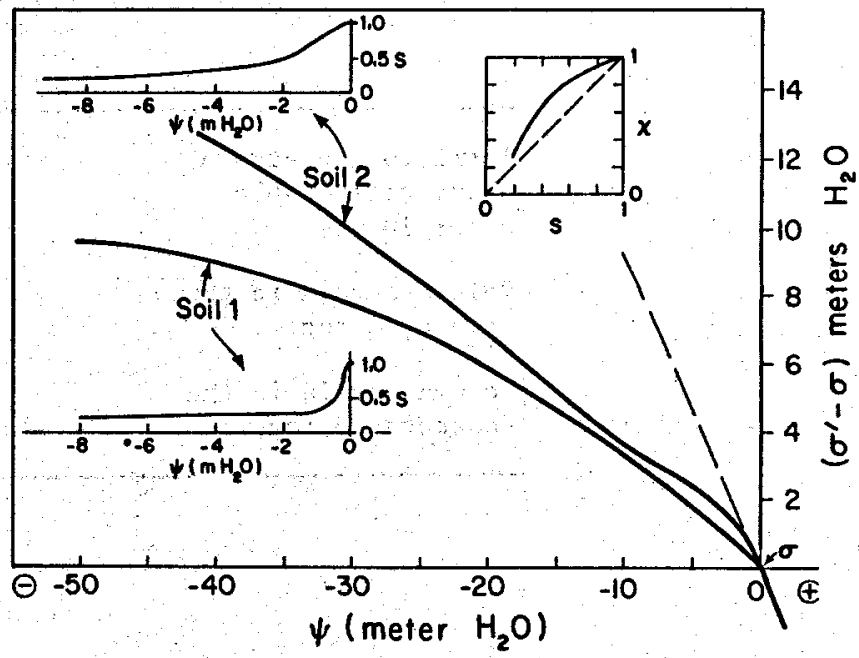

xeL To3-447

Figure 2. Earth fissure problem: variations of effective stress with $\psi$ for two hypothetical soils. 


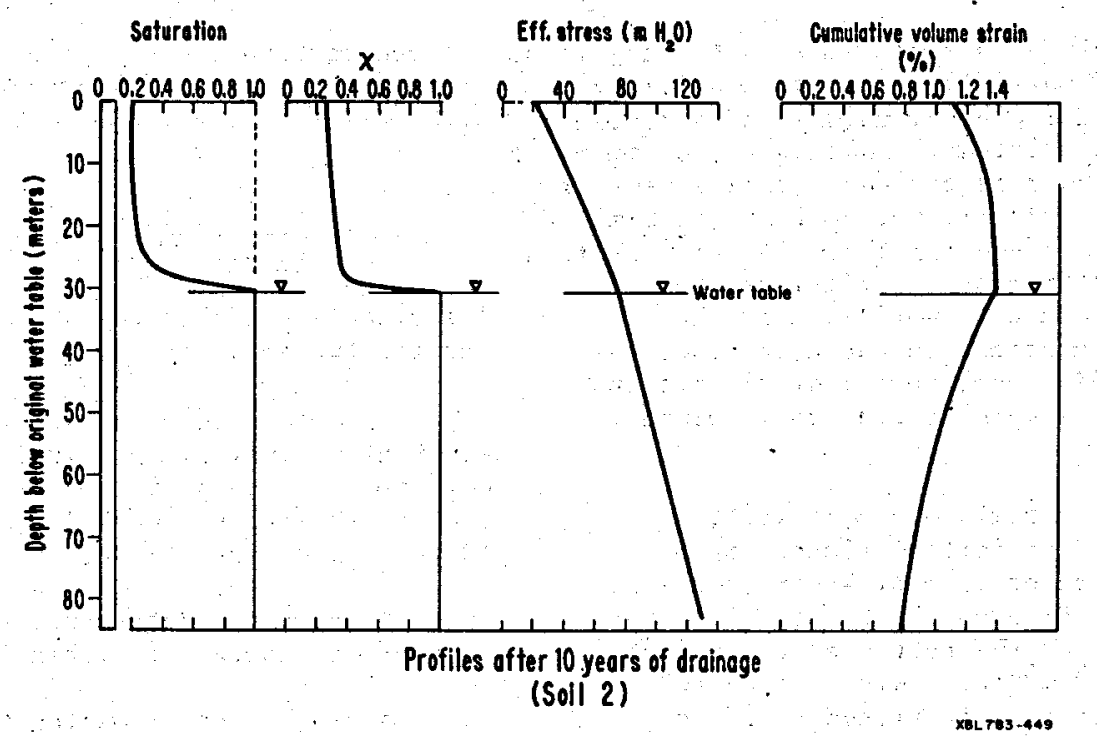

Figure 3. Earth fissure problem: profiles of $S, x, \sigma^{\prime}$, and volume strain after $t=10$ years.

Table 1. Computed deformations in the unsaturated zone.

\begin{tabular}{|c|c|c|c|}
\hline & \multirow{2}{*}{$\begin{array}{l}\text { Soil assumed } \\
\text { rigid in un- } \\
\text { saturated zone } \\
\qquad(\bar{x})\end{array}$} & \multicolumn{2}{|c|}{$x=x(s)$} \\
\hline & & $\begin{array}{l}\text { Soil } 1 \\
(\gamma)\end{array}$ & $\operatorname{soil}^{2}$ \\
\hline $\begin{array}{l}\text { Total volue strain } \\
\text { above water table } \\
\text { after } 10 \text { yr }\end{array}$ & 0.95 & 1.31 & 1.24 \\
\hline $\begin{array}{l}\text { Volume strain in the } \\
\text { saturated regime }\end{array}$ & 0.95 & 0.96 & 0.91 \\
\hline $\begin{array}{l}\text { Volume strain in the } \\
\text { unsaturated regime }\end{array}$ & 0 & 0.35 & 0.33 \\
\hline
\end{tabular}

\section{REFERENCES CITED}

Davis, S. N., 1978. Origins of earth fissures. Geol. Soc. Am., Abstracts with Programs, v. 10 , no. 3, p. 102 .

Narasimhan, T. N., 1978. The significance of the storage parameter in saturatedunsaturated groundwater flow. Berkeley, Lawrence Berkeley Laboratory, LBL-7041.
Narasimhan, T. N., and Holzer, T. H., 1978. Possibility of soil deformation in the partially saturated zone due to pore pressure changes. Geol. Soc. Am., Abstracts with Programs, v. 10, no. 3, p. 188.

Narasimhan, T. N., and Witherspoon, P. A., 1977. The significance of the storage parameter in saturated-unsaturated groundwater flow. Invited Paper, Symposium on Unified Studies of American Geophysics Union, Annual Meeting, Washington, D.C. 


\title{
USE OF AQUIFER RESPONSE TO EARTH TIDES AS A MEANS OF DETERMINING
}

AQUIFER CHARACTERISTICS

\author{
T. N. Narasimhan and B. Y. Kanehiro
}

\section{INTRODUCTION}

The use or observation of periodic fluctuations of water levels in wells resulting from aquifer response to tidal phenomena is not new. The earth is within the gravitational fields of the sun and the moon, and as such is subject to tidal forces. Because the motions of these celestial bodies are very nearly periodic, the strains in the earth related to tidal forces also exhibit periodic variations in time. Because these tidal strains arise from forces that are gravitational in nature, they must exist in all parts of the planet. In general, however, tidal forces only cause readily observable responses in the hydrosphere in the form of ocean tides. While tides do exist in the atmosphere and lithosphere, they are of very small magnitude. For these reasons, a substantial body of knowledge exists on the use of aquifer response to ocean tides under various circumstances, but comparatively little is known about the response to atmospheric (barometric) or lithospheric (earth) tides. In the former case, the barometric tide is generally lost in the daily variations in barometric pressure that are not related to tidal forces. In the latter case, the inability to make accurate measurements in deep wells of small changes in pore-fluid pressure has thwarted attempts to quantify the response of aquifers to earth tides.

With the advent of the present generation of extremely sensitive pressure transducers using quartz crystal sensors, good measurements of small pressure fluctuations have become possible. Further, these measurements can be made in artesian (flowing) wells that have been shut in where there is reason to believe that larger responses to earth tides occur.

\section{ACTIVITIES IN FISCAL YEAR 1978}

In fiscal year 1978, the authors studied some aspects of the practical utility of the response of aquifers to earth tides for the determination of aquifer characteristics. The result of this study was a preliminary means for estimating the specific storage of an aquifer. A sumary of the derivation of this method is presented below.

The determination of aquifer characteristics based on response to earth tides requires that the fluctuation at well be related to the tides by a theory incorporating coefficients describing the desired aquifer characteristics. The intrinsic complexities of the tide, accentuated by the presence of spurious fluctuations, generally necessitates the decomposition of the well signal into sine-wave components before any theory can be applied. Finite Fourier analysis is used to determine the amplitudes of five tidal components of the signal at the well together with the tide itself (Kanehiro et al., 1978).
In the analysis presented here, the aquifer is considered to be a closed system with a small shut-in well that does not affect the system. The well merely provides a means of observing the change in the fluid pressure of the system. Fluid is not being added to or withdrawn from the system, so the problem is an undrained one. This implies that the pressure response of the aquifer is related to the compressive properties of the skeleton and the fluid, and the relative proportions of each. In groundwater hydrology it is comon to combine these properties into a coefficient called specific storage, $\mathbf{S}_{\mathrm{s}}$. Specific storage is defined as the volume of fluid removed from or taken into storage per unit volume per unit change in hydraulic head. Defined as such, specific storage is basically related to a drained problem. If specific storage is to be determined from the pressure response of aquifers to earth tides, a definition directly relating specific storge to the compressibilities of the skeleton and fluid will have to be employed. Specific storage may be written as

$$
\begin{aligned}
& \text { where } s_{g}=P_{f g}\left(n c_{w}+m_{v}\right) \\
& \rho_{f}=\text { density of the fluid, } \\
& g=\text { acceleration due to gravity, } \\
& n=\text { porosity, } \\
& c_{w}=\text { compressibility of the fluid, and } \\
& m_{v}=\text { compressibility of the skeleton. }
\end{aligned}
$$

In this definition, $\rho_{f}, g$, and $c_{w}$ are reasonably well known, leaving $n$ and $m_{v}$ to be determined. The purpose of this study was to estimate $\mathrm{m}_{\mathrm{v}}$, and hence $S_{s}$.

The earth tide can be expressed as a potential, which in turn can be used to determine a dilatation by adopting an earth model. Knowing this dilatation and the pressure response as measured at the we11, it is not possible to determine both the porosity and the compressibility of the skeleton. It is, however, relatively easy to estimate the porosity of an aquer within about 5\%. This leaves only. the skeleton compressibility, or change in volume of voids with respect to the bulk volume per change in effective stress. That is

$$
m_{v}=\frac{d v_{v}}{v_{b}} \frac{1}{d \sigma} ;
$$

where

$$
\begin{aligned}
& v_{v}=\text { volume of the voids, } \\
& v_{b}=\text { bulk volume, and } \\
& \sigma^{\prime}=\text { effective stress. }
\end{aligned}
$$


With appropriate substitution this may be written ss

$$
m_{v}=n c_{w} \frac{d p_{f}}{d \sigma^{\prime}-d p_{f}}
$$

where everything is known (or assumed) except the total stress, and with the assumption that for undrained response, change in void volume equals change in water volume.

The change in the total stress on the aquifer is due to the change in weight of the overburden and the deformation of the earth. The change in weight of the overburden results from the change in gravity. This effect can be shown to be comparatively small even for relatively deep aquifers, and hence can be neglected. The estimation of the deformation of the earth requires some knowledge or assumption about the nature of the earth.

In spherical coordinates, dilatation is defined as

$$
\Delta=\varepsilon_{\mathbf{T I}}+\varepsilon_{\theta \dot{\theta}}+\varepsilon_{\phi \phi}
$$

where $\varepsilon$ refers to strain. Near a free surface

$$
\sigma_{r I}=0=\lambda \Delta+2 \mu \varepsilon_{r I}
$$

where $\mu$ is rigidity or shear modulus and $\lambda$ is Lamé's constant.

Further, it can be shown that:

$$
\varepsilon_{\theta \theta}+\varepsilon_{\phi \phi}=\left\{\frac{2 \bar{h}-6 \bar{l}}{a}\right\}\left\{\frac{W_{2}}{8}\right\},
$$

where

$$
\begin{aligned}
& \bar{h}=\text { Love number, } \\
& \bar{l}=\text { Love number, } \\
& z=\text { radius of the earth, } \\
& W_{2}=\text { potential, and } \\
& \bar{z}=\text { acceleration due to gravity. }
\end{aligned}
$$

Dilatation may therefore be written as

$$
\Delta=\left\{\frac{1}{1+\frac{\lambda}{2 \mu}}\right\}\left\{\frac{2 \bar{h}-6 \bar{l}}{8}\right\}\left\{\frac{w_{2}}{8}\right\}
$$

The situation is now analogous to having a confined sample in a lab where the change in fluid pressure and the dilatation resulting from an unknown change in confining pressure are known. Because the problem is undrained, the change in fluid pressure is not equal to the change in effective stres8. The change in total stress is therefore needed to evaluate the compressibility of the skeleton.
This would seem to imply that the bulk modulus, $\mathrm{K}$, will have to be known or estimated. The bulk modulus, however, can be related to $\mu$ and $\lambda$ as

$$
X=\lambda+(2 / 3) \mu .
$$

Because $\lambda$ and $\mu$ already appear in the equation for dilatation, the change in total octahedral stress can be written as

$$
d \sigma_{\text {oct }}=\left(\lambda+\frac{2}{3} \mu\right)\left|\frac{1}{1+\frac{\lambda}{2 \mu}}\right|\left\{\frac{2 \bar{h}-6 \bar{l}}{g} \mid\left\{\frac{d W_{2}}{g}\right\}\right.
$$

without introducing any new coefficients. Before accepting this expression, however, sone consideration should be given to the applicability of the previous equation for dilatation. The change in potential can be calculated for any point on the earth from astronomical considerations. The values for $\bar{h}, \bar{l}, \mu$, and $\lambda$, however, are estimated for a very large region of the earth at best. The expression for dilatation, therefore, really represents a given region of the earth. The question then becomes one of using the values of $\lambda$ and $\mu$, already inherent in the expression for dilatation, to get the implied change in octahedral stress or estimate a bulk modulus that may be more representative of the region near' the aquifer. At least, conceptually, the dilatation may be thought of as the result of measuring a large region of the earth with strain meters. This would seem to indicate that although the dilatation represents a regional value, it might be more reasonable to use an estimate for some local value of $\mathrm{K}$ to calculate the change in total stress.

In practice, using the earth model and coefficients of Takeuchi (1950), $\mathrm{K}=1 \times 10^{11} \mathrm{~Pa}$. The expected bulk modulus of a deep aquifer would be on the order of $1 \times 10^{10} \mathrm{~Pa}$ to $1 \times 10^{11} \mathrm{~Pa}$. This is extrapolated from measured values for various rocks. Of course, the absolute lower limit is $2 \times 10^{9} \mathrm{~Pa}$, the bulk modulus of vater.

Preliminary calculations using a range of values for bulk modulus were made for wells at Raft River, Idaho, and East Mesa, California. Although there are data problems associated with both areas which are further complicated by ocean loading problems at East Yesa, reasonably good results were obtained.

\section{PLANNED ACTIVITIES FOR FISCAL YEAR 1979}

Final calculations and comparison with a numerical model is planned for the first quarter of the next fiscal year.

\section{REFERENCES CITED}

Kanehiro, B. Y., Narasimhan, T. N., and Tsarg, C. F., 1978. Preliminary analysis of tidal data. This report.

Takeuchi, H., 1950. On the earth tide of the compressible earth of variable density and elasticity. Trans. Am. Geophys. Union, v. 31, pp. 651-689. 
PRELIMINARY ANALYSIS OF TIDAL DATA

B. Y. Kanehiro, T. N. Narasimhan, and C. F. Tsang

\section{INTRODUCTION}

The earth is theoretically within the gravitational fields of all other celestial bodies and as such is subject to tidal forces. The sun and the moon, because of their respective size and proximity, account for virtually all the tidal forces experienced by the earth. The ocean tides of the hydrosphere provide, by far, the most dramatic evidence of the tidal forces at work. The same tidal forces also act on the atmosphere and the lithosphere generating atmospheric and solid earth tides, respectively. These tides, however, are of small magnitude and are relatively difficult to measure accurately.

The time dependency of the tides results from the relative movements of the earth, sun, and moon and as such is very nearly periodic. Unfortunately, this periodicity is complicated and has superposed on it substantial amounts of nonperiodic noise. Although the solid earth tide and the reservoir response to this tide do not suffer from problems like those associated with the period of free oscillations of the ocean basins, it is still desirable to do some preliminary analysis.

From a practical point of view it is sufficient to determine the amplitudes and phase relations for the five or six largest components of the tide; at least in theory, this should remove much of the nonperiodic noise.

\section{ACTIVITIES IN FISCAL YEAR 1978}

Two methods for analyzing tidal signals were tried. The first is the widely used finite Fourier analysis. This approach is based on the fact that the finite Fourier series for an odd number of points $(2 N+1)$ may be written as:

$F(x)=\frac{A_{0}}{2}+\sum_{k=1}^{N}\left[A_{k} \cos \left(\frac{2 \pi k}{L} x\right)+B_{k} \sin \left(\frac{2 \pi k}{L} x\right)\right]$

where $F(x)$ is a function that is defined over the set of points $\left\{x_{p}\right\}$, and $A_{0}, A_{k}$, and $B_{k}$ are coefficients such that:

$$
A_{k}=\frac{1}{N} \sum_{p=0}^{2 N} F\left(x_{p}\right) \cos \left(\frac{\pi}{L} k x_{p}\right)
$$

and

$$
B_{k}=\frac{1}{N} \sum_{p=0}^{2 N} F\left(x_{p}\right) \sin \left(\frac{\pi}{L} k x_{p}\right)
$$

with $k$ being the harmonic number and I being the length of the interval considered (Haming, 1973).
To avoid the problem of having coefficients that are not invariant under translation, the series may be written as:

$$
F(x)=\frac{c_{0}}{2}+\sum_{k=1}^{N} c_{k} \cos \left(\frac{2 \pi k}{L} x\right)+\phi_{k}
$$

where

$$
C_{k}=\left(A_{k}{ }^{2}+B_{k}\right)^{1 / 2}
$$

and

$$
\phi_{k}=\arctan \frac{B_{k}}{A_{k}}
$$

The algorithm actually used to calculate the series is based on a Fourier transform scheme rediscovered by Cooley and Tukey (1965). This calculational scheme is significantly faster than the more direct calculational scheme of the coefficients based on the equations above.

The second method of tidal decomposition is one specifically designed for earth-tide analysis by Lecolazet (1956). This method is not as direct or conceptually simple as the finite Fourier analysis. It is basically a filtering scheme where specially designed band-pass filters are employed. The method allows for the examination of a larger number of tidal components and a greater degree of accuracy.

As an offshoot of the above, attempts were made to remove tidal noise from data to be used for well-test analysis. Both least-square filtering schemes and schemes based on the analysis above were tried with very limited success.

\section{FISCAL YEAR 1979}

The simple finite Fourier analysis presented above has proved to be adequate for the present needs of examining aquifer response to earth tides.

The removal of tidal noise without seriously degrading the desired signal is not a simple problem. Attempts to improve methods of dealing with this noise will continue.

\section{REFERENCES CITED}

Cooley, J. W., and Tukey, J. W., 1965. Algorithm for the machine calculation of complex Fourier series. Mathematics of Computation, v. 19 , no. 90 , pp. 297-301.

Haming, R. W., 1973. Numerical methods for scientists and engineers. New York, McGraw-Hill.

Lecolazet, R., 1956. Application à l'analyse des observations de la marée gravimétrique de la méthode de $\mathrm{H}$. et $Y$. Labrouste dite par combinaisons linéaires d'ordonnées. Annales de Geophysique, v. 12, no. 1, pp.59-71. 
BEHAVIOR OF ROCK-FLUID SYSTEMS AT ELEVATED PRESSURES AND TEMPERATURES W. H. Somerton, A. Ghaffari, R. Greenwald, V. Hoang, L. F. Martínez-Baez,

H. J. Su, and L. Wong

\section{INTRODUCTION}

The objective of this project is to develop methods and apparatus to measure rock-fluid properties at temperature, pressure, and fluid saturation conditions that may be encountered in deep high-temperature oil and gas reservoirs, geothermal reservoirs, and reservoirs in which high temperatures are used in the extraction process. These properties include porosity, permeability, electrical resistivity factor, thermal properties including thermal expansion, pore and bulk compressibilities, compressional and shear velocities, and the dynamic elastic properties that may be derived from these properties.

Methods of measuring most of the above properties have been developed as reported in an earlier work (Somerton, 1977). These methods permit measurement of only two properties at the most in a single apparatus, and the measurements are limited to temperatures of $200^{\circ} \mathrm{C}$ and $1 \mathrm{kbar}$ stress. Correlation of the results of measurements of properties in different apparatuses, using different test specimens and with the possibility of different stress histories, is very difficult. A second objective of the present work, therefore, is to develop an apparatus in which all or most of the desired properties may be measured at the same time under identical test conditions. Basic design of this apparatus has been presented earlier (Somerton, 1977).

Measurement of physical properties and behavior of rock-fluid systems at elevated temperatures and pressures is difficult and very time consuming. A third objective of the present work is to develop models and correlations that will make it possible to predict properties and behavior from more easily measured characteristics of the rock-fluid system. The greatest progress has been made in the case of thermal properties. Having estimates of such characteristics as mineral composition, porosity, and grain size, models have been developed for predicting thermal conductivity under any fluid saturation condition at a base pressure and temperature. Other correlations have been developed to permit prediction of thermal behavior at other pressure and temperature conditions. Well-log data may also be useful in this regard. An investigation is currently in progress for predicting relative thermal conductivity by analysis of temperature gradients in wellbores.

Some applications of data obtained in this and related projects are also currently under investigation. One application is the role of the 8o-called heat-pipe effect observed in earlier work (Somerton, 1975), in high-temperature fluid flow systems in which phase changes may occur. Under certain conditions of temperature and pore fluid pressure, some shallow formations could behave as heat thiefs from geothermal and steam injection wells.

\section{RESEARCH ACTIVITIES IN FISCAL YEAR 1978}

Much of the research accomplished during fiscal year 1978 is presented in reports prepared by the six coauthors (Ghaffari, 1978; MartínezBaez, 1979; Hoang, 1978; Su, 1978; Wong, 1978; Greenwa1d, 1978). These activities will be reviewed briefly here. Following this, progress on the multirock properties apparatus will be reviewed.

Thermal Properties and Behavior

Ghaffari (1978) has developed his threedimensional model of heat conduction in porous media to obtain excellent agreement between predicted and experimental thermal conductivities, particularly for unconsolidated media. The agreement for a number of materials is shown in Figure 1. Figure 2 is a working graph based on model results. From Figure 2, we can predict the effective thermal conductivity. The agreement of model results for consolidated media is not as favorable as for unconsolidated sands. Some additional flattening of the cubic packing of

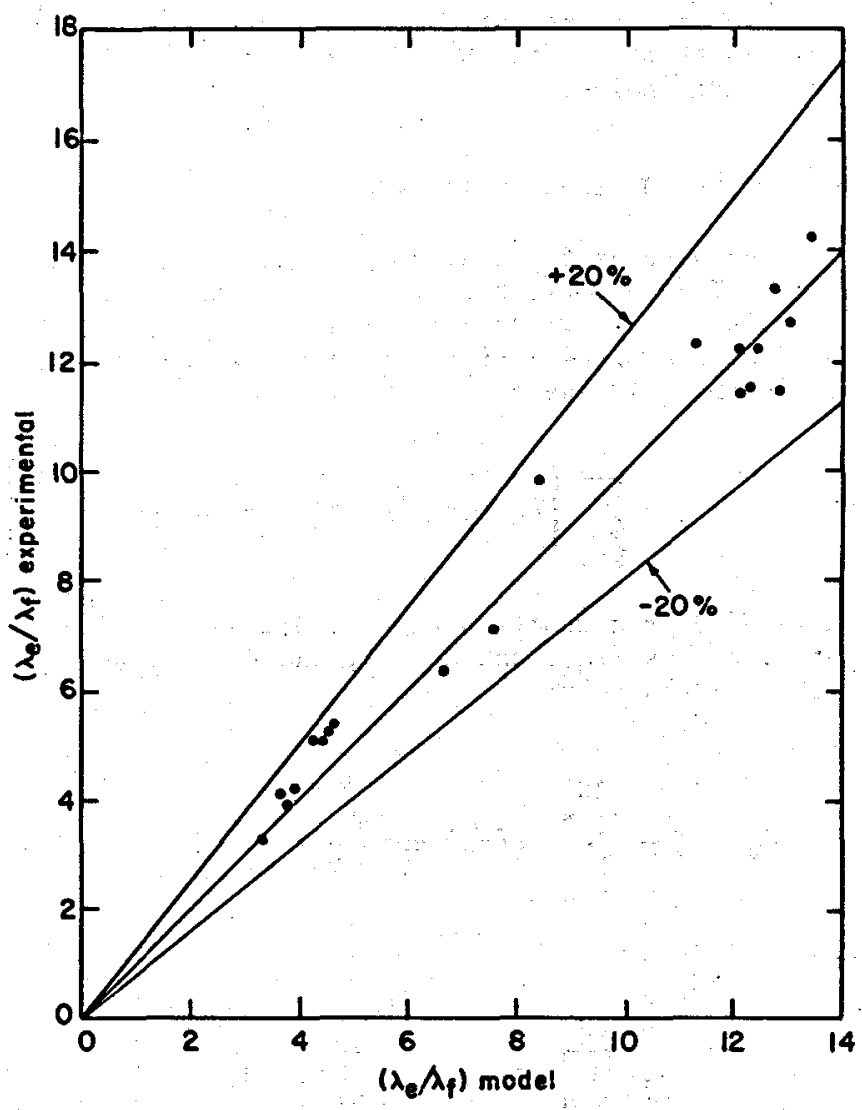

$X B L 7811-8208$

Figure 1. Agreement between experimental conductivities and conductivities predicted from the model. 


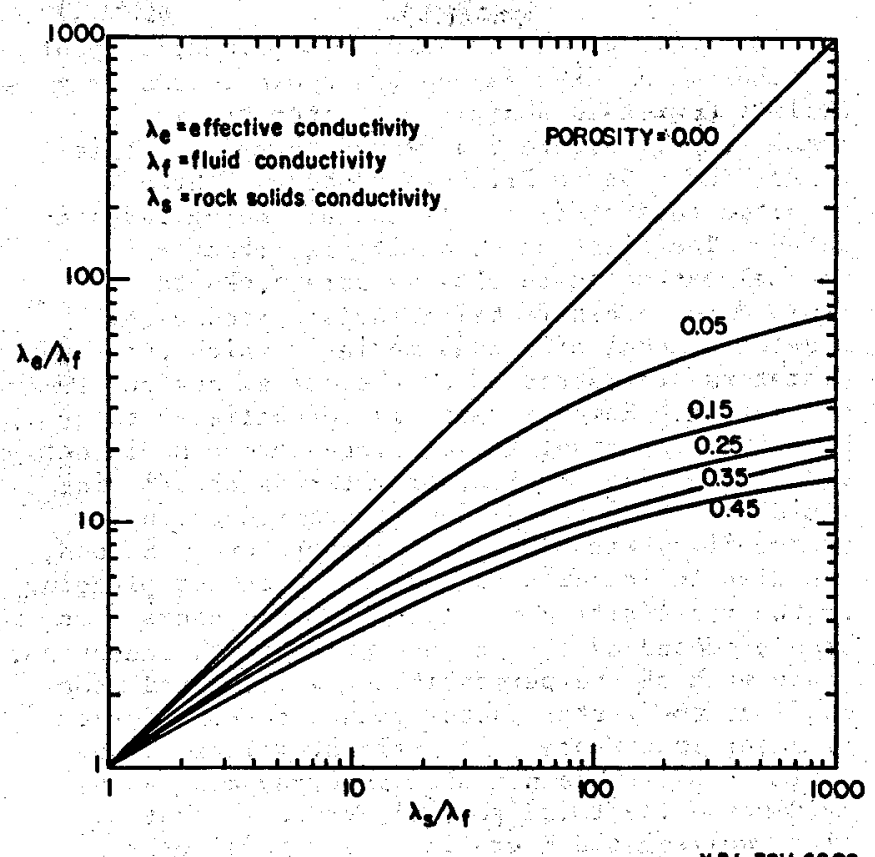

XEL Te11-62 Oo

Figure 2. Graph for predicting effective thermal conductivities based on model results.

8 pheres used in the model in the horizontal planes of contact will be applied. The degree of flattening will be related to the formation resistivity factor. In addition, a grain-size parameter will be incorporated into the model to express the effects of contact resistance.

Mart Inez-Baez (1979) has used methods developed in earlier work (Anand et al., 1973) to obtain correlations of the thermal behavior of Cerro Prieto core samples. By use of regression analysis, he correlated experimental measurements with physical properties of the rock-fluid system. The best fit to the experimental data was found when the following properties were included in the correlations: porosity, median grain sire, grain size distribution $\left(\delta_{90} / \delta_{10}\right)$, and conductivities of the saturating fluid and the rock solids. The multiple regression coefficient was 0.924 , which means that the correlation may be used with considerable confidence for similar rocks from this area having properties within the range of the samples tested. The change of conductivity with temperature for the cores tested showed quite consistent results but were at some variance with previous correlations. Figure 3 shows that some modification of the correlation would be needed in order to predict the thermal conductivitytemperature behavior of these Cerro Prieto cores with accuracy.

Hoang (1978) has studied temperature gradients in wells as a means of predicting in-situ thermal conductivities. Assuming the earth's heat flux through the formations surrounding a well to be constant in magnitude and direction, calculations have been made to show the effects of differences in thermal conductivities of formations on the temperature gradients in $a$ well. Calculations were based on initial conditions in the well being at a state of quasi-equilibrium for fluid flowing at

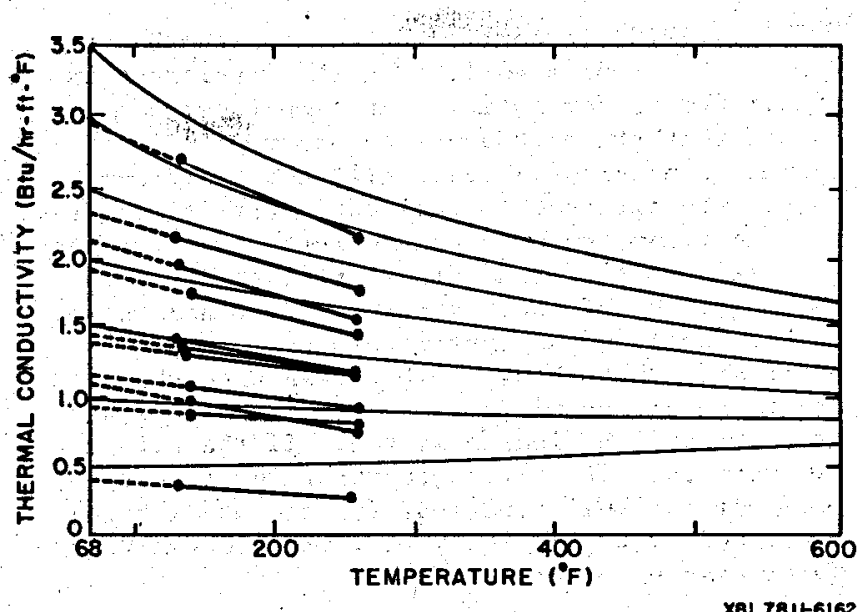

Figure 3. Thermal conductivity temperature behavior of Cerro Prieto cores.

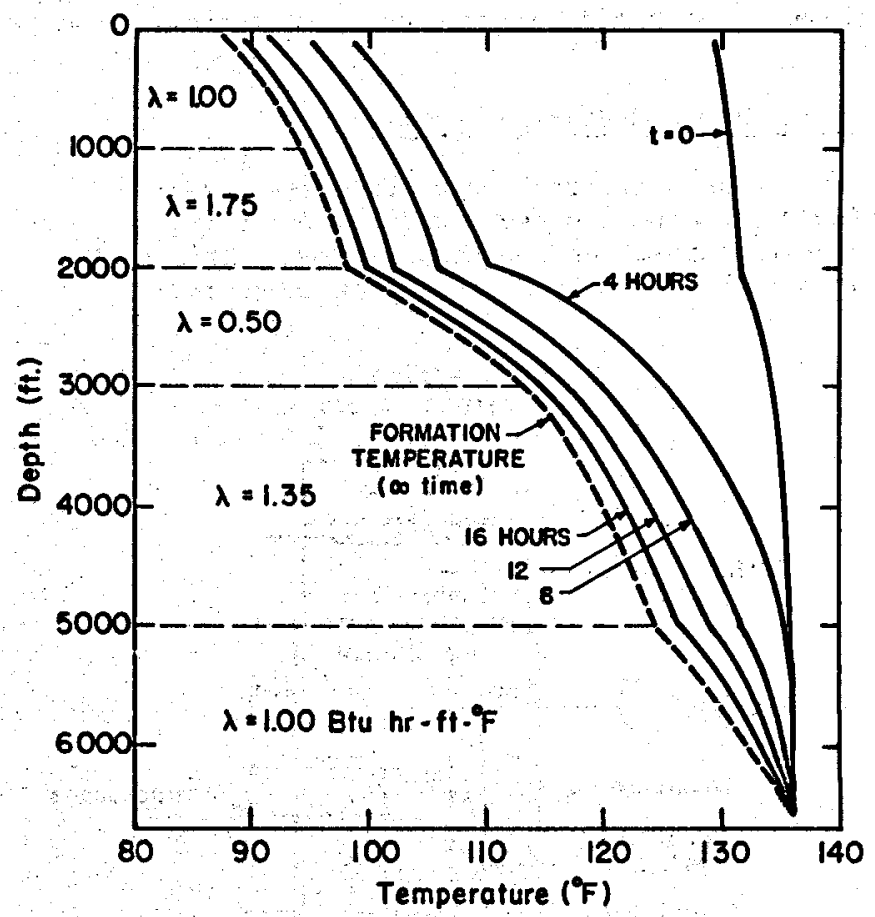

XEL $7811-6207$

Figure 4. Calculated temperatures in we11s for various shut-in times with variable thermal conductivities.

a constant prescribed rate from the lowest (highest-temperature) formation. The well was then shut in and temperatures were calculated for various times, as shown in Figure 4. It is apparent that the variation in temperature gradients after as little as 4 hours shut-in time will clearly reflect the variation in thermal conductivities of surrounding formations. These results are now being tested against actual wellbore measurements where thermal conductivity data on cores from the well are available. Hoang is also developing the modified needle-probe technique for measuring themal properties in the mul tiproperty apparatus. 
Su (1978) is continuing work on the heatpipe effect and is evaluating its importance in fluid flow in porous media at temperatures high enough that phase changes may occur. In the thermal conductivity test cell (about $3.28-\mathrm{cm}$ long), the apparent thermal conductivity may be several times the true conductivity for two-phase systems. Some of the parameters that determine the magnitude of the heat-pipe effect are known. Su has developed an experimental apparatus (Figure 5) that should help to evaluate the magnitude of the mixing zone and its nature and properties in a flowing system. If the effect is important, it will be incorporated into a three-dimensional finite-difference model being developed by Su for study of fluid flow where phase changes occur.

In addition to the above thermal work, the several investigators have an ongoing program of peasuring thermal properties of an increasing number and range of rock types. These results are being used to test the various correlations and models and to add to our catalog of thermal data.

\section{Fluid Flow and Storage Capacity}

Work is progressing on the messurement of fluid flow and storage capacity of rocks at elevated pressures and temperatures. This work is partly funded by a grant from industry.

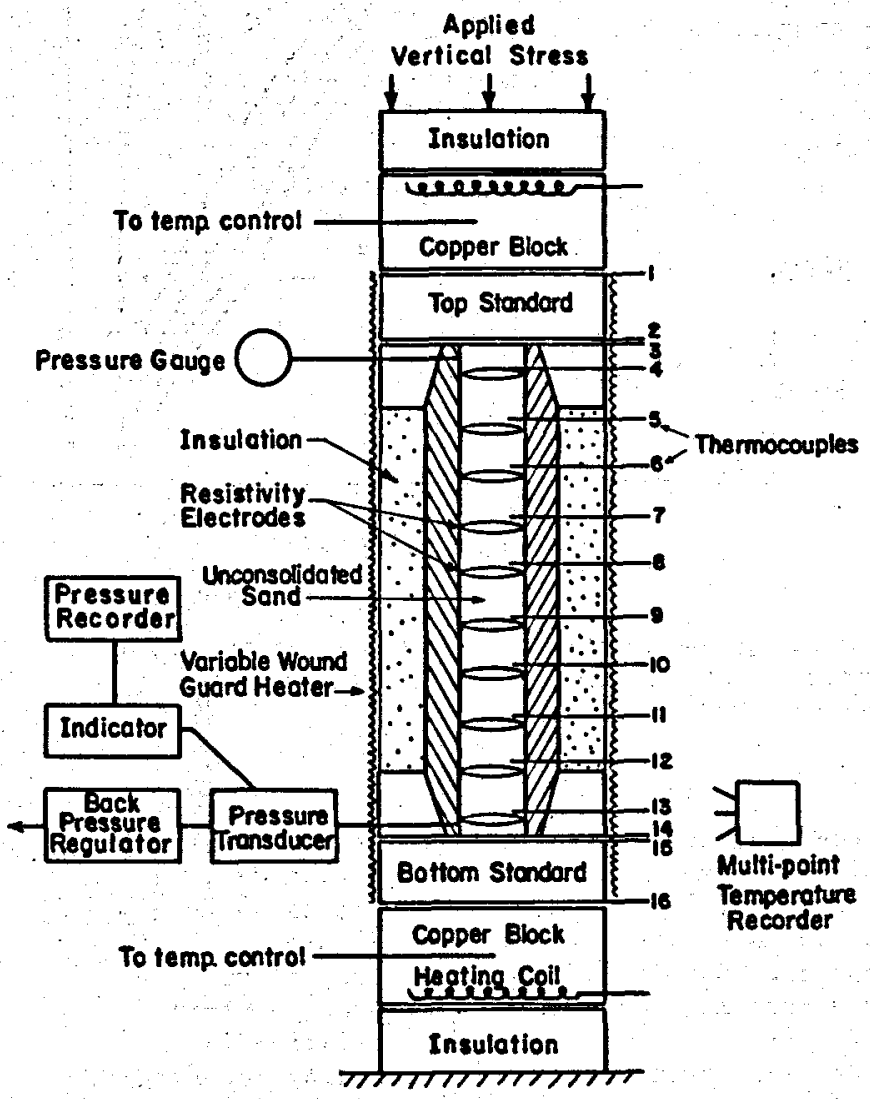

XBL $7811-6210$

Figure 5. Experimental apparatus for evaluating the magnitude of the heat-pipe effect in flowing systems.
Wong (1978) has measured the permeability of $a$ number of sandstones and has shown that permeability decreases sharply with incresse in temperature. Figure 6 shows an example of this effect for a Cerro Prieto sandstone. Three possible causes of this effect are being investigated. The first of these is the effect of thermal expansion in closing pore necks to fluid flow. This is being investigated using a network model of porous medis in which tube diameters are decreased by thermal expansion of the matrix. However, this is not believed to be a very important effect since porous media not containing clay, quartz, or water as the flowing fluid do not show any significant reduction in permeability with increased temperature. Second, the dissolution of quartz with subseguent plugging by the redeposition of silica in pore necks has been proposed as a cause of permeability reduction. Since much of the permeability is recovered upon cooling, the latter factor cannot be considered of major importance. Analysis of silica in the effluent water has not disclosed any conclusive evidence. The third possible cause is that of clay swelling and migration. For this to be a cause of permeability reduction, clay swelling and migration would have to be greatly increased at elevated temperatures. A current study of clay swelling pressures at elevated temperatures may shed some light on this matter.

An epparatus for measuring pore and bulk compressibilities at elevated temperatures has been designed by Greenwald (1978), constructed in LBL shops, and is now being tested. The bulkcompressibility part of the apparatus makes use of three deflection sensor cartridges (DSC) transducers, which are able to measure deflections up to 0.015 in. and operate at temperatures as high as $480^{\circ} \mathrm{C}$. The pore volume compressibility portion of the apparatus makes use of a high-pressure Jergesen sight gauge. This latter component is somewhat limiting and will be replaced in the multiproperties apparatus by a gas-pressure balanced displacement cylinder (displacement being measured by a linear potentiometer). Problems with leaks in the system have hindered the calibration of the apparatus and its application to measurements

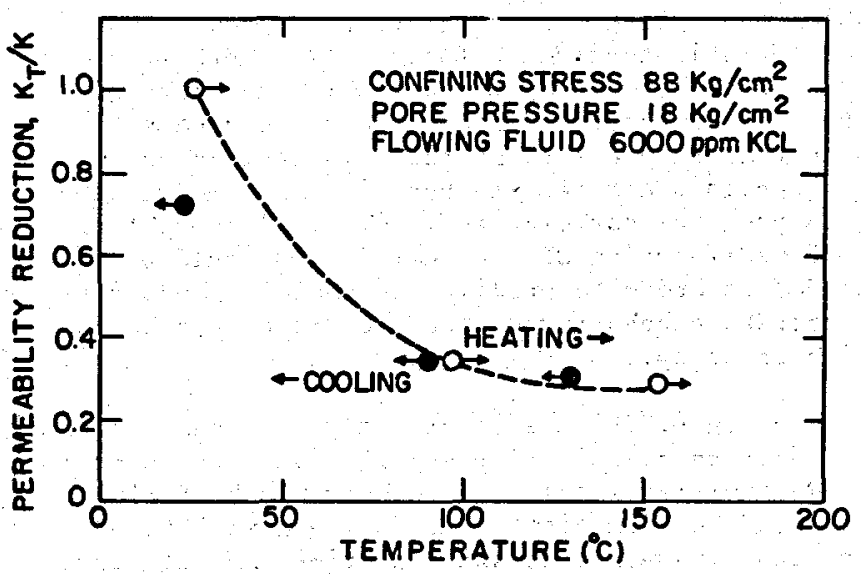

XBL $7812-13605$

Figure 6. Effect of temperature on the permeability of a Cerro Prieto sandstone. 
on actual 1 cores. However, progress has been made on the development of a model that will attempt to duplicate the volume changes in a two-component rock system (solid framework subjected to confining stress, and softer inner pore lining subjected to pore pressure). This two-component model may also be important in analysis of the fluid-flow capacity at elevated temperatures. It should finally be noted that bulk and pore thermal expansions may also be measured with the experimental apparatus described above.

\section{Electrical Resistivity Factor}

Wong (1978) has designed a new control system for measuring the electrical resistivity factor at elevated temperature. This sytem has been constructed in the electronic shop of the U.C. Berkeley Mechanical Engineering Department. This new control system makes it possible to impose a constant alternating current at various levels across a radial electrode system. The current is imposed only long enough to obtain a constant voltage across the system and at specified interva1s. The frequency of the current may be varied over a wide range, making it possible to evaluate any frequency-dependent effects. Some preliminary tests have been made using the new control system. Good contact of the center electrode with the rock test specimen was found to be very important in order to obtain useful results.

\section{Sonic Velocities}

During this period, Palen (1978) completed his thesis dealing with the measurement of $P$ - and $S$-wave velocities in fluid-saturated rocks at high temperatures and pressures. His most significant results were the substantial effects of temperature in reducing both compressional and shear-wave velocities. From these data, he calculated elastic moduli with the expected results that bulk and Young's moduli decreased with temperature.

Poisson's ratio also decreased with temperature. An important finding in this work was the nearly twofold difference in Poisson's ratio between dry and liquid-saturated cores, as may be seen for Cerro Prieto sandstone shown in Figure 7 . These results confirm earlier observations made by A1-Khafaji (1975).

Dr. Michael S. King, University of Saskatchewan at saskatoon, spent several weeks at LBL during spring 1978, helping to improve the design of our sonic measuring equipment. He dealt in particular with special design problems associated with the multiproperties measuring apparatus. We now feel confident that we will be able to measure $P$ - and S-wave velocities with good precision, and measure other properties concurrently.

\section{Multiproperties Testing Apparatus}

Considerable progress has been made on the new rock-properties test facility. Having received the assurance of industry participation in funding of the facility, design engineer was

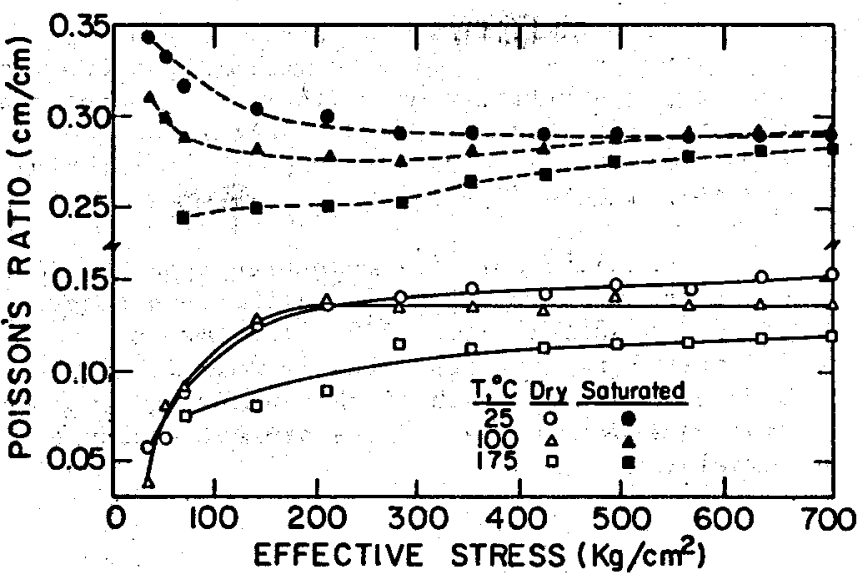

XBL $7812-13610$

Figure. 7. Bffect of temperature, stress, and fluid saturation on Poisson's ratio for Cerro Prieto sandstone.

retained to complete the final design and to supervise the construction and installation of the apparatus, The pressure vessel will soon go out for bids and the pressuring system has been obtained on loan from Lawrence Livermore Laboratory. Preparations for space, power; and peripheral equipment and facilities are well under way. Mockups of the various control and measuring components are being made for testing in our present pressure vessels. The target date for running the first test with this new apparatus is July 1, 1979 .

\section{PLANINED RESEARCH PROGRAM, FISCAL YEAR 1979}

Research on all fronts as described above will be continued in fiscal year 1979, with particular emphasis on the multiproperties measuring apparatus. Two new projects will be started. The first of these will be a cooperative project with Greenwald's research, in which pore and bulk thermal expansions will be measured during the heating period of the pore and bulk compressibility runs. These tests will be run at constant confining stress and pore-fluid pressure. The second new project will be an attempt to correlate sonic velocities with thermal conductivities. Such a correlation may make it possible to deduce in-situ thermal properties from sonic velocity $10 \mathrm{~g}$ data.

In the area of thermal properties, completion of the thermal conductivity model is planned by the end of fiscal year 1979. We expect enough progress on the one-dimensional heat-pipe experiment and the three-dimensional finite-difference model for fluid flow with phase changes to begin construction of a laboratory model to confirm these effects. In the wellbore temperature-gradient studies, the effects of convective heat transfer in the well lbore and in the surrounding formations will be studied. Thermal conductivity measurements with the steadystate comparator apparatus will be continued as core and drill-cutting samples become available. 
In the fluid flow and reservoir storage capacity studies, we plan to measure permeabilities and compressibilities on wellbore core samples at reservor conditions. The data obtained from these tests will be used to test the theoretical models now being developed.

The multiproperties measuring apparatus will be in the final testing and calibration stage by the end of fiscal year 1979. The target date for installing the apparatus is July $1,1979$. Before this date, each of the measuring components will have been tested in the present pressure vessels.

\section{REFERENCES - CITED}

A1-Khafaji, A. B., 1975. The effect of temperature on shear wave propagation in dry and liquid saturated rocks. M.S. thesis, Berkeley, University of California.

Anand, J., Somerton, W: H., and Gomaa, E., 1973. Predicting thermal conductivity of formations from other known properties. Soc. Pet. Eng. Jour., v. 13, no. 5 , p. 267.

Gaffari, A., 1978. Thermal conductivity of porous systems. Berkeley, University of California, Pet. Eng. Lab., progress report.

Greenwald, R., 1978. Design of apparatus for measuring compressibilities of reservoir type rocks at elevated temperatures. Berkeley, University of California, Pet. Eng. Lab., research progress report.

THERMODYNAMICS OF HIGH-TEMPERATURE BRINES K. S. Pitzer, D. J. Bradley, P. Z. Rogers, and J. C. Peiper

\section{INTRODUCTION}

An understanding of brines is essential to the exploitation of many geothermal resources. Consequently, a study of the solution thermodynamics of brine systems, both simple and complex, weak and strong, covering a wide temperature and pressure range, and combining both modeling and experimental work, began in 1975 .

The initial work involved analysis of existing thermodynamic data on simple electrolyte systems using equations developed by Pitrer. and coworkers (Pitzer, 1973; Pitzer and Mayorga, 1973, 1974; Pitzer and $\mathrm{Kim}, 1974)$. The goal of the modeling was to provide a compact set of equations capable of reproducing, at various temperatures and pressures, the existing data within experimental error up to practical concentrations ( $6 \mathrm{M})$ in terms of parameters having physical significance.

The program to measure heat capacities arose because of inadequate literature data on electrolyte systems. The primary goal of the experimental program is to supply data on simple and complex electrolyte systems at high temperatures and
Hoang, V. T., 1978. Estimation of in-situ thermal conductivities from temperature gradient measurements. Berkeley, University of Califorria, Pet. Eng. Lab., research project report.

Martínez-Baez, L. F,, 1979. Thermal conductivities of core samples from the Cerro Prieto geothermal field and an improved prediction method, in Proceedings, First Symposium on the Cerro Prieto Geothermal Field, Baja California, Mexico, September 20-22, 1978 , San Diego. Berkeley, Lawrence Berkeley Laboratory, LBL-7098.

Palen, W. A.; 1978. The effect of temperature, pressure, and saturation on sonic velocities and dynamic elastic moduli of reservoir sandstones. M.S. thesis, Berkeley, University of California.

Somerton, W. H., 1975. Thermal properties of partially liquid-saturated rocks at elevated temperatures and pressures. Berkeley, University of Californis, final report of API research project 155 .

1977. Apparatus for measurements of properties and behavior of rock-fluid systems at high temperatures and pressures. Berkeley, University of California, Pet. Eng. Lab., report.

Su, H. J., 1978. Heat transfer in porous media with fluid phase changes. Berkeley, University of Californis, Pet. Eng. Lab., research proposal.

Wong, I., 1978. The effect of temperature on absolute permeability and formation factor. Berkeley, University of California, Pet. Eng. Lab., research project report. pressures, both along and away from the liquidvapor saturation curve. In addition to the direct use of these data, they will provide a base for checking and refining various models.

Though the modeling and experimental work relate directly to electrolyte systems common to geothermal brines, the results are applicable to such areas as biological fluids, battery electrolytes in aqueous and nonaqueous solvents, plating baths, waste effluents, materials corrosion from electrolyte systems, and marine chemistry.

\section{PROGRAM, IN FISGAL YEAR 1978}

During the period of this report, modeling calculations were undertaken for several areas of interest.

of most general interest is an expression for the Debye-Hückel parameters for aqueous electro1ytes over the full range of temperature and pressure. This requires equations for both the volumetric and dielectric properties of water. In connection with this program, Silvester and 
Pitzer (1977) proposed dn equation, for the dielectric constant for water, which was quite satisfactory along the saturation curve. But the pressure derivatives of this equation failed to fit the data as well as desired; hence we sought an improved form of equation. The result is an equation that is valid from 0 to $350^{\circ} \mathrm{C}$, and saturation pressure to 2,000 bars below $100^{\circ} \mathrm{C}$ an $1,5,000$ bars above $100^{\circ} \mathrm{C}$. The equation has the following form:

$$
D=D_{1000}+C \log \left[\frac{B+P}{B+1,000}\right]
$$

where

$$
\begin{aligned}
D_{1000} & =U_{1} \exp \left[U_{2} T+U_{3} T^{2}\right] \\
c & =U_{4}+U_{5} /\left(U_{6}+T\right), \text { and } \\
B & =U_{7}+U_{8} / T+U_{9} T
\end{aligned}
$$

The temperature, $T$, and the pressure, $P$, have units of Kelvin and bars, respectively. The uncertainty in the fit is approximately $0.1 \%$ below $70^{\circ} \mathrm{C}$ and better than 17 at higher temperatures. The values of $U_{1}$ to $U_{9}$ are as follows:

$$
\begin{aligned}
& U_{1}=3.4279 \mathrm{E} 2 \\
& U_{2}=-5.0866 \mathrm{E}-3 \\
& U_{3}=9.4690 \mathrm{E}-7 \\
& U_{4}=-2.0525 \\
& U_{5}=3.1159 \mathrm{E} 3
\end{aligned}
$$$$
U_{6}=-1.8289 E 2
$$$$
\mathrm{v}_{7}=-8.0325 \mathrm{E} 3
$$$$
\mathrm{V}_{8}=4.2142 \mathrm{E} 6
$$

$U_{9}=2.1417$

With the volumetric equation of Keenan et al. (1969) and this expression for the dielectric properties of water, the Debye-Hickel parameters for activity and osmotic coefficients, enthalpy, heat capacity, apparent molal volume, compressibility, and expansivity were calculated over the range from $0^{\circ}$ to $350^{\circ} \mathrm{C}$, and saturation pressure to 1,000 bars.

Values of the various parameters have been compared with those believed to be reliable from the literature and found to agree to within 17 over the range of $10^{\circ}$ to $50^{\circ} \mathrm{C}$, and to within $5 \%$ from $0^{\circ}$ to $70^{\circ} \mathrm{C}$ A direct check of the parmeters at temperatures above $70^{\circ} \mathrm{C}$ is not possible; however, indications are that the error is less than $10 \%$ at temperatures below $300^{\circ} \mathrm{C}$. At temperatures above $300^{\circ} \mathrm{C}$ and pressures near the saturation pressure, the error probably increases to as much as $25 \%$. Tables of values of the slopes have been prepared and will be published soon, as a part of a complete report of this work (Bradley and Pitzer, 1979).

The thermodynamic properties of very highvalance electrolytes were considered and a paper published (Pitzer and Silvester, 1978). By combination of both enthalpy and Gibbs energy data with theoretical guidance; previously confused results have been given a satisfactory interpretation.

Partially in preparation for the treatment of our own experimental results, the literature data for both volumetric and thermal properties of NaCl and XCl solutions were modeled for the full range of temperature and pressure. Although reasonably satisfactory representations were obtained, the limitations of accuracy and range of data were also most apparent. If our own measurements can be added soon, that will be done before publishing on these topics. However, interim equations are available if desired.

Our experimental instruments are described below. Each is now in operation and beginning to yield useful data.

\section{Calorimeter}

The flow calorimeter follows the basic design of Picker et al. (1971).- Water flows through stainless steel tubing past a wire resistance heater, and the temperature rise of the water is measured using a platinum resistance thermometer. Solution is displaced at the same rate through a second unit of identical construction. Either the difference in the two temperature rises, or the change in heating power needed to balance the temperature rises, can be measured to yield the heat capacity difference between water and solution. Because platinum resistance thermometers are used as the temperature sensors, the absolute temperature rise can also be determined, giving an accurate measurement of the power loss of the heaters. Heat capacity measurements accurate to 0.17 or better can be obtained.

The calorimeter is encased in an evacuated copper block, which can be heated to over $300^{\circ} \mathrm{C}$ by a fluidized bath. A fluid pump designed for use in high-pressure liquid chromatography provides constant flow rates at pressures up to 10,000 psi. Thus, heat capacity measurements as a function of both pressure and temperature can be taken over these ranges.

\section{Densimeter}

A mercury displacement densimeter of the type described by Ellis (1966) has been constructed. The only major design change from Ellis's is that the volume of displaced mercury is messured with a cathetometer and a precision-bore glass capillary, rather than by weighing.

The densimeter is designed for use at temperatures up to $300^{\circ} \mathrm{C}$ and pressures to 600 bars. The sample reservoir has been constructed of a corrosion-resistant nickel-based alloy, which should be suitable for investigating the densities of very corrosive salts like $\mathrm{MgCl}_{2}$.

The accuracy of the measurements depends on the accuracy of the volumetric data for water, which is used to calculate the volume of the sample chamber. The data on water over the temperature and pressure range to be investigated is accurate to approximately $100 \mathrm{ppm}$. The equipment is designed to give a precision of approximately $15 \mathrm{ppm}$ at $200^{\circ} \mathrm{C}$, and $30 \mathrm{ppm}$ at $300^{\circ} \mathrm{C}$. 
PLANS FOR FISCAL YEAR 1979

First priority will be given to experimental heat capacity and density measurements for the primary brine components, $\mathrm{NaCl}, \mathrm{MgCl}_{2}, \mathrm{Na}_{2} \mathrm{SO}_{4}$, and $\mathrm{KCl}$. The results for $\mathrm{NaCl}$ and $\mathrm{KCl}$ will be added to the data bases from the literature to complete the already well-advanced modeling programs for these substances. Similar modeling work will follow for $\mathrm{MgCl}_{2}$ and $\mathrm{Na}_{2} \mathrm{SO}_{4}$. Thereafter we will examine mixed electrolytes and other special topics such as carbonate solutions.

\section{REFERENCES CITED}

Bradley, D. J., and Pitzer, R. S., 1979. Thermo dynamics of electrolytes, XII, dielectric properties of water and Debye-Hückel parameters to $350^{\circ}$ and $1 \mathrm{kbar}$. Jour. Phys. Chem. ; v. 83, p. 1599.

Ellis, A. J., 1966. Partial molal volumes of alkali chorides in aqueous solutions to $200^{\circ} \mathrm{C}$. Jour. Chem. Soc. A, p. 1579.

Keenan, J. H., Reyes, F. G., Hili, P. G., and Hoore, J. G., 1969. Steam tables. New York, John Wiley.
Picker, P., Leduc, P., Philip, P., and Desnoyer, J., 1971. Heat capacity of solutions by flow microcalorimetry. Jour. Chem. Thermo., v. 3, p. 631 .

Pitzer, K. S., 1973. Thermodynamics of electrolytes: I, theoretical basis and general equations. Jour. Phys. Chem., v. 77, p. 268.

Pitzer, K. S., and Kim, J. J., 1974. Thermodynamics of electrolytes. Jour. Amer. Chem. Soc, v. 96, p. 5701 .

Pitzer, K. S., and Mayorga, G., 1973. Thermodynamics of electrolytes: II, activities and osmotic coefficients for strong electrolytes with one or both ions univalent. Jour. Phys. Chem., v. 77, p. 2300.

1974. Thermodynamics of electrolytes, III, activities and osmotic coefficients for 2-2 electrolytes. Jour. Soln. Chem., v. 3, p. 539 .

Pitzer, K. S., and Silvester, L. F., 1978. Thermodymamics of electrolytes: XI, properties of $3-2,4-2$, and other high-valence types. Jour. Phys. Chem., v. 82, p. 1239.

Silvester, L. F., and Pitzer, K. S., 1977. Thermodynamics of electrolytes, VIII, hightemperature properties, including enthalpy and heat capacity, with application to sodium chloride. Phys. Chem., v. 81, p. 1822.

\title{
SOLUBILITY OF ALBITE IN THE AQUEOUS PHASE AT ELEVATED TEMPERATURES
}

\author{
J. M. Neil and J. A. Apps
}

\section{INTRODUCTION}

Albite, NaAlsi $0_{8}$, is a comion rockforming mineral belonging to a group of minerals called the feldspars. It crystallizes in a variety of rock types, including such diverse types as saline lake beds, limestones, altered tuffs and basalts, and many igneous and metamorphic rocks. These different rock types are formed over a wide range of temperatures and pressures. Albite is, therefore, of interest not cnly because of its comon occurrence, but also because of the diverse range of environments in which it forms.

The purpose of this study is to find out bow albite affects the groundwater composition over a range of temperatures from $25^{\circ}$ to $400^{\circ} \mathrm{C}$ and from pressures from 1 to 500 bars. This temperature-pressure range encompasses the conditions likely to be found in all exploitable geothermal resources, waste isolation sites, hot-water storage aquifers, oil reservoirs, and uranium resources. The study is designed to investigate not only the equilibrium relations between the albite and the groundwater, but also the rates of equilibration expected under differing conditions of $\mathrm{pH}$ and salinity.

The most stable albite structure at low temperatures consists of a framework of ordered silica and aluminum atoms each surrounded by a tetrahedron of oxygen atoms. Interstices of the tetrahedral framework contain sodium atoms. However, most naturally occurring albites are subject both to disordering of the silicon and aluminum atoms and substitution of potassium and calcium for sodium. Charge is conserved in the latter substitution by additional aluminum in place of silicon.

For a precise evaluation of the kinetics of solution and equilibrium relations, the albite must be well characterized so that the effect of solid solutions and ordering can be determined. For this reason, care was taken to analyze and measure the crystallographic. properties of several albites before begiming the experimental program (Apps and Neil, 1978). A metamorphic albite from the Franciscan formation at Cazadero in northern California was finally selected on the basis of its purity and degree of ordering. The following is a description of the equipment and experimental techniques used to measure aqueous solubility, the characterization of the starting materials, and preliminary results so far achieved.

\section{ACTIVITIES IN FISCAL YEAR 1978}

\section{Equipment}

The heart of the system is a 1-liter autoclave manufactured by Autoclave Engineers, Inc., 
which can be operated to pressures of 7,500 psi, at temperatures up to $400^{\circ} \mathrm{C}$. It is fabricated out of Hastelloy-C 276, an alloy that is highly resistant to corrosion by hot brines. The atoclave is equipped with an air-driven stirring system with a magnetically coupled sealed shaft, thereby eliminating contamination from the bearing packing. The sampling system allows us to sample either the vapor phase at the top of the vessel or the liquid phase $2 \mathrm{in}$. from the botcom of the vessel.

A recharge system has been assembled so that the autoclave can be refilled while maintaining pressure and temperature within the vessel. The principal components of the system consist of a 1:150 air-driven Sprague pump, a 1/2-liter oilwater separator, and an adjustable $(5,000$ to 10,000 psi) relief valve. The pump and relief valve work against each other to balance the pressure in the autoclave when it is refilled. Auxiliary plumbing permits refilling of the oilwater separator. Figure 1 is a schematic diagram of the system.

Heat is provided by an external resistance furnace. A Leeds \& Northrup recorder with D.A.T. controller is used to operate the furnace and provide a record of the temperature in the autoclave. The temperature-sensing element is a chrome1-alumel thermocouple, which is located in a thermocouple well that is the same length as the liquid-phase sampling tube.

Although the autoclave meets the ASME code for manned-area bafe operations, a safety shield of 1/4-in. iron plate with 3/4-in. plywood lining has been erected around it. These specifications are recommended by Holloway (1971) for high-pressure systems. In addition to the rupture disk installed by the manufacturer on the at toclave, a second rupture disk assemby has been added to the high-pressure line from the separator. Both rupture disks are rated $10 \%$ over the maximum working pressure of the autoclave.

\section{Characterization of Starting Material}

The initial results of a search for a chemically pure albite have been described elsewhere (Apps and Neil, 1978). The reported analyses of a Franciscan vein albite from Oregon (Coleman, 1978, unpub. data) did not contain calcium at the level reported in the provisional analyses (1.1 wt 7 ). Therefore, we decided to make point chemical analyses of the selected Cazadero albite with an electron microprobe to check the bulk chemical analyses and to identify and determine the chemical composition of coexisting phases.

The analyses were made with an ARL, elght channel, electron microprobe (Model SEMQ), using standards of similar composition to the unknowns. All results were corrected for background and machine drift, and the empirical matrix correction of Bence and Albee (1968), and of Albee and Ray (1970) were applied to 811 results. The albite analyses are listed in Table 1. The albite analyses have been normalized to 32 oxygens using the method of Deer et al, (1966) and are tabulated in Table 2. An Amelia Courthouse albite analysis from Deer et al. (1963) is included for comparison.

With the exception of two points on a traverse across a twinned albite where the calcium concentration attained 0.26 and 0.24 wtz $(\mathrm{Ab}-007 \mathrm{C})$, the calcium analyses were 0.06 wt $\%$ or less. The normalized analyses give the molecular percentage of albite in the range of 98.8 to 99.8 , which indicates that the material being used for the tudy is almost pure albite.

The accessory minerals observed include lawsonite, omphacite, quartz, and an unidentified phyllosilicate. Lawsonite is the probably source of calcium contamination in the bulk analysis. In the future, heavy liquid separations will be used to remove traces of this phase from the albite.

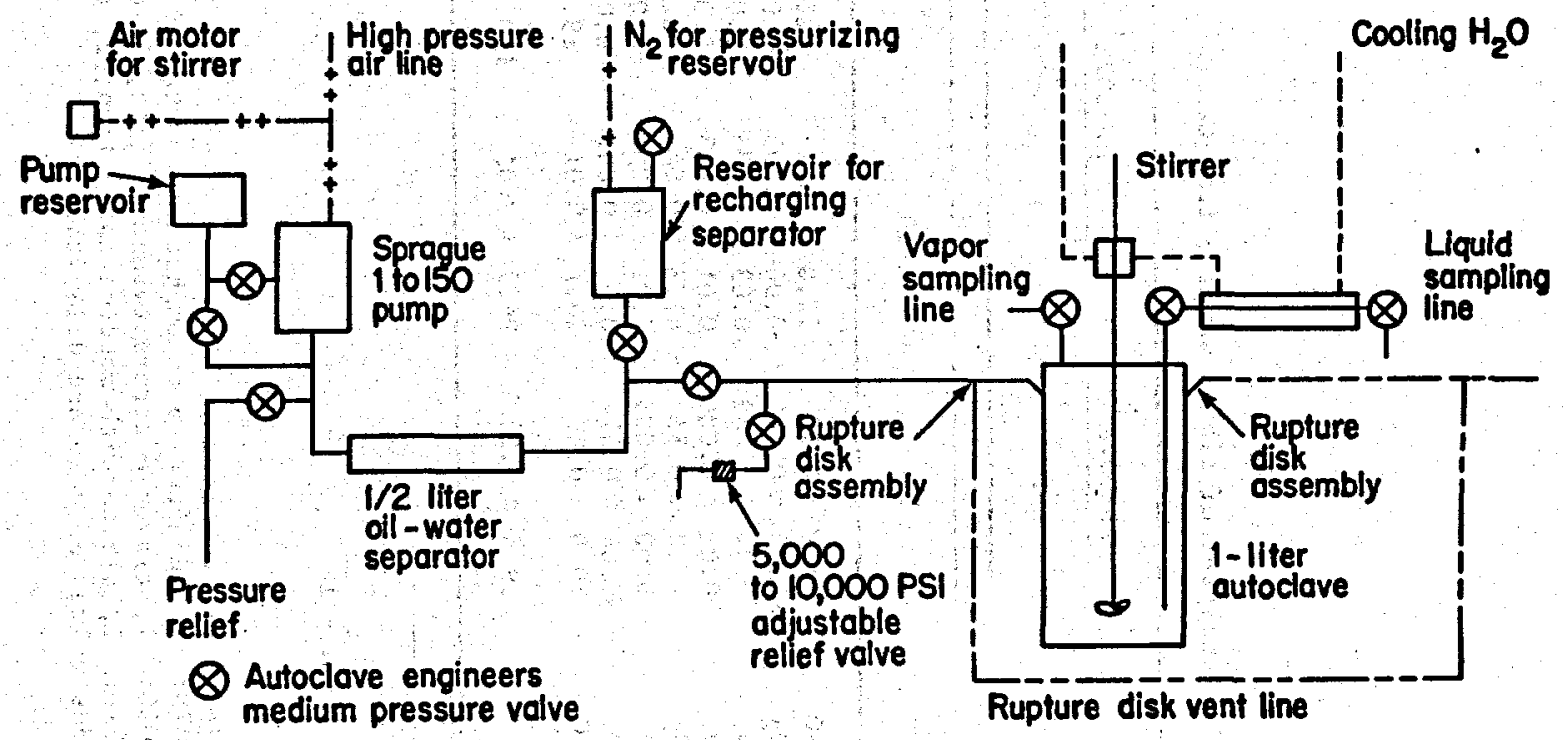

XBL $794 \cdot 1237$

Figure 1. Schematic dlagram of the 1-11ter autoclave and its support system. 
Table 1. Analyses of albite samples from Cazadero, California, in wt $\pm 8 . *$

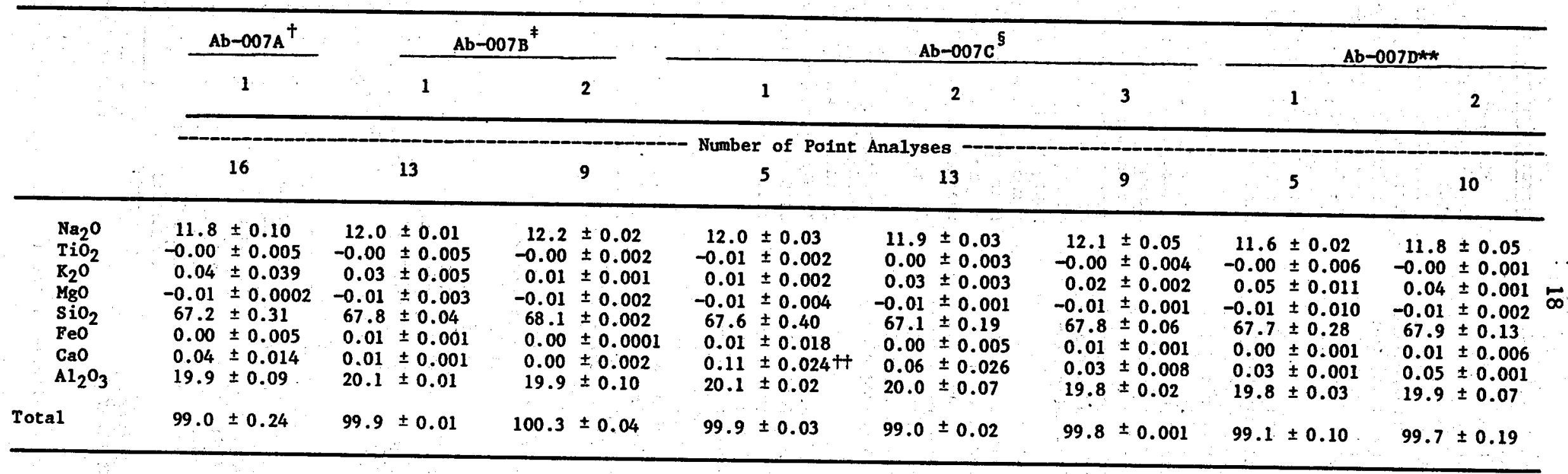

$*_{g}=\sqrt{\frac{\sum\left(x_{1}-x\right)^{2}}{n-1}}$

${ }^{+} \mathrm{Ab}-007 \mathrm{~A}: \mathrm{i}$, traverse.

F Ab-007B: 1, ad jacent to an omphacite crystal; 2 , traverse

Ab-007C: 1, traverse across twinned albite; 2 , crystal with good cleavage; 3 , traverse

$\mathrm{Ab}-007 \mathrm{D}: \mathrm{l}$, albite with mott led extinction; 2 , traverse
${ }^{+}$Includes values of 0.26 and 0.24 wt $\%$. 
Table 2. Cazadero, California, albite analyses calculated on the basis of 32 oxygen atoms $\mathrm{Z}_{4} \mathrm{z}_{16} \mathrm{O}_{32}(\mathrm{Na}, \mathrm{K}, \mathrm{Ca})\left[\mathrm{Al}_{4} \mathrm{Si} 12 \mathrm{O}_{32}\right]$.

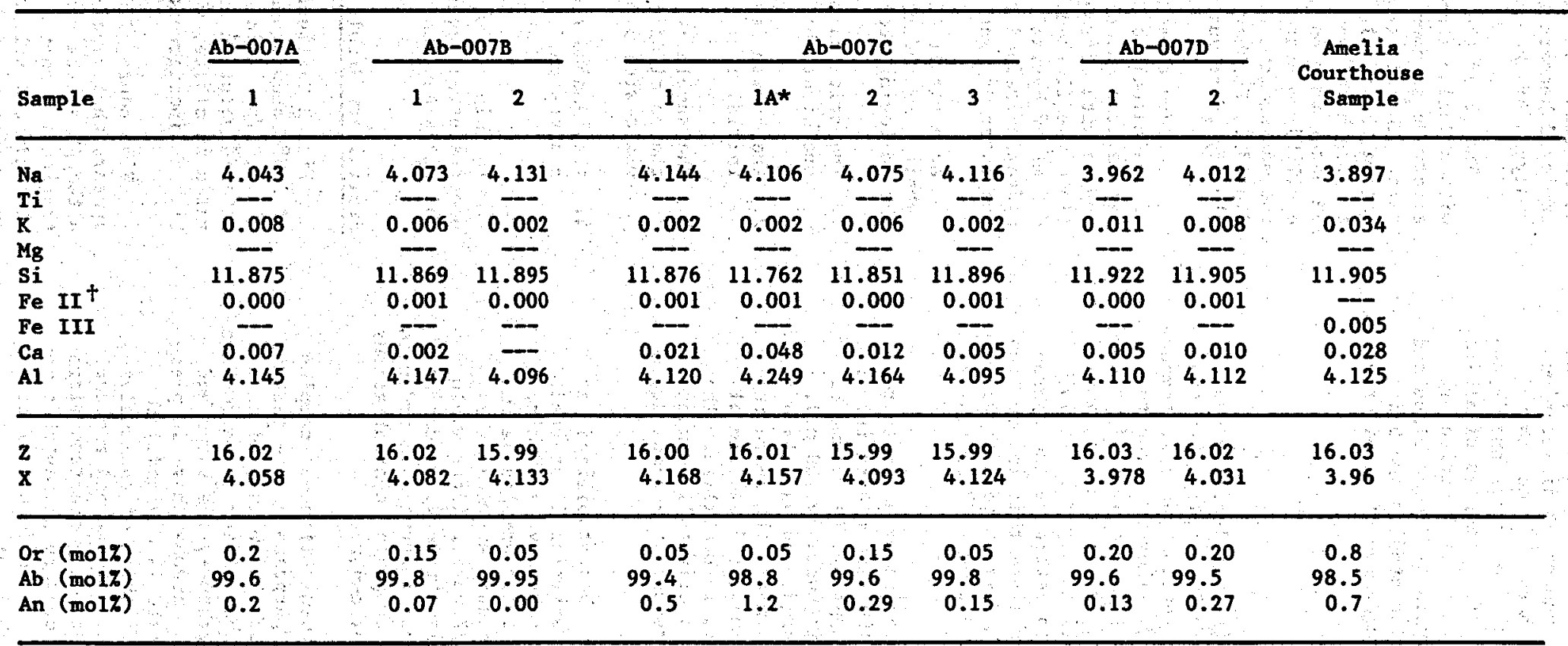

*Average of two analyses from Ab-007c-1 containing 0.26 and 0.24 wtz CaO.

total iron reported as Fe II. 
Ion-beam-thimed sections of the Cazadero albite were also examined by transmission electron micros copy at magnifications up to 100,000 in order to determine whether or not the albite is homogeneous (consists of one phase only). Phase homogeneity was confirmed. However, the albite has a very large number of dis locations $\left(10^{8} / \mathrm{cm}^{2}\right.$ of exposed surface) and bent twins, which is indicative of a high stress and is unusual for albite. Currently, samples of albite growing into vugs from the same location are being prepared for analysis of dislocations and single crystal diffraction studies are being conducted to confirm the degree of Al-Si order in the sample.

Experimental Procedure

So far, five preliminary solubility experiments have been successfully completed on the saturation curve of the aqueous phase at temperatures of $125^{\circ}$ and $250^{\circ} \mathrm{C}$. They were run to verify the experimental plan, to identify problems, and to develop and verify analytical procedures on typical solution samples. It is particularly important to determine the appropriate rates of reaction since this information allows us to estimate the time needed to achieve equilibrium between the albite and the aqueous phase.

The generalized procedure of a run is to load 25 grams of $-65+100$ mesh albite into the autoclave, and add the appropriate volume of $0.1 \mathrm{NaCl}$ solution to it (usually $700 \mathrm{m1}$ ). Once the closure is secured, the autoclave takes approximately 45 min. to reach the operating temperature, and approximately 2 additional hours for the temperature to stabilize. The controller functions as a critically damped oscillator once it has reached the temperature of the run.

After the temperature has stabilized, a sample is taken and the stirring is started. Initially, samples were taken every $2^{n}$ min. When $n=12$, the time between samples became excessive and subsequent samples were taken approximately every $11 / 2$ days. After evaluating the results of this strategy, we decided to sample at 5 -hr or $10-\mathrm{hr}$ intervals in order to clarify fluctuations in component concentrations during the latter part of any run.

A run is completed when sufficient samples have been taken for the purposes of the test or when the water level drops below the end of the liquid-phase sampling tube. After the autoclave has cooled to room temperature, the water and albite are removed. The aqueous phase is pressure-filtered, and filtrate is divided into three aliquots for verification of the analytical procedures. The filter cake and residual albite is retained for scaming electron microscopy to identify any secondary phases that may have formed and to observe the amount of corrosion of the starting material.

Solution samples were initially anslyzed by atomic absorption spectroscopy for $\mathrm{Si}, \mathrm{Al}, \mathrm{Na}$, and $\mathrm{Ca}$ concentrations. Additional confirmatory analyses for aluminum and silica have been made using respectively an aluminon method (Packham, 1958), and the molybdosilicate method (American Public Health Ass., 1975). These colorimetric techniques have proven satisfactory and will be employed henceforth for aluminum and silica analyses of the solutions.

The pH of the solution samples are measured with a Vanlab standard combination glass $\mathrm{pH}$ electrode as soon as they cool to room temperature. The electrode is standardized immediately before the sample $\mathrm{pH}$ is determined. The $\mathrm{pH}$ of samples have: been observed to change during the pH determination and probably reflect the disequilibirum state of the solution at the time of the measurement or uptake of atmospheric carbon dioxide. Further studies are under way to clarify $\mathrm{pH}$-measurements.

Because of some concern regarding corrosion of the autoclave due to the presence of residual oxygen, the autoclave atmosphere is purged of oxygen with nitrogen. During one run, the autoclave was flushed with nitrogen for 5 min., and $0.5 \mathrm{ml}$ of hydrazine was added. However, the hydrazine raised the $\mathrm{pH}$. In succeeding runs, the autoclave, was flushed with nitrogen only.

As a result of the preliminary runs, the sampling procedure has been modified to include the following steps:

1. The agitator of the autoclave is stopped for one minute before sampling.

2. The sample is taken after rejection of the initial $5 \mathrm{ml}$ of solution.

3. The sample is centrifuged for $5 \mathrm{~min}$, and the $20 \mathrm{ml}$ of clear solution is drawn off and mixed with $5 \mathrm{ml}$ of $0.01 \mathrm{~N} \cdot \mathrm{KOH}$ solution.

4. The remainder of the solution is used to measure $\mathrm{pH}$.

In this way we hope to avoid some current uncertainties regarding the stability of the solutions between sampling and analysis.

\section{Preliminary Results}

Figure 2 illustrates the results of one run at $240^{\circ} \mathrm{C}$ showing analyses for silica and aluminum. The ratio of silica to aluminum that has entered solution exceeds the stoichiometric ratio in albite, which indicates that dissolution is incongruent.

Five hours after agitation comenced, it appears that aluminum saturated the solution, although silica continued to increase in concentration for another 25 hours. Thereafter, both aluminum and silica concentrations declined, suggesting precipitation of a secondary phase. Further study is required to determine if and when albite reaches 8 aturation in the $0.1-\mathrm{N}$ NaCl solution. 


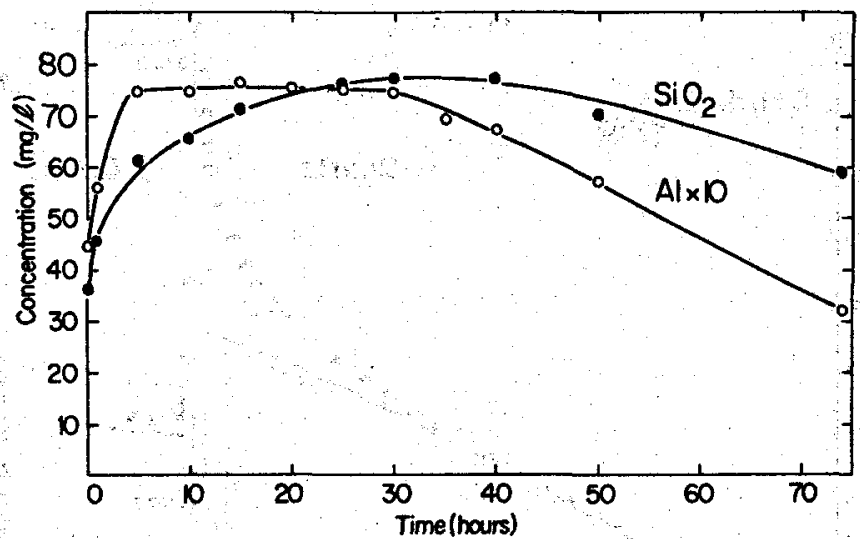

$\cos$ ration

Figure 2. The dissolution of $25 \mathrm{~g}$ of $-65+100$ mesh Cazadero albite in $0.1 \mathrm{~N} \mathrm{NaC1}$ at $250^{\circ} \mathrm{C}$.

A comparison of scanning electron microscope images of the albite charge, both before and after the dissolution study, indicates that the albite cleavage fragments suffered minor corrosion or erosion through rounding of the edges, and $s$ calloping and pitting of the faces. There is no evidence of epitaxial growth of secondary phases, or any indication that the finer fractions of the particulate material is other than dust originally adhering to the charge.

\section{FUTURE WORR}

The immediate need will be to continue solubility measurements of albite along the saturation curve of water between $125^{\circ}$ and $300^{\circ} \mathrm{C}$ in $0.1 \mathrm{~N} \mathrm{NaCl}$ solutions. After sufficient experience has been gained in sampling and analyzing the solutions, an extended study will be made of solutions of varying $\mathrm{NaCl}$ concentration between $0.001 \mathrm{~N}$ and $1.0 \mathrm{~N}$, and of $\mathrm{NaOH}$ between $0.001 \mathrm{~N}$ and $0.1 \mathrm{~N}$. Al1 solubility mea surements will be made along the saturation curve of water. At this point the pressurized system operated at 500 bars will be tested, and further solubility measurements made up to $400^{\circ} \mathrm{C}$ at that pressure.

Data reduction and evaluation will continue. A refined model to describe activity coefficients of the species in solution at elevated temperatures will be investigated, and
Improved thermodynamic data for alteration products and aqueous species will be calculated from recent calorimetric data described in the published literature.

The equilibration studies currently under way and projected will provide much valuable semiquantitative information on reaction rates between albite and the aqueous phase. Such information will be evaluated with the objectives of identifying the mechanisms of albite dissolution and precipitation, and of predicting rates of albite growth under a wide range of environmental conditions.

\section{ACKNOWLEDGEMENT}

The authors are indebted to Professor H. R. Wenk, University of California, Berkeley, for making the TEM study of albite.

\section{REFERENCES CITED}

Albee, A. L., and Ray, L., 1970: Correction factors for electron probe microsnalysis of silicates, oxides, phosphates, and sulfates, Analytical Chem.; v. 42, pp. 1408-1414.

American Public Health Association, 1975. Standard methods for the examination of water and wastewater, 14 th ed. Amer. Pub. Health Assoc. pp. 486-490.

App 8, J. A., and Neil, J. K., 1978. Selected albites as candidates for hydrothermal solubility measurements. Berkeley, Lawrence Berkeley Laboratory, LBL-7058, pp. 10-13.

Bence, A. E., and Albee, A. L., 1968. Empirical correction factors for electron microanalysis of silicates and oxides. Jour. Geology, v. 76, pp. 382-403.

Deer, W. A., Howie, R. A., and Zussman, J., 1963. Rock-forming minerals in framework silicates. London, Longmans, Green and Co., Ltd., v. 4, p. 110 .

1966. An introduction to the rock-forming minerals. New York, John Wiley, Pp. 515-517.

Holloway, J. R., 1971. Interna11y heated pressure vessels, in Ulmer, G. C., ed., Research techniques for high pressure and high temperature. New York, SpringerVerlag, PP. 247-249.

Packham, R. F., 1958. The absorptrometric determination of aluminum in water, in Proc. Soc. Water Treat. Exam. 1. pp. 226-7 $\overline{34}$.

\section{THERMODYNAMIC PROPERTIES OF SILICATE MATERIALS} I. S. E. Carmichael, M. S. Chiorso, L. Moret, and S. A. Nelsón

\section{INTRODUCTION}

The liquid state is the essence of igneous activity and therefore a significant part of the way the earth works. A great deal is now known of the composition of natural liquids, but the physical and thermodynamic properties of sili- cate liquids are hardly known at a11. This project was designed to rectify this situation, and al so to contribute to the more extensive knowledge of the solid phases which initially saturate a cooling silicate liquid either on or below the surface. 


\section{ACTIVITIES IN FISCAL YEAR 1978}

In siliceous liquids, one of the earliest phases to precipitate is quartz $\left(\mathrm{SiO}_{2}\right)$. If this phase is accompanied by others, it is possible to calculate, the pressure at which the crystal assemblage equilibrated. This pressure, equivalent to depth, places a limiting value on the source region of a particular siliceous magma. Thus quartz crystals occurring as early crystallizing phases (phenocrysts) in a wide variety of lavas were examined to determine the extent of solid solution, the variation in the temperature of the $\alpha-\beta$ transition $(\sim 848 \mathrm{~K})$, the enthalpy associated with this transition, and the heat capacity of both $\alpha$ and B-quartz.

We found that the $\alpha-\beta$ inversion temperature, $T_{\alpha-\beta}$, is strongly influenced by the $A 1$ content of quartz, which ranged between 17 and $380 \mathrm{ppm}$. The enthalpy associated with the $\alpha-\beta$ transition, $\Delta \mathrm{H}_{\alpha-\beta}$, was measured over a range of $9.0^{\circ} \mathrm{C}$ by differential scaming calorimetry (DSC), but there is no measurable compositional effect on $\Delta \mathrm{H}_{\alpha-\beta}$. However, the finer the samples are crushed, the smaller the value of $\Delta \mathrm{H}_{\alpha-\beta}$. The observed decrease in $\Delta \mathrm{F}_{\alpha-\beta}$ as a function of grain size could be attributed to a surface energy of $682 \mathrm{ergs} / \mathrm{cm}^{2}$. A single piece of quartz requires $107.7 \pm 1.4 \mathrm{cal} / \mathrm{mole}$ for the temperature interval of 842 to $851 \mathrm{~K}$, which includes the enthalpy ssociated with the $\alpha-\beta$ inversion.

The heat capacity of two samples of quartz were measured by heating on the DSC, and there is a marked premonitory effect, which starts about $200^{\circ} \mathrm{C}$ below $\mathrm{T}_{\alpha-\beta}$ (Figure 1 ). Values

\section{2}

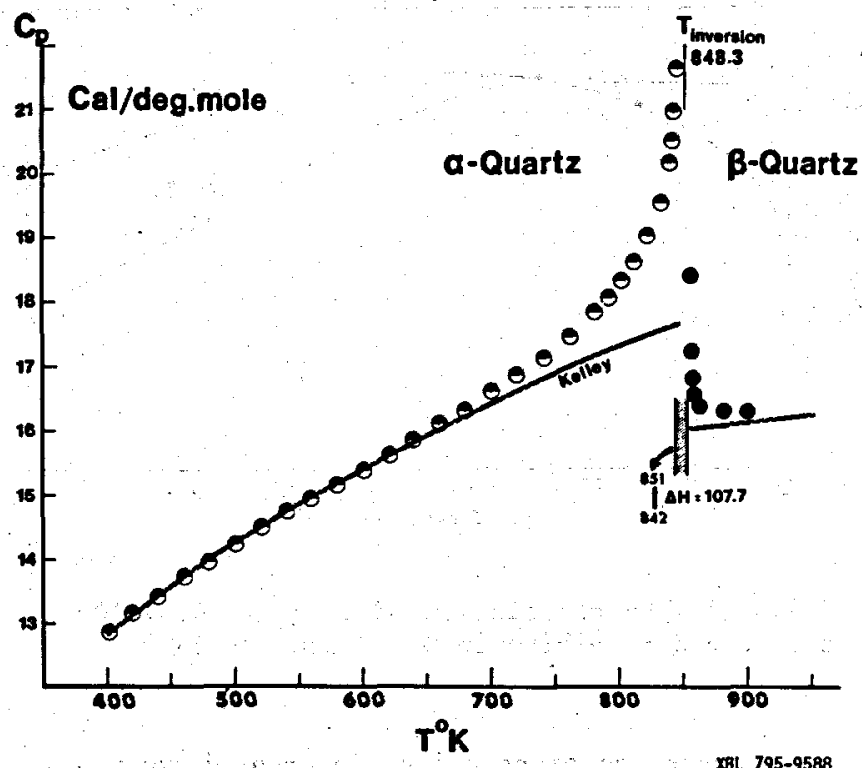

Figure 1. Heat capacity of quartz, $C_{p}$, as a function of temperature obtained by DSC. Halfcircles are values for $\alpha$-quartz and filled circles for $\beta$-quartz. The shaded area represents the temperature range 842 to $851 \mathrm{~K}$, for wich $\Delta H$ is $107.7 \mathrm{cal} / \mathrm{mole}$ (Table 2). The variation of $\mathrm{Cp}$ with temperature taken from Kelley (1960) is also shown.

of Cp at $10^{\circ}$ intervals are given in Table 1 , but at smaller interals as $\mathrm{T}_{\alpha-\beta}$ is approached because $C_{p}$ rises to very high values on both sides of the inversion interval.

Table 1. Molar heat capacity of $\alpha$-quartz and $\beta$-quartz ( $C_{p}$ in cal/mole-deg.).

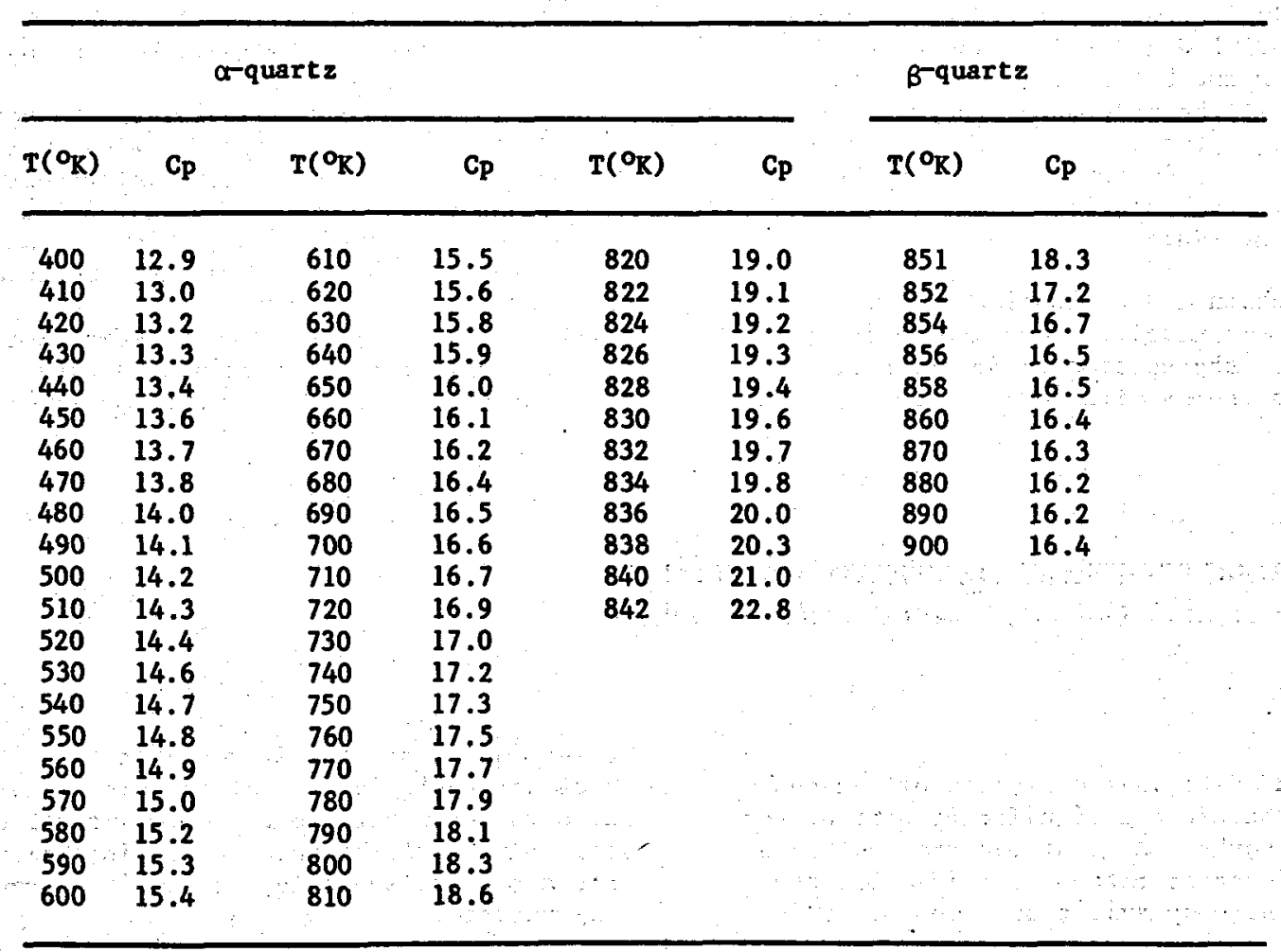


Table 2. Values of enthalpy of $\alpha-\beta$ transition and integrated ( $C_{p}$ from 400 to $900 \mathrm{~K}$ ).

\begin{tabular}{lll}
\hline & $\Delta \mathrm{H}_{\alpha-\beta}$ & $\mathrm{H}$ \\
& $(\mathrm{cal} / \mathrm{mole})$ & $\int_{400}^{900} \mathrm{CpdT}$ \\
& $(\mathrm{cal} / \mathrm{mole})$ \\
\hline This report: & $107.7 \pm 1.4$ & 7,891 \\
Relley (1960): & 290 & 8,090 \\
Robie et al. $(1978)=114$ & 7,930 \\
\hline
\end{tabular}

Values of $\mathrm{H}_{900}-\mathrm{H}_{4} \mathrm{OO}$ for quartz may be obtained by integrating the area under the $\mathrm{Cp}_{\mathrm{p}}$ curve from 400 to 842 , and from 851 to 900 , then adding the measured value of $\Delta H_{\alpha-\beta}$ obtained over the range of 842 to $851 \mathrm{~K}$. Our values are compared with published values in Table 2 , and the agreement with the more modern data is excellent. This study on quartz, which includes the measurement of lattice parameters and cell volumes of 52 specimens of quartz phenocrysts (which grew in the B-quartz stability field) is presently in press (Ghiorso et al., 1979).

The density, or specific volume, of $12 \mathrm{sili-}$ cate liquids of widely varying composition have been measured over the temperature range of $1,100^{\circ}$ to $1,550^{\circ} \mathrm{C}$. The preparation of starting glassy material free of gas bubbles; which would strongly affect the measured density, involves care and considerable time at high temperature in the furnace. The density was measured by weight loss of a Pt Wob of known volume that was suspended just above the silicate liquid, and then imersed a known distance into it. Surface tension corrections for the suspensi on wi re were avoided by using two Pt bobs of different volumes, but with suspension wires of similar radius. Al1 liquids, quenched to glasses at room temperature, were then analyzed by wet chemical techniques, and in $a 11$ cases considerable amounts $(200 \mathrm{ppm})$ of dissolved Pt were found. At the high temperatures of these experiments, the tips of the Pt bobs were prone to recrystallize to a few large crystals. This effectively prevented the bob entering the silicate liquid, for it was immediate ly drawn to the side of the crucible on touching the liquid, where it became welded to the walls of the Pt crucible. This effect could only be eliminated by machining new Pt bobs every two of three months.

The 12 liquids whose densities have been measured are composed of the following oxide components: $\mathrm{SiO}_{2}, \mathrm{TiO}_{2}, \mathrm{Al}_{2} \mathrm{O}_{3}, \mathrm{MgO}$, $\mathrm{CaO} \mathrm{Na}_{2} \mathrm{O}$, and $\mathrm{K}_{2} \mathrm{O}$. Preliminary values of the partial molar volumes of these oxide components are plotted in Figure 2, together with error bars representing plus or minus twice the standard error. Included in these data are published measurements, and all data were regressed

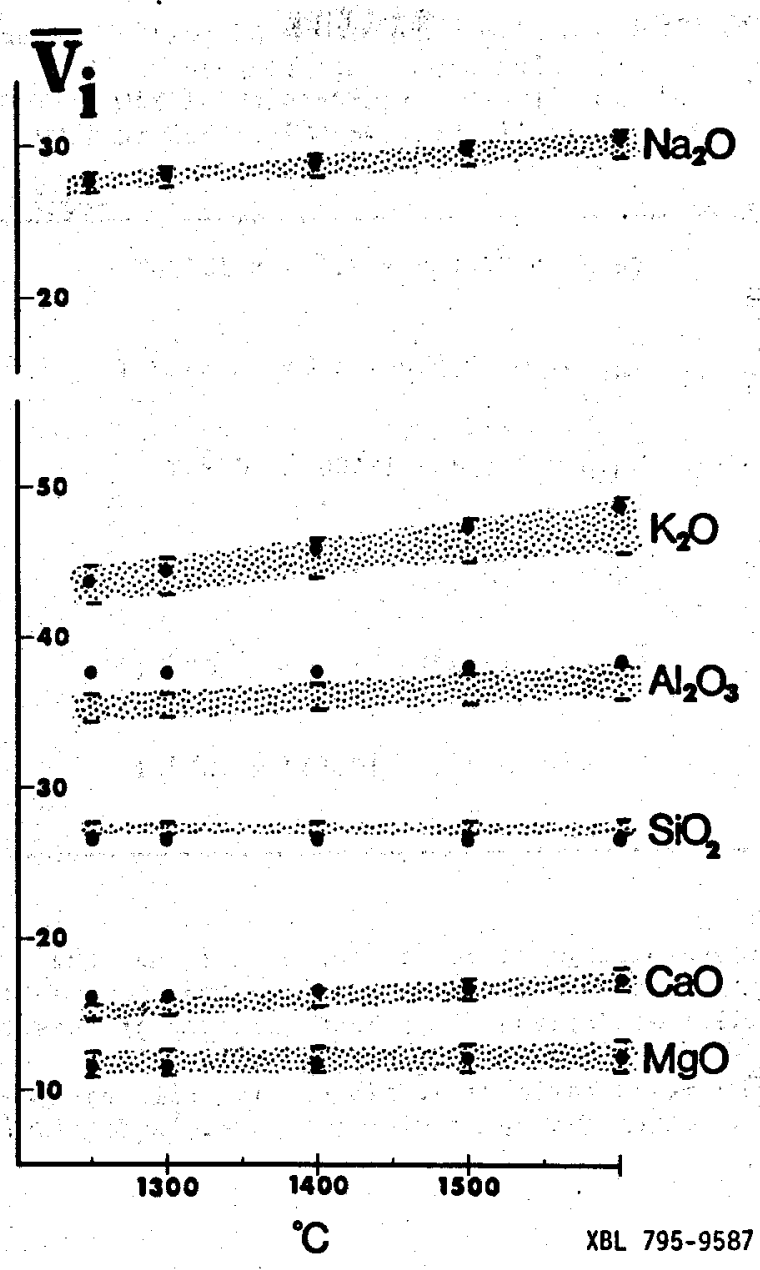

Figure 2. Partial molar volumes of oxide components (labeled) in silicate liquids obtained from 91 compositions. The width of the shaded areas represents \pm 2 standard errors sbout the mean. Published values of these quantities (Bottinga and Weill, 1970) are represented by solid circles.

by the multiple regression program in the SPSS package version 7.0 . Figure 2 shows that published values (Bottinga and Weill, 1970) of the partial molar volumes may lie outside the $95 \%$ confidence limits, particularly for $\mathrm{Al}_{2} \mathrm{O}_{3}$. Least squares analysis of the partial molar volumes with temperature leads to the value given in Table 3 .

Particular molar volumes for $\mathrm{TiO}_{2}$ have not been given, as these are notably compositiondependent, and at $1,400^{\circ} \mathrm{C}$ may vary between 22.5 and $28.8 \mathrm{~cm}^{3} /$ mole. In $\mathrm{Al}_{2} \mathrm{O}_{3}$-free silicate liquids, $\mathrm{dV} \overline{\mathrm{TiO}}_{2} / \mathrm{dt}$ has a positive s lope, but in the presence of $\mathrm{Al}_{2} \mathrm{O}_{3}$ this becomes negative. The interactions of $\mathrm{TiO}_{2}$ with other components in silicate liquids are presently being investigated.

\section{PLANNED ACTIVITIES FOR FISCAL YEAR 1979}

The density of silicate liquids with $\mathrm{FeO}$ and $\mathrm{TiO}_{2}$ as additional components will be measured 
Table 3. Preliminary values of partial molar volumes of oxide components in silicate liquids without $\mathrm{FeO}$ or $\mathrm{TiO}_{2}$ Applicable range is 1,523 to $1,873 \mathrm{~K}$, and data are in $\mathrm{cm}^{3} /$ mole.

$$
\begin{aligned}
& \overline{\mathrm{V}}_{\mathrm{SiO}_{2}}=27.138+9.939 \times 10^{-5} \mathrm{~T} \\
& \overline{\mathrm{v}}_{\mathrm{Al}_{2} \mathrm{O}_{3}}=27.500+5.095 \times 10^{-3} \mathrm{~T} \\
& \overline{\mathrm{V}}_{\mathrm{MgO}}=9.608+1.406 \times 10^{-3} \mathrm{~T} \\
& \overline{\mathrm{V}}_{\mathrm{CaO}}=5.811+6.115 \times 10^{-3} \mathrm{~T} \\
& \overline{\mathrm{V}}_{\mathrm{Na}_{2} \mathrm{O}}=17.831+6.340 \times 10^{-3} \mathrm{~T} \\
& \overline{\mathrm{v}}_{\mathrm{K}_{2} \mathrm{O}}=26.982+10.839 \times 10^{-3} \mathrm{~T}
\end{aligned}
$$

over a range of temperatures, and thus the partial molar volumes of the se two components will be derived. The heat capacity of densified glasses, made of $\mathrm{Na}_{2} \mathrm{O}-\mathrm{Al}_{2} \mathrm{O}_{3}-\mathrm{siO}_{2}$, will be measured in an attempt to identify any coordination change of Al from four-fold to six-fold as a function of pressure. The high-temperature heat content of compositions in the system $\mathrm{NaAlSi} \mathrm{O}_{8}-\mathrm{CaAl}_{2} \mathrm{Si}_{2} \mathrm{O}_{8}-\mathrm{CaMgSi}_{2} \mathrm{O}_{6}$ will be measured in order to obtain heats of fusion of these three components. We anticipate that a study of the thermal expansion of silicate glasses of various compositions, as a function of termperature, will allow any compositional effect on the galss transformation temperature to be isolated.

\section{REFERENCES CITED}

Bottinga, Y., and Weil1, O. F., 1970. Densities of liquid silicate systems calculated from partial molar volumes of oxide components. Amer. Jour. Sci., v. 269 , p. 169.

Ghiorso, M. S., Carmichael, I. S. E., and Moret, I. K., 1979. Inverted high-temperature quartz: unit cell parameters and properties of the $\alpha+\beta$ inversion. Contrib. Mineral. Petrol. (in press).

Kelley, K. K., 1960. High temperature heatcontent, heat capacity, and entropy data for the elements and inorganic compounds. U. $S$. Bureai of Mines Bu11. 584,232 p.

Robie, R. A., Hemingway, B. S., and Fisher, J. R., 1978. Thermodynamic properties of minerals and related substances at $298.15 \mathrm{~K}$ and 1 bar $\left(10^{5}\right.$ pascals) pressure and at higher temperatures. U. S. Geol. Survey Bul1. 1452, 456 p.

\title{
DEVELOPMENT OF A DATA BASE FOR AQUEOUS SOLUTIONS
}

\author{
R. J. Otto, H. Ozbek, and S. L. Phillips
}

\section{INTRODUCTION}

The research and development of geothermal energy depends on the availability of adequate transport and thermodynamic reference data. However, the necessary data are widely scattered, varying in quality and generally unevaluated. One objective of the National Geothermal Information Resource is to provide a single; comprehenstve data base on the basic energy proppertles of aqueous solutions to elevated pressures and temperatures. To this end, a bibliographic data base contalning references to over 1,000 articles and reports providing basic physiochemical data relevant to geothermal energy has been estbalished (Phillips et al., 1978; Fair and Phillips, 1976). The computerized bibliography is maintained by the Berkeley Database Management System (BDMS).

The primary objective of the aqueous solutions data base is to provide evaluated and correlated transport and thermodynamic data, compilation, and recommended interpolating equations for generating tables of smoothed values. The initial focus has been on properties of aqueous sodium chloride solutions in the temperature region between 0 and $350^{\circ} \mathrm{C}$ and having pressures between vapor saturation and $50 \mathrm{MPa}$. The compilation, evaluation, and correlation covering viscosity, thermal conductivity, solubility, density, enthalpy, and heat capacity is nearing completion and will constitute a data book of current information on $\mathrm{NaCl}$ for research, deve1opment, modeling, and construction for both electrical power and direct use of geothermal energy. In addition, the results of this work include identification of areas where data are either lacking or inadequate, and recommendations for research designed to provide the needed data.

The data base is complled from the following principal sources of information: (a) experimental values and correlations in the published literature; (b) reports from 0 . S. Department of Energy contractors; (c) reports from other government agencies and their contractors, for example, U. S. Geological Survey; (d) data from the CODATA system; and (e) data synthesis and correlation from computer-assisted interpolation and extrapolation. 
FISCAL YEAR 1978 ACCOMPLISHMENTS

The compilation of data for the enthalpy, density, viscosity, thermal conductivity, and solubility were completed and represent comprehensive surveys of the literature from 1929 to September 1978. The need for enthalpy and heat capacity data above $200^{\circ} \mathrm{C}$ at all NaCl concentrations is strikingly apparent. New results on the heat capacity and heat of solution up to $300^{\circ} \mathrm{C}$ have become available since the most recent and comprehensive thermodynamic compilation of Silvester and Pitzer (1977). These data have been refit, and a new revised set of values for the total enthalpy and heat capacity of solution has been generated in tabular form.

Information on solubility is comparatively complete for the entire temperature region between $0^{\circ}$ and $800^{\circ} \mathrm{C}$ and has recent ly been reviewed by Potter et al. (1977). Published values for the thermal conductivity of aqueous NaCl solutions are sparse and only available up to $150^{\circ} \mathrm{C}$. Between $100^{\circ}$ and $150^{\circ} \mathrm{C}$, only the six data points published by Korosi and Fabuss (1968) for water desalination studies are available. A Russian publication by Yusufova et a1. (1975) contains figures that show over 50 points from 100 to $330^{\circ} \mathrm{C}$, slong with a correlation expression. We have selected this correlation as a preliminary interpolating equation for providing tables of smoothed values.

Over 1,000 experimental values for the density of $\mathrm{NaCl}$ solutions are available for evaluation and correlation. We have established two subsets: (a) data of geothermal interest up to $350^{\circ} \mathrm{C}$ and $50 \mathrm{MPa}$ and (b) data to $750^{\circ} \mathrm{C}$ and 200 MPa. A parametric correlation expression is being developed that will fit the data in all regions except near the critical region.

The previously published viscosity compilation and correlation (Ozbek et al,, 1977) was revised mainly to include a new correlation for temperatures up to $150^{\circ} \mathrm{C}$; recent data up to $35 \mathrm{MPa}$ pressure provided by Kestin and Khalifa (unpublished); and the extrapolating procedure developed by Potter (1978), which provides for values to $300^{\circ} \mathrm{C}$.

\section{FISCAL YEAR 1979 PLANS}

In fiscal year 1979, we expect to complete our critical evaluation of the following pro- perties of aqueous NaCl solutions: density, enthalpy, heat capacity, viscosity (revision), thermal conductivity, and solubility. The result of the evaluations are mathematical equations that reproduce the data, generally to $350^{\circ} \mathrm{C}, 50 \mathrm{MPa}$ pressure, and to saturation concentrations. We expect to begin critical evaluation and correlation for the scale-causing substances: silicates and silica, calcite, and sulfides.

\section{REFERENCES CITED}

Fair, J. A., and Phillips, S. L., 1976. Establishment of a computer data base on geothermal properties of aqueous $\mathrm{NaCl}, \mathbf{K C l}$, $\mathrm{CaCl}_{2}$ solutions, in selected papers relevant to energy. 5th International coDATA Conference, Boulder, June 28-July 1, 1976. CODATA Bu11. 23.

Korosi, A., and Fabuss, B. M., 1968. Thermophysical properties of saline water. Monsanto Research \& Development Corp., Office of Saline Water, Report No. 363.

Ozbek, H., Fair, J. A., and Phillips, S. L., 1977. Viscosity of aqueous sodium chloride solutions from $0-150^{\circ} \mathrm{C}$. Berkeley, Lawrence Berkeley Laboratory, LBL-5931.

Phillips, S. L., Ozbek, H., and Otto, R. J., 1978. Basic energy properties of electrolyte solucions database. Sixth International CODATA Conference, Santa Flavia (Palermo), Italy, May 22-25, 1978, and Berkeley, Lawrence Berkeley Laboratory, LBL-7827.

Potter, R. H., 1978. Viscosity of Geothermal Brines. Trans., Geothermal Resources Council, v. 2, p. 543-544.

Potter, R. W., Babcock, R. S., and Brown, D. L., 1977. A new method for determining the solubility of salts in aqueous solutions at elevated temperatures. Jour. Res., U. S. Geol. Survey, v. 5 , p. 389 .

Silvester, L. F., and Pitzer, R. S., 1977. Thermodynamics of electrolytes: VIII, high temperature properties, including enthalpy and heat capacity, with application to sodium chloride. Jour. Phys. Chem., v. 81 p. 1822

Yusufova, V. D., Pepinov, R. I., Nikolaev, V. A., and Guseinov, G. M., 1975. Thermal conductivity of aqueous $\mathrm{NaCl}$ solutions. Inj. Phiz. Journ. v. 29, no. 4; pp. 600-605.

\section{KINETICS OF PRECIPITATION OF AMORPHOUS SILICA FROM AQUEOUS SOLUTION $O$. Weres, A. Yee, and L. Tsao}

\section{INTRODUCTION}

A large amount of high-quality experimental data has been generated on the kinetics of the conversion of dissolved silica in geothermalbrine-like aqueous solutions to solid amorphous silica (AS). Two processes have been separately studied: molecular deposition of dissolved silica onto preexisting amorphous silica surfaces (using comercially available colloidal silica of we 11-defined properties), and the formation of new colloidal silica particles through the process of homogeneous nucleation.

We found that, within the accuracy required for practical applications, the rate of molec- 
ular deposition is fully determined by the concentration of dissolved silica, temperature, $\mathrm{pH}$, and concentrations of univalent anions in solution. In geothermal practice, onity chloride and fluoride need to be considered. Most of these data have already been reduced and the results are ready for use in preliminary form.

The rate of homogeneous nucleation depends upon the free energy of a colloidal silica particle of critical nucleus size, and the rate of molecular deposition. The nucleation-free energy is a function of the surface tension of the $\mathrm{H}_{2} \mathrm{O} / \mathrm{SiO}_{2}$ interface, dissolved silica concentration, and temperature; the surface tension is itself a function temperature, salinity, and $\mathrm{pH}$. Our approach to analyzing the homogeneous nucleation data is to model the process numerically, and ad just the value of the surface tension until the calculated curve of dissolved silica vs. time, under any given condition, matches the experimental curve. A sophisticated computer code has been developed for this purpose and data reduction has been completed. The code itself and its documentation will be publicly released.

\section{ACCOMPLISHMENTS IN FISCAL YEAR 1978}

\section{Mechanisms of Silica Precipitation}

It appears that under most conditions, silica precipitates as relatively pure amorphous silica. This conclusion is supported by geothermal field experience; laboratory research, and theoretical considerations. The scope of our study wa restricted accordingly.

The process of amorphous silica precipitation from supersaturated bulk aqueous phase consists of the following steps:

1. Growth of polymeric silicic acid complexes to critical nucleus size

2. Nucleation of an amorphous silica (AS) phase in the form of colloidal particles

3. Growth of the supercritical AS particles by further molecular deposition of silicic acid on their surfaces

4. Coagulation or flocculation of colloidal particles to give a gel

5. Cementation of the particles in the gel by chemical bonding and further deposition of silica between the particles.

6. Rarely, growth of a secondary phase in the interstices between the AS particles (Such secondary deposition of Fes and of calcite has been reported, but is uncomion,)

The above process occurs when the concentration of dissolved silica is high enough for homogeneous nucleation to occur at a significant rate. Very roughly, this requires a saturation ratio (concentration divided by the equilibrium solubility) of 2 or greater. If this condition is met, massive precipitation occurs. This is the case with the residual (flashed) brine at Niland, California, Cerro Prieto, Mexico, and Wairakei, New Zeland. Dealing with the consequences of precipitation presents the greatest technical problems encountered at these sites.

If the concentration of dissolved silica is too low for massive homogeneous nucleation to occur, relatively slow molecular deposition upon solid surfaces becomes the major precipitation mechaniom. The product of this process (essentially step 3 of the above scheme alone) is a dense vitreous silica. This material has been observed to form in portions of the surface piping at Cerro Prieto at a rate of about 1 momr. This is a very small rate, but the vitreous silica is almost impossible to remove once formed.

The goal of this study has been to generate sufficient experimental data and theoretical analysis concerning steps 1 to 3 to enable us quantitatively to predict and interpret their phenomenology and kinetics over most of the range of practical concern.

\section{Bomogeneous Nucleation of Colloidal AS}

The voluminous gel-like deposits encountered at Niland, Cerro Prieto, and Wairakei consist of flocculated colloidal AS. The crumbly grey and white scales associated with the gel-like materials are cemented colloidal aggregates. This colloidal silica is produced by homogeneous nucleation in the liquid phase, that is, nucleation by growth of polymers to critical nucleus size without the participation of some preexisting solid particle.

With most substances, heterogeneous nucleation is dominent, and homogeneous nucleation is very. slow, rare in nature, and difficult to study in the laboratory. The precipitation of AS is an apparent exception to this because of the very low surface tension of the silica-water inter face-between 35 and 50 ergs cm-2 over the range of major practical interest. (By comparison, the surface tension of the water-air interface is about 70 to $80 \mathrm{ergs} \mathrm{cm}^{-2}$.) This means that enormous numbers of particles can be produced by homogeneous nucleation (on the order $10^{17}$ to $10^{19}$ per liter), and this completely swamps the effects of heterogeneous nucleation.

A practical consequence of the dominance of homogeneous nucleation is that the precipitation of AS is experimentally reproducible and predictable. This is because the rate of homogenous nucleation is determined by basic thermodynamic and chemical variables (concentration, surface tension), and not by often unknown trace contaminants, as is the case with heterogeneous nucleation.

Figure 1 shows some typical experimental results, which depict the decline of dissolved 


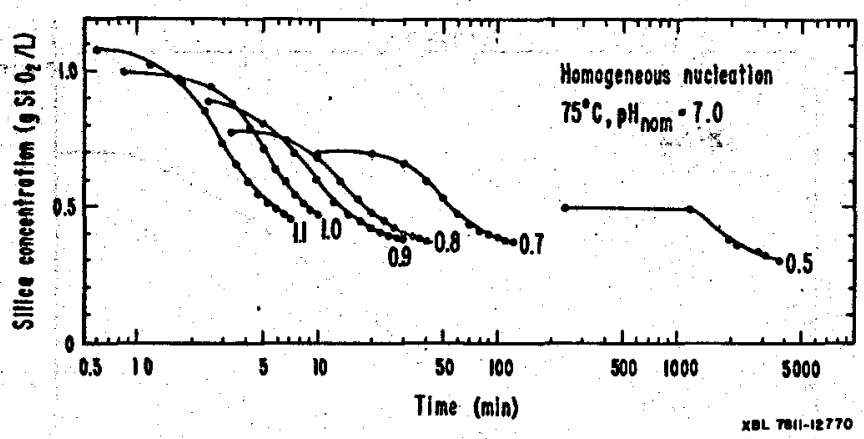

Figure 1. Decrease of dissolved silica concentration with time under conditions of homogeneous nucleation at $75^{\circ} \mathrm{C}, \mathrm{pH} 7.0$, and sodium activity = $0.069 \mathrm{M}$. Numbers Indicate Inftial dissolved silica concentrations.

silica with time via the homogeneous nuclestion mechanism. These experiments were performed at various $\mathrm{pH}^{\prime} \mathrm{s}$ in a low-salinity buffered medium in which the sodium ion activity was approximately $0.069 \mathrm{M}$, and the time scales were shifted to convert ali data to a nominal $\mathrm{pH}$ of 7.0 .

These conditions are approximately equivalent to an $0.088 \mathrm{M}$ ( $\approx 5,200 \mathrm{ppm}) \mathrm{NaC1}$ solution at $\mathrm{pH} 7$. Note that the time scale in Figure 1 is logarithmic. With an initial concentration of 1.1 $\mathrm{g} / 1$ of $\mathrm{SiO}_{2}$, the reaction runs most of the way to completion in less than $10 \mathrm{~min}$. (Here and elsewhere in this paper, concentrations expressed in terms of grams or moles/11ter refer to room temperature. Therefore, this solution would contain $1.1 \mathrm{~g} / 1 \mathrm{~S} 10_{2}$ if cooled to room temperature, but not necessarily at $75^{\circ} \mathrm{C}$ ).

With an Initial concentration of $0.5 \mathrm{~g} / 1$, the reaction takes about 5,000 min. In other words, with a large initial saturation ratio, amorphous silica gels may form within the process equipment and associated piping. This is observed at Cerro Prieto and Niland. With small saturation ratios $(0.5 \mathrm{~g} / 1$ corresponds to $\mathrm{s}=1.9$ at this temperature), massive precipitation will not occur within the process equipment, but just as certainly will occur somewhere further downstream. Al 60 note that 0.5 and $0.7 \mathrm{~g} / 1$ curves show an induction period during which the concentration does not change noticeably.

We have generated a large quantity of such nucleation data from room temperature to $100^{\circ} \mathrm{C}$, and have written a computer program that can numerically (and rigorously) model the homogeneous nucleation process. That is, it can reproduce the curves in Figure 1 . We are now able to model and predict the process quantitatively, even under the experimentally inaccessible conditions characteristic of field practice. This program will be documented and made available to interested outside users.

\section{Molecular Deposition on Solid Surfaces}

Molecular deposition means the formation of compact, nonporous amorphous silica by chemical bonding of dissolved silica molecules directly onto solid surfaces.

Below about $100^{\circ} \mathrm{C}$, homogeneous nucleation is usually the dominant precipitation mechanism. The major significance of molecular deposition here is that it is the molecular mechanism of the growth of colloidal particles and of the conversion of gel-like deposits to solid scale. However, at higher temperatures molecular deposition from solution may, by itself, produce scale at a significant rate. Although the deposition rate is very small (about $1 \mathrm{~mm} / \mathrm{yr}$ in the flashed brine pipes close to the steam separators at Cerro Prieto), this scale is almost indestructible once formed.

We studied the molecular deposition process by adding known amounts of colloidal silica of known specific surface area to the solutions. Deposition rates at $\mathrm{pH} 7,\left[\mathrm{Na}^{+}\right]=0,069$ and various temperatures and dissolved silica concentrations were calculated (and extrapolated) from our experimental data and are presented in Figure 2. The dashed line represents the approximate concentration 1 imit above which homogeneous nucleation supersedes deposition on

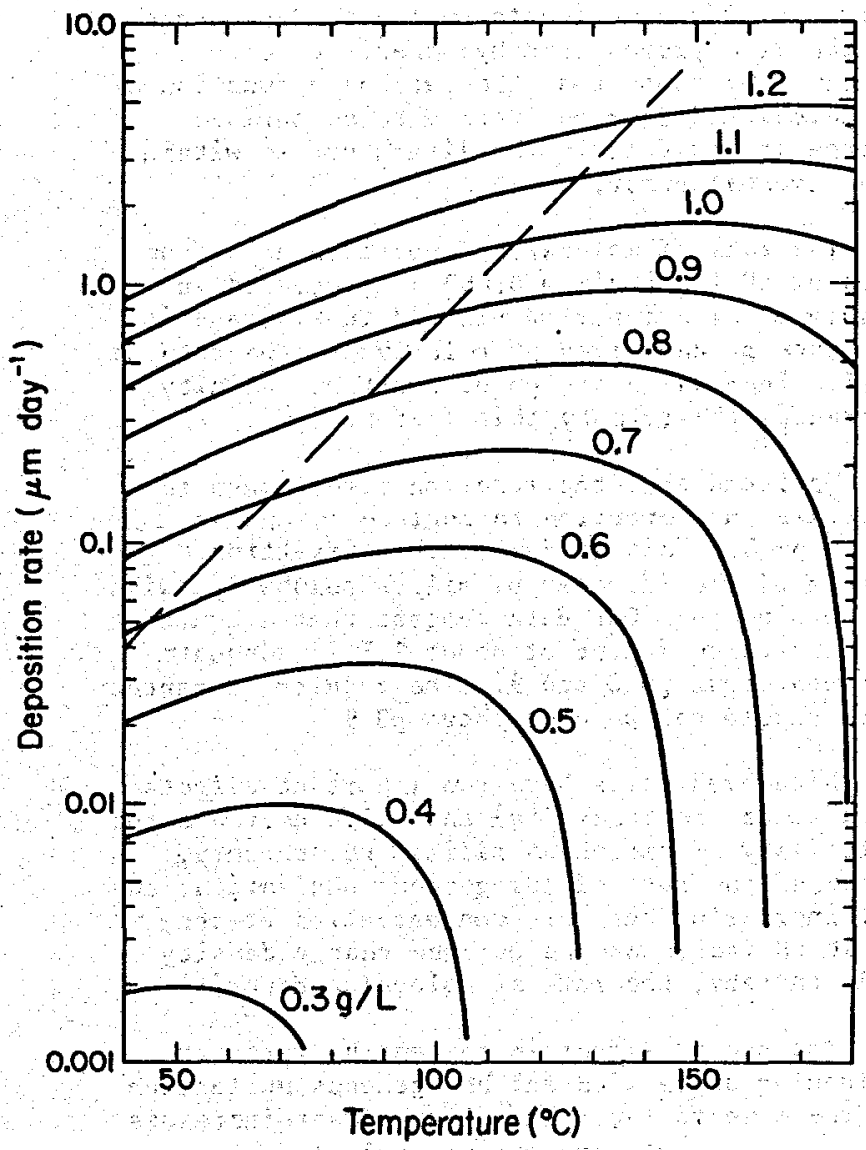

Figure 2. Rates of molecular deposition of silica on a flat surface at pH 7.0 and sodium activity $=0.069 \mathrm{M}$. Dissolved silica concentrations corresponding to each curve indicated in g/1 refer to room temperature. 
added particles as the dominant mechanism. Our data actually cover only the range between $50^{\circ}$ and $100^{\circ} \mathrm{C}$ and below the dashed line. However, we believe the extrapolated values to be good enough for practical application.

At any given concentration, there is a temperature at wich the deposition rate has a maximum value. Below this temperature, the rate of deposition increases with temperature in the usual way. Above this temperature, the rate of deposition decreases because the increasing solubility of silica causes the rate of the back-reaction (dissolution) to increase even more rapidly. At the saturation temerature for any given concentration, the deposition rate goes to zero. The practical consequence of this is that the molecular deposition rate is a weak function of temperature at lower than $15^{\circ} \mathrm{C}$ bel ow the saturation temperature. However, the rate varies strongly with silica concentration. (Our data are best fitted by an apparent fourthorder rate law.)

\section{Effects of $\mathrm{pH}$ and Salinity}

It has long been believed that the rate of AS deposition is proportional to the surface density of ionized silanol groups on the silica surface. Our experiments on the $\mathrm{pH}$ dependence of the rate proved this hypothesis conclusively. We found that the rate as a function of $\mathrm{pH}$ calculated from our data matched surface charge vs. pH data in the literature to within experimental error.

The rate of molecular deposition as a function of $\mathrm{pH}$ for $\left[\mathrm{Na}^{+}\right]=0.069$ is presented in Figure 3. The function plotted in Figure 3 is the rate at any given $\mathrm{pH}$ relative to the rate at $\mathrm{pH} 7$. Increasing the $\mathrm{pH}$ at constant salinity increases the rate by this factor.

We found that the reaction rate ceases to increase in proportion to surface change at about $\mathrm{pH} 8$. This is due to the offsetting effect of the increase of silica solubility with increasing $\mathrm{pH}$. Our data suggest that a constant pH correction factor of about 2.7 is adequate between about $\mathrm{pH} 8$ and 9 . The results presented here should not be used above pH 9 .

Dissolved salts have two important effects upon these processes: (a) the salts decrease the solubility of amorphous silica and, thereby, increase the rate of homogeneous nucleation; and (b) increasing the salt concentration at constant $\mathrm{pH}$ increases the surface charge density and, thereby, the rate of molecular deposition.

The second effect increases the rates of molecular déposition and homogeneous nucleation by the same factor. The first effect increases only the rate of homogeneous nucleation.

Except at very low salinity, most of the dissociated silanols on the silica surface have cations bound to them--in our experiments, sodium. This means that sodium and hydrogen ion activity does not have independent effects upon

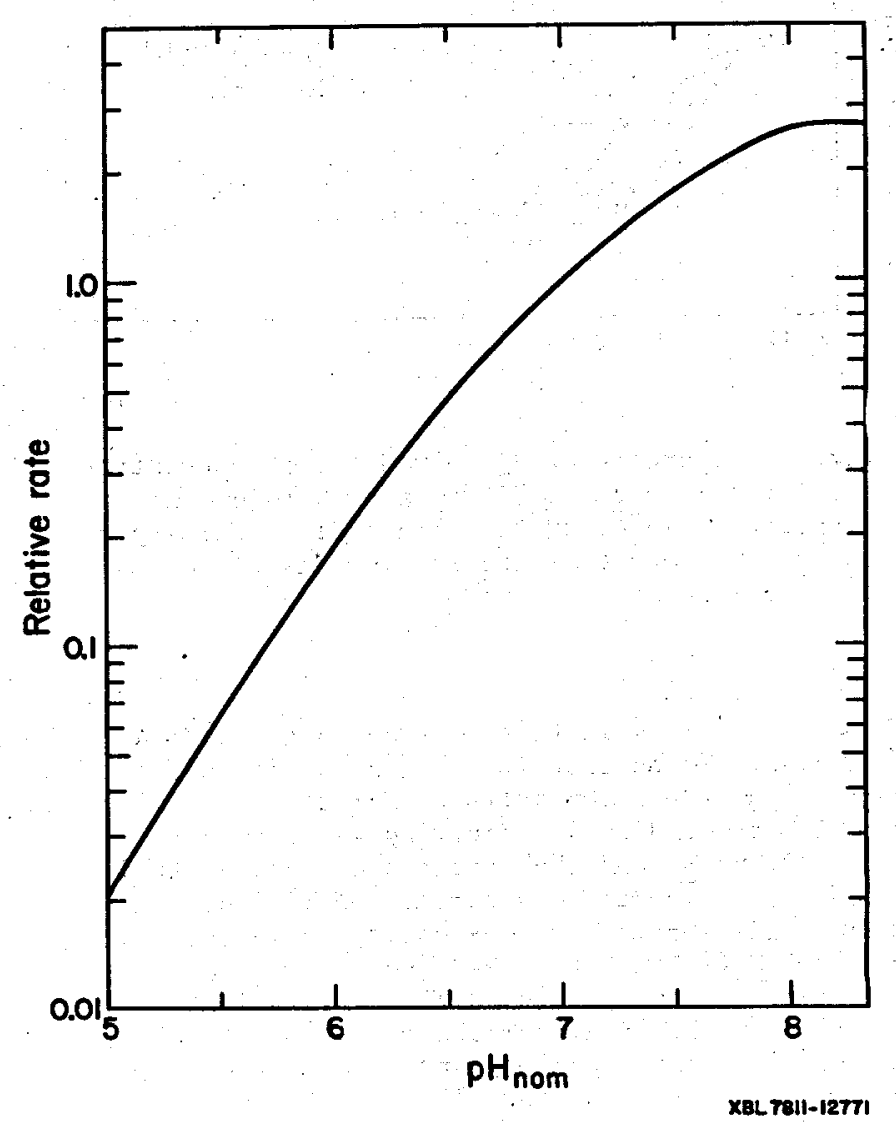

Figure 3. Variation of molecular deposition rate with $\mathrm{pH}_{\text {nom. Curve gives the rate as }}$ a function of $\mathrm{pH}_{\text {nom }}$ relative to the rate at $\mathrm{pH}_{\text {nom }}=7.0$. At $\mathrm{pH}_{\text {nom }}$ greater than 8 , the value of the $\mathrm{pH}$ correction factor is 2.7 . When sodium activity $=0.069 \underline{\mathrm{K}}, \mathrm{pH}_{\mathrm{nom}}=\mathrm{pH}$.

the rate. Rather, it is the ratio of sodium to hydrogen activity that is important. Therefore; Figure 3 may be used to calculate the effect of salinity upon the molecular deposition rate as we 11 .

To do this, calculate a "nominal pH value" de fined by

$$
\mathrm{pH}_{\text {nom }}=\mathrm{pH}+\log \frac{\mathrm{Na}^{+} \mathrm{]}}{0.069} \text {, }
$$

and then read off the $\mathrm{pH}$ correction factor from Figure 3 using the nominal $\mathrm{pH}$ value instead of the real one.

For example, to calculate the molecular deposition rate at $100^{\circ} \mathrm{C}, \mathrm{pH} 6.5,\left[\mathrm{Na}^{+}\right]=0.69 \mathrm{M}$ and $0.7 \mathrm{~g} / 1$ dissolved silica, follow this procedure. F1rst read the deposition rate at $\mathrm{pH} 7.0$ and $\left[\mathrm{Na}^{+}\right]=0.069 \mathrm{M}$ from figure 2. This value is $0.22 \mu \mathrm{m} /$ day. Second, calculate $\mathrm{pH}_{\text {nom }}$ using equation (1). This is 7.5. Third, read the $\mathrm{pH}$ correction factor for $\mathrm{pH} 7.5$ from Figure 3 . This is 1.8. Finally, multiply the two numbers together to obtain the deposition rate, which is $0.40 \mu \mathrm{m} /$ day. 
Our data suggest that this procedure is adequate for solutions that contain up to at least $1 \mathrm{M} \mathrm{NaCl}$ and may be adequate at even higher salinities. However, we cannot recomend this procedure for use at salinities much below 5,200 ppm. At very low salinities, dissociation without ion pairing becomes important, and the basic assumption of the equivalent and opposite effects of hydrogen and sodium activity collapses.

The dissolved solids in real geothermal brines are usually predominantly sodium chloride, but other salts are also present. We have found that, in most cases, it is oufficient to use an "effective sodium ion activity" calculated as 0.77 times the (molar) concentration of chloride. If bicarbonate is present as a major ion, use the sum of the chloride and bicarbonate concentrations in place of chloride alone. The rationale for this procedure is that the various other major cations that may be present have essentially the same effects as sodium, and the activity-lowering effects of divalent anions approximately compensate for the concentration of the cations that accompany them.

Some Practical Examples

Case 1. Consider a hypothetical geothermal development at which the spent brine contains $5,200 \mathrm{ppm} \mathrm{NaCl}, 0.5 \mathrm{~g} / 1$ dissolved $\mathrm{SiO}_{2}$, and is delivered to the reinjection we 11 at $75^{\circ} \mathrm{C}$ and pH 7. The brine delivered to the reinjection we 11 is completely clear and goes right through a membrane filter. The decision is made to reinject. Reinjection commences at $400 \mathrm{t} / \mathrm{hr}$ into an aquifer of $200^{\circ} \mathrm{C}$ initial temperature, $\phi=0.1, h=20 \mathrm{~m}$, and volumetric solid-rock heat capacity $=2,460 \mathrm{~kJ} / \mathrm{m}^{3} \mathrm{C}$. After about 12 days, the thermal front is about $60 \mathrm{~m}$ into the formation, and the fluid travel time from wellbore to thermal front is about $50 \mathrm{hr}$ (= 3,000 min.). Referring to Figure 1 , we see that there is now ample time for homogeneous nucleation to occur before the fluid reaches the thermal front. The result is that the injectability of that horizon is damaged by silica precipitation. Furthermore, well treatments with caustic or $\mathrm{HF}$ are not effective because the damage is 30 to $60 \mathrm{~m}$ away from the wellbore.

Case 2. Can one reinject straight from the first-stage steam separators at Cerro Prieto?
Assume the following typical brine conditions at the injection we 11 : $160^{\circ} \mathrm{C}, 0.95 \mathrm{~g} / 1$ dissolved $\mathrm{SiO}_{2}$, effective $\left[\mathrm{Na}^{+}\right]=0.25$, and negligible suspended solids. The brine $\mathrm{pH}$ at injection temperature is not known, but is approximately 7.8 at room temperature. This gives a nominal pH of about 8.3 (which is within the range of weak $\mathrm{pH}$ dependence) and a $\mathrm{pH}$ factor of 2.7 (from Figure 3). The $\mathrm{pH}_{\text {nom }}=7.0$ deposition rate, from Figure 2, is about $1.3 \mu \mathrm{m} / \mathrm{day}$. Correcting for $\mathrm{pH}$, we obtain the actual deposition rate of $3.5 \mu \mathrm{m} /$ day. Correcting for $\mathrm{pH}$, we obtain the actual deposition rate of $3.5 \mu \mathrm{m} / \mathrm{day}(=1.3$ $\mathrm{mm} / \mathrm{yr}$ ). This is consistent with the observed rate of vitreous silica deposition near the separators at Cerro Prieto. Because pore permeability is dominant at Cerro Prieto, it is clear that injecting this brine would rapidly plug the in jection we 11.

We hope that such mistakes will be avoided. However, we emphasize that both of these brine streams would be injectable under the criteria presently in vogue. They would be able to pass freely through a micron-sized membrane filter and would not cause visible fouling of metal surfaces during field tests of a few days duration. It is precisely the refinement of such criteria that we hope to have accomplished with the work sumarized here.

\section{ACTIVITIES PLANNED FOR FISCAL YEAR 1979}

Our group is presently engaged in three areas of activity. First, we are completing the reduction of the experimental data generated during fiscal year 1978. Second, we are studying the chemistry of silica in the spent brines at the Cerro Prieto power plant by means of laboratory simulation. This work is oriented toward developing a prereinjection brine treatment for Cerro Prieto. It is supported by the Cerro Prieto project at LBL. Third, we are developing a computer model of a surface condenser in a geothermal power plant. The goal of this work is to enable the chemical operating characteristics of such a condenser to be interpreted and predicted. This model will first be applied to studying The Geysers Unit 15, which is the first geothermal power plant to be equipped with a surface condenser. This work is being funded by the Pacific Gas and Electric Company.

\section{ENHANCED OIL RECOVERY WITH MOBILITY AND REACTIVE TENSION AGENTS}

\section{J. Radke and W. H. Somerton}

\section{INTRODUCTION}

Use of alkaline solutions to recover selected actd crude ofls has considerable economlc advantage over commercial surfactant solutions. In spite of the longevity of the idea, however, a question remains as to its displacement effectiveness (Johnson, 1976). The objectives of the present study are: (a) to establish the conditions required for tertinary-mode displacement of acidic oils with high $\mathrm{pH}$ agents; and (2) to elucidate the dominant recovery mechanisms, 
and hence permit development of an improved caustic flooding package, The overall project includes studies on core displacements from synthetic and natural systems, interfacial tensions, emulsion theology and stability in porous media, and caustic 108 .

\section{CORE DISPLACEMENTS}

\section{Oil Field studies}

Caustic flooding tests have been run at reservoir temperature on a number of Ranger-zone cores using Ranger crude oil and simulated formation water. The test apparatus is similar to that used previously (Radke and Somerton, 1977) except that the core is mounted in a water bath maintained at a constant temperature of $125^{\circ} \pm$ $1 \% \mathrm{~F}$. During saturation of the cores with Ranger-zone crude, the temperature of the system is increased to $180^{\circ} \mathrm{F}$ to ensure that all the asphaltenes are in solution in the crude, since the se constituents may play an important role in the crude-oil behavior. This high temperature has led to failure of several types of plastic core holders, which have been used to minimize the corrosive effects of the caustic solutions. Current1y, a thick-walled Tefion tube is used as the core holder with moderate success.

Frozen Ranger-zone cores are diamond-drilled using liquid nitrogen and then are quickly packed into the Teflon core holder under moderate pressure. The packed core is then mounted in the system and $810 \mathrm{wly}$ brought to reservoir temperature. in the first series of tests, the native-state cores, were first water-flooded with 1.437 NaCl brine. In all cases, the oil saturation was too low to recover oil (Table 1). The water flood was then followed by a caustic flood at a rate of $1.5 \mathrm{ft} / \mathrm{day}(0.1 \mathrm{wtZ} \mathrm{NaOH}$ in softened Colorado River water followed by 0.1 wtz. $\mathrm{NaCl}$ in the same water). Again the oil saturation was too slow to recover oil.

The native-state cores were extracted in situ using toluene followed by an acetone wash. (Because acetone was contributing to failure of the plastic tubes, the cleaning procedure was later changed to use Chevron $410 \mathrm{H}$ solvent followed by isopropyl alcohol.) After extracting and drying, the cores were saturated with brine and the brine was displaced with crude oil to irreducible water saturation. The water flooding and caustic flooding procedures were as

Table 1. Ranger-zone core floods.

\begin{tabular}{lllllllll}
\hline & & & $K$ & $S_{w i}$ & $S_{0 i}$ & $E_{\text {rw }}$ & $E_{\text {rc }}$ \\
Test & Condition & $\phi$ & md & & & & \\
\hline A-1 & Native & 0.35 & - & 0.24 & 0.25 & 0 & 0 \\
A-2 & Resat. & 0.36 & 460 & 0.26 & 0.74 & 0.46 & 0.66 \\
B-1 & Native & 0.39 & - & 0.40 & 0.24 & 0 & 0 \\
B-2 & Resat. & 0.40 & 430 & 0.43 & 0.57 & 0.27 & 0.37 \\
C-1 & Resat. & 0.27 & 65 & 0.43 & 0.57 & 0.51 & 0.82
\end{tabular}

given above, following THUMS planned procedure for field tests (City of Long Beach, 1977).

Results of several of the tests are summarized in Table 1. The earlier test cores ( $A$ and B) had high porosities and permeabilities. By improved packing techniques in later cores (C), the porosity and permeability were greatly reduced. The resaturated core, $A-2$, recovered 467 of the oil in place by water flood and an additional $20 \%$ by caustic flood, for a total recovery efficiency of $66 \%$. The second resaturated core gave much lower recovery efficiencies: $27 \%$ by water flood and an additional $10 \%$ by caristic. The large difference in the behavior of these two similar cores can probably be attributed to the lower initial oil saturation in the latter case.

Test core $\mathrm{C}-1$ was prepared by a modified packing procedure giving much lower porosity and permeability. The core was extracted in situ, without running native state tests. The high recovery by both water flooding and caustic flooding ( 517 and $31 \%$, respectively) was surprising for this $10 \mathrm{w}$ permeability core. Extraction of the core after the test confirmed the low residual oil saturation of $18 \%$.

Figure 1 shows the recovery history of core C-1 plotted as a fraction of initial oil in place recovered as a function of pore volumes of water and caustic injected. It is interesting to note that no tertiary oil was recovered until nearly 2-1/2 pore volumes of caustic had been injected. The $\mathrm{pH}$ of the effluent remained $10 \mathrm{w}$ until after the first tertiary o1l was recovered. This would indicate a very large consumption of caustic (probably most of it being adsorbed by the fine-grained, clayey reservoir rock) before any oil was produced. Thereafter, the $\mathrm{pH}$ and recovery curves tend to be parallel. The oil was produced in 8 lugs with no sign of emulsification until the very last oil produc-

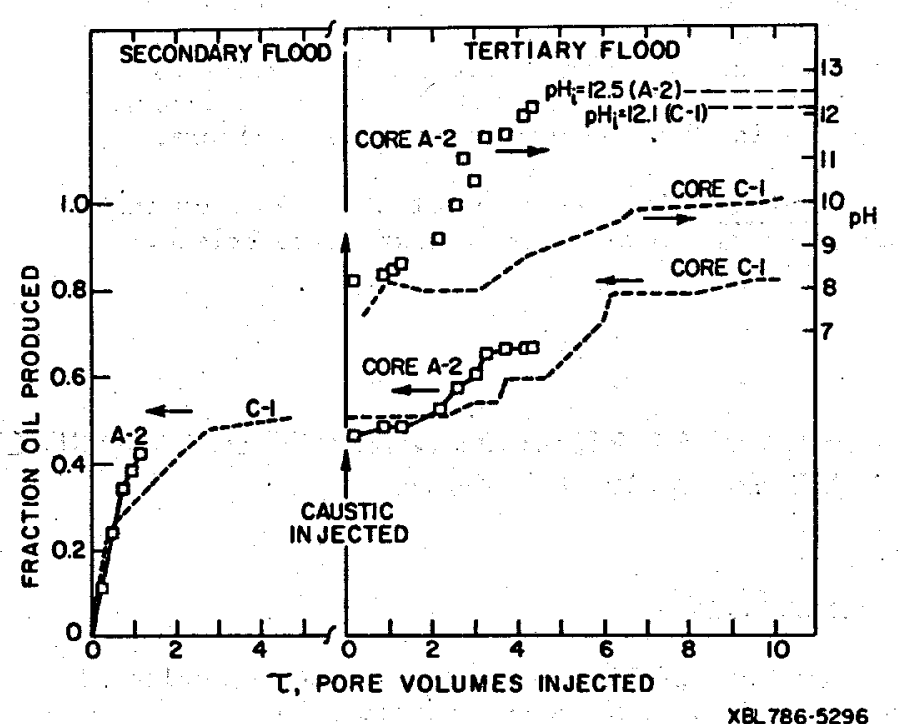

Figure 1. Production performance and $\mathrm{pH}$ history for core C-1. Tertiary flood is $0.2 \mathrm{PV}$ of 1 wtz NaOH followed by 0.1 wt\% $\mathrm{NaCl}$ with 1 wt\% $\mathrm{NaOH}$. 
tion increment, which was in the form of a small oil slug followed by a very dilute oil in water emul sion.

In Figure 2, the production performance of core $A-2$ is compared with $C-1$; Recalling that the $A-2$ core was much more permeable than $C-1$, the much earlier recovery (from a pore-volume standpoint) might be expected for the $\mathrm{A}-2$ core The caustic consumption is al so much lower in the case of the more permeable core, although the $\mathrm{pH}$ and oil-recovery curves are again parallel with oil production, ceasing as the effluent $\mathrm{pH}$ approaches the value for the injected fluid. A possible difference between the se two cores is that A-2, the lower caustic consumer, was previously flooded with caustic in the native state, and all the adsorption may not have been reversed.

No sweeping conclusions can be reached from this limited number of tests on oil field cores. However, certain observations seem irrefutable. It is clear that with sufficient initial oil saturation, oil can be recovered in the tertiary mode by caustic injection, at least under laboratory conditions. Consumption of caustic by the fine-grained, clayey reservoir rock is high, especially for the low-permeability cores. The recovery mechanism with the oil field cores and fluids does not appear to involve emulsification. The vast majority of the oil produced was emulsion-free so if emulsions were formed in the core, they must have been of the unstable variety. No large changes in pressure gradients were noted and this would have occurred if emulsion entrapment were present.

The recovery of tertiary oil appears to be associated with caustic consumption. No oil is recovered until the effective caustic concentration in the core exceeds a critical level. At this point some oil is accumulated and produced in a mini-bank. This process continues in a step-like manner as the critical caustic saturation level is reached progressively down the

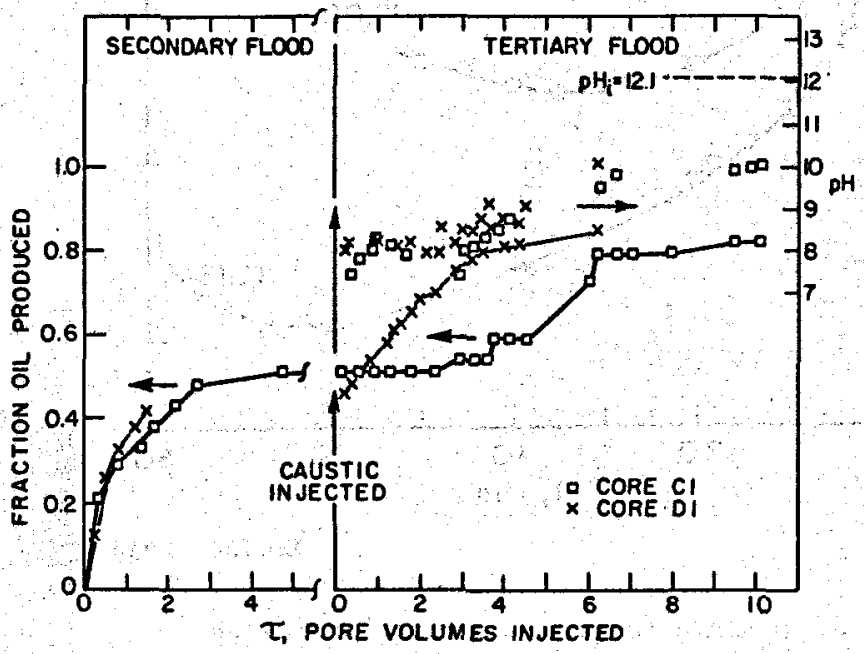

XEL7B6-5297

Figure 2. Production performance and $\mathrm{pH}$ history for $\mathrm{A}-2$ compared with core $\mathrm{C}-1$. tube. The recovery mechanism in this case may involve wettability reversal with sharp wettability gradients.

\section{Synthetic System}

To understand the complicated chemistry involved in alkali flooding, we are studying the displacement of oleic acid-doped mineral oil ( $1.5 \mathrm{cp}$ and acid \$2) from Ottawa sand packs (about 5 darcy) at a scaled rate (7 ft/day). Details of the experimental apparatus and procedures are available (Radke and Somerton, 1977).

Experimental results for the percentage recovery of oil remaining after water flooding to residual, as a function of $\mathrm{pH}$ at two $\mathrm{NaCl}$ salt contents, are shown in Figure 3 . Without salt, no tecovery of tertiary oil is found. As discussed previously (Radke and Somerton, 1977) nonsaline, high-pH (about 12) solutions lead to core plugging but not to tertiary oil recovery. However, high-saline solutions exhibit recovery, which is a strong function of $\mathrm{pH}$. At $\mathrm{pH}$ values below about 11, the alkaline solutions are buffered to provide sufficient neutralizing capacity.

Interfacial tensions for the solutions in Figure 3 are all above 0.1 dyne/cm giving capillary numbers less than $10^{-3}$. Hence recovery cannot be explained by the low-tension mechanism. Figure 4, however, provides considerable insight into the underlying surface chemistry. For salt solutions below 1 wt $\%$, emulsions are of the oil-in-water type, whereas above $1 \%$ they invert to the water-in-oil type. Also above 1 wtz salt, the receding contact angles (measured

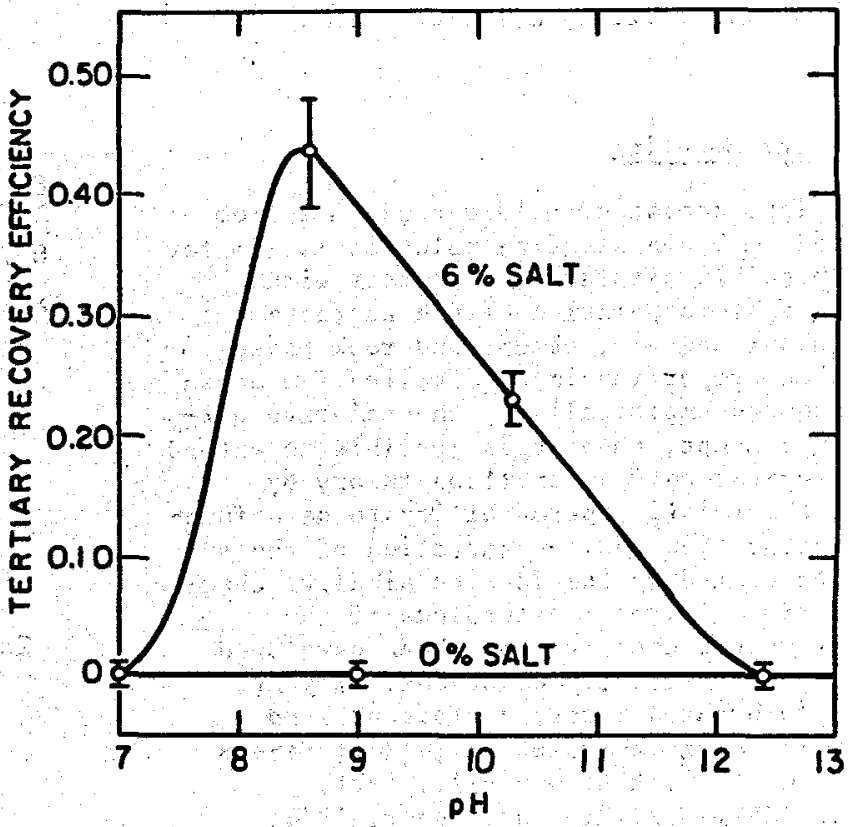

XBL 786-5295

Figure 3. Tertiary recovery efficiency as a function of $\mathrm{pH}$ for two salt weight concentrations. 


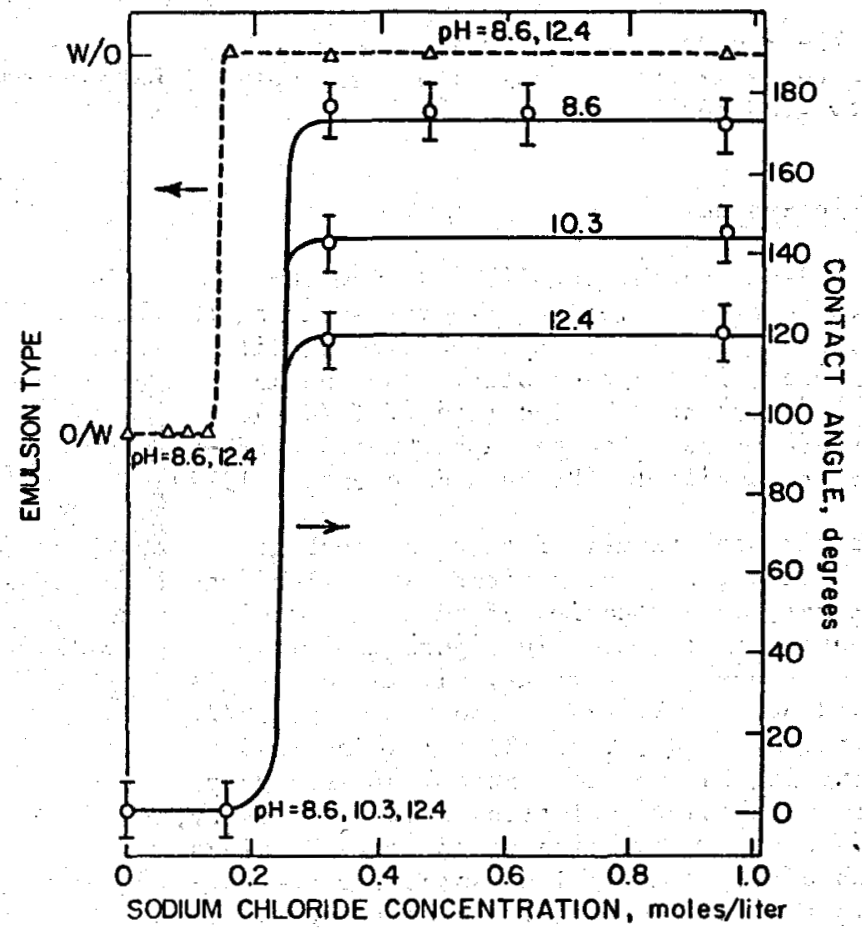

XBL 786-5294A

Figure 4. The effect of salt on emulsion type and contact angle.

through the water-phase against quartz) show a reversion to oil-wet. The degree of oil wetness is a function of solution $\mathrm{pH}$. Note that the degree of oil wettability exactly parallels the recovery efficiencies in Figure 3. In this system, only solutions that form water-in-oil emulsions and that exhibit strong oil-wet conditions give tertiary oil production.

\section{Displacement Modeling}

The displacement of acidic crude oil from a porous medium by an alkaline solution is similar to an inuiscible displacement process with chromatographic separation of the surfactant species among the oil, water, and rock phases. If the flow properties in an alkaline flood can be represented empirically by the relative permeability concept, then it is possible to extend the Buckley-Leverett water flood theory by allowing the relative permeability to be a function of saturation and concentration of the surfactant generated by the in-situ alkaline chemical reaction. Similar extensions of the Buckley-Leverett equation have been developed for enriched gas drives, detergent, polymer, alcohol, carbonated water, surfactant, and micellar flooding (Welge et al., 1961; Fayers and Perrine, 1959; Patton et al., 1971; Wachmann, 1964; Claridge and Bondor, 1974; Larson and Hirasaki, 1976; and Kremesec and Treiber, 1976, respectively).

\section{IKTERFACIAL TENSION}

\section{Crude 0 il}

Spinning drop (Cayias et al., 1975) interfacial tensions of Ranger-zone crude oil against different sodium hydroxide solutions are shown in Vigure 5. ambient temperature. As previous1y observed (Radke and Somerton, 1977; McCaffey, 1976), acid crude-oil tensions, show a dynamic minimum. For the ultralow tensions, the return to high tension is not experimentally available. . This is because the contracting drop succumbs to inevitable external disturbances and breaks into satellite drops.

Figure 5 also indicates the sensitivity of the minimum dynamic tension to small changes in hydroxyl ion concentration. This sensitivity to $\mathrm{pH}$ is further accenturated in Figure 6 , which gives the minimum tension $a 8$ a function of caustic $\mathrm{pH}$. Here the narrow range of ultralow tensions typical of synthetic surfactants is evident.

The effect of aqueous salt content and $p H$ on Ranger-zone crude oil minimum dynamic tension is portrayed in Figure 7. Addition of sodium chloride shifts the $\mathrm{pH}$ for dynamic minimum tensions less than $\left(10^{-3}\right)$ dyne $/ \mathrm{cm}$ to lower values. Also for the lower salt concentrations, the $10^{-3}$ dyne $/ \mathrm{cm}$ isotension well broadens.

similar general conclusions can be drawn from

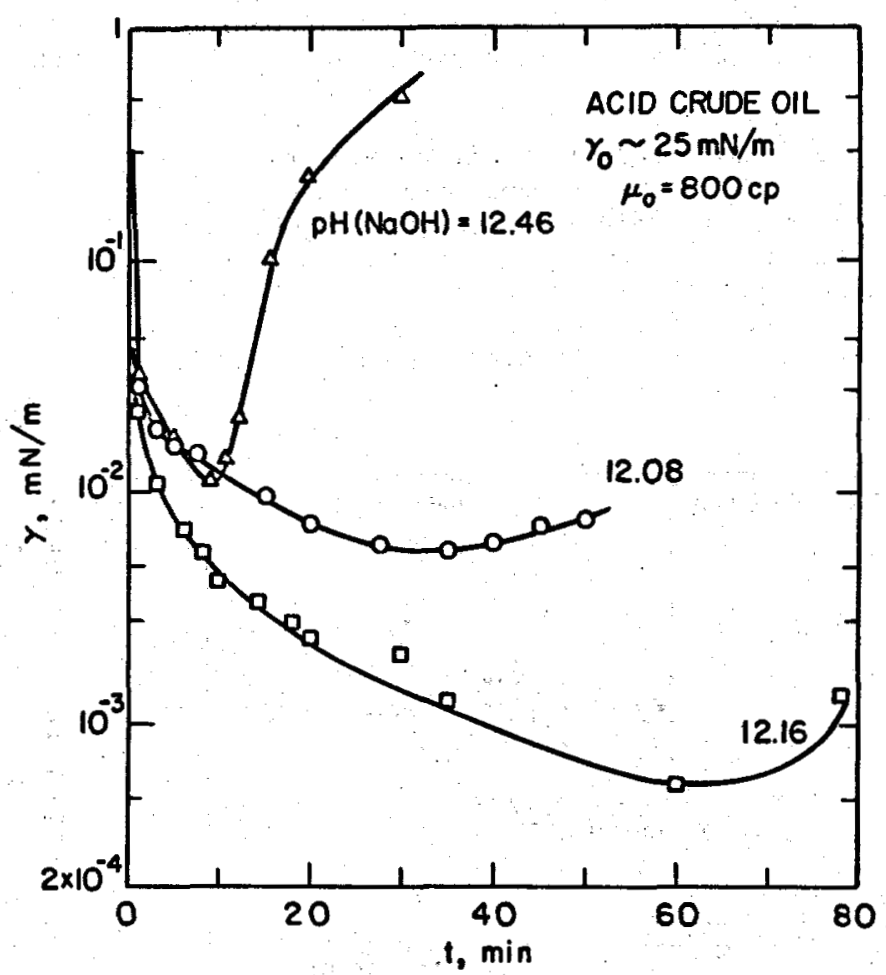

$X 8 L 786-52934$

Figure 5. Dynamic tensions as functions of $\mathrm{pH}$ for Ranger-zone crude oil. 


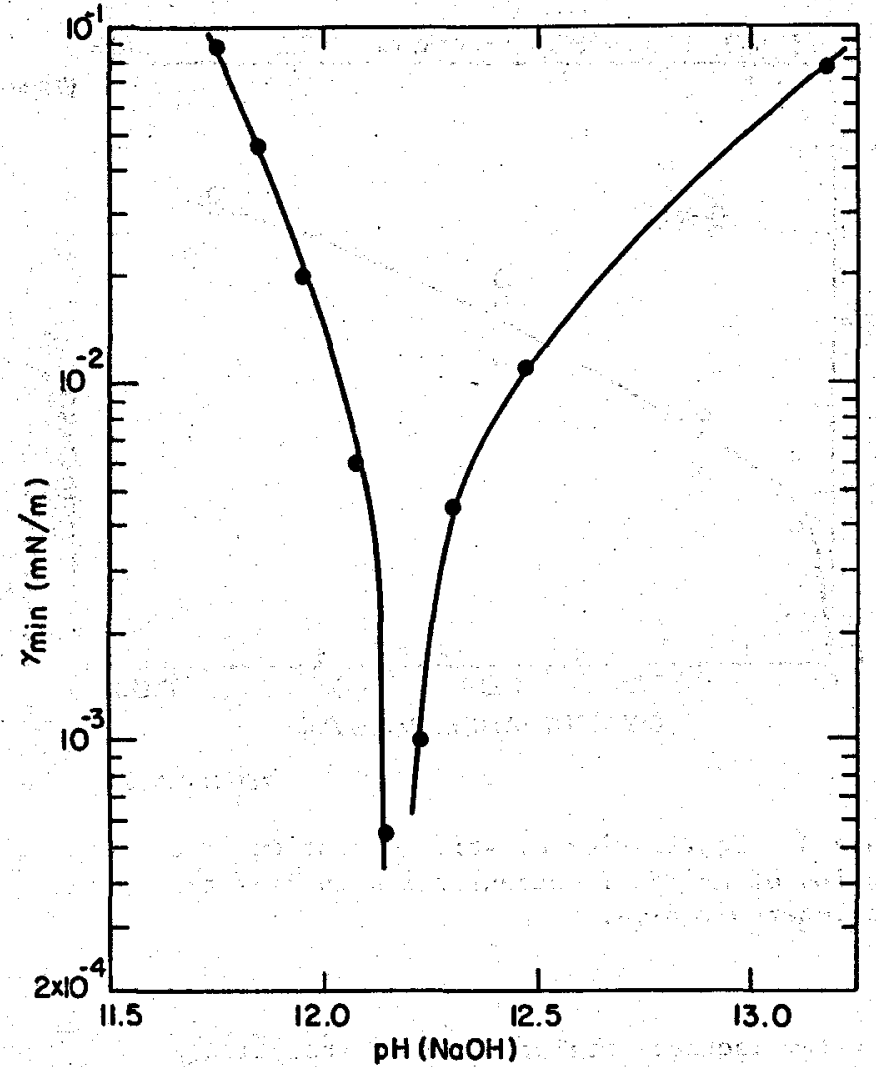

XBL $786-5292$

Figure 6. Minimum in dynamic tensions as a function of $\mathrm{pH}$.

the data of Jennings (1975). One important result from $F$ igure 7 is that the original THUMS flood design does not appear to fall in the lower tension composition region (i.e., pH 12.5 and $[\mathrm{NaCl}]=1 \mathrm{wtz}$.

\section{Dynamic Tensions}

Previous reports (Radke and Somerton, 1977), as well as literature work show that dynamic tensions can exhibit a sharp minimum (McCaffery, 1976; Farmanion et a1., 1978; Mansfield, 1952; England and Berg, 1971). This minimum is especially dramatic when an acidic California crude oil, or synthetic oils containing an oil-soluble hydrolyzable surfactant, are brought in contact with an aqueous alkaline solution (Figure 5). An appropriate explanation of this tension minimum is important not only in the proper interpretation of interfacial tension measurements, but in the potential exploitation of this phenomena for enhanced oil recovery.

A minimum in dynamic tension indicates a period when surfactant concentration at the interface reaches a maximum value (Radke and Somerton, 1977). During this period, emulsification into small oil droplets can occur with negligible shear energy input (e.g., spontaneous emulsification). If the duration of low interfacial tensions is long enough, emulsification

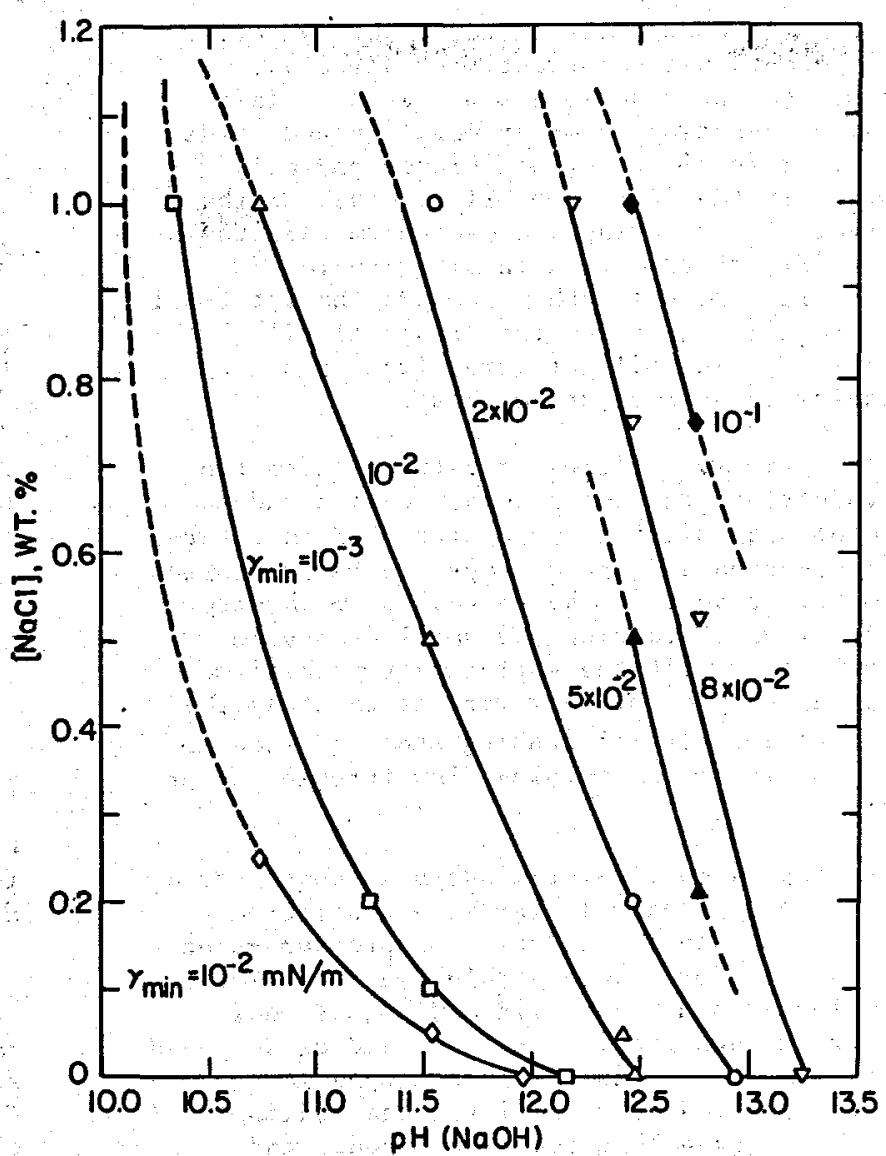

XEL 786-5291

Figure 7. Constent dynamic minimum tensions for varying $\mathrm{pH}$ and salt contents.

may be possible with very low acid concentrations in the oil phase. However, if after the minimum, the tension rapidly rises back to a high value, propagation of the entrained droplets cannot take place except through the larger pores or by coalescence into an oil bank. A low-tension minimum followed by a rapid rise to a high-equilibrium tension seems well suited to the entrapment recovery mechanism.

\section{EMULSION FLOW}

\section{Porous Media Flow}

Two of the fundamental o1l recovery mechanisms that have been suggested to alkall flooding involved emulsions (Johnson, 1976). These are emulsification and entrainment and emulsification and entrapment. The former was first. discussed by subkow (1942), who believed that the crude oil is emulsified in situ by lowering the interfacial tension, and then entrained as a continuous flowing alkaline water phase. This mechanism precluded any increase in recovery before caustic breakthrough, and the oil recovery is as an emulsion, flowing with the caustic front. The latter mechanism was proposed by McAuliffe $(1973 a, b)$, who noted that the size of the emulsion droplets generated in situ 
is not sma1l enough to penetrate through all smail pore-throat constrictions. Instead, entrapment occurs between sand grains. This causes a reduction of water mobility and leads to an increase in sweep officiency and oil recovery in the low-permeability zones of the reservoir. The entrapment mechanism results in no significant reduction in ultimate residual oil saturation, but rather reduces the water-oil ratio required to reach this residual oil saturation. The oil recovered from this mechanism is as a separate phase.

The primary differences between these two mechanisms are the interfacial tension and the ratio of drop sizes to pore sizes. High interfacial tension and large drop-size to pore-size ratio will result in the entrapment mechanism. Low interfacial tension and small drop-size ratio will exhibit the entrainment mechanism. Thus, the purpose of this work is to study the effect of interfacial tension and drop-size to pore-size ratio on emulsion flow through porous media.

An experimental system has been constructed, as described previously (Radke and Somerton, 1977), to obtain the relation of pressure-drop to flow rate for dilute stable emulsion flow in consolidated and unconsolidated porous media. Further, a quantitative model, based on deep-bed filtration theory, has been developed to describe the bed permeability. The rudiments of this theory have been published (Radke and Somerton, 1977) and the details will be available in $a$ forthcoming manuscript.

\section{Caustic Loss}

In this work, caustic consumption by reservoir rock is measured by frontal-analy sis chromatography using a liquid chromatograph. This allows determination of both equilibrium consumption and band-brosdening resistances in the same experiment. Equilibrium loss is obtained from the solute-residence time of an input concentration step-change and an overall solute material balance (Wang et al., 1978). Experimental determination of sdsorption of sodium hydroxide on oil-free Ranger-zone sand at $20^{\circ} \mathrm{C}$ is shown in Figure 8 . Because hydroxyl and hydrogen ion concentrations are never independent, the adsorption in Figure $8, \Gamma$, is actually the difference between hydroxyl ion adsorption $\left(\Gamma_{\mathrm{OH}^{-}}-\Gamma_{\mathrm{H}^{+}}\right)$, and not the hydroxyl ion adsorption alone. Further, $\Delta \Gamma$ is measured relative to water of $\mathrm{pH} 7$, since hydroxyl ion concentration in water is always finite. Experimental data in Figure 8 include those obtained after reflushing the colum to neutral $\mathrm{pH}$, thus indicating reversible caustic adsorption ambient temperature. The alkali adsorption 1088 given in Figure 8 falls in line with other reported reservoir data (Jennings et a1., 1974). However, Figure 8 shows the strong influence of hydroxy 1 concentration.

The elution curve also gives information on adsorption kinetics. For simple external mass transfer and controlled adsorption in the linear

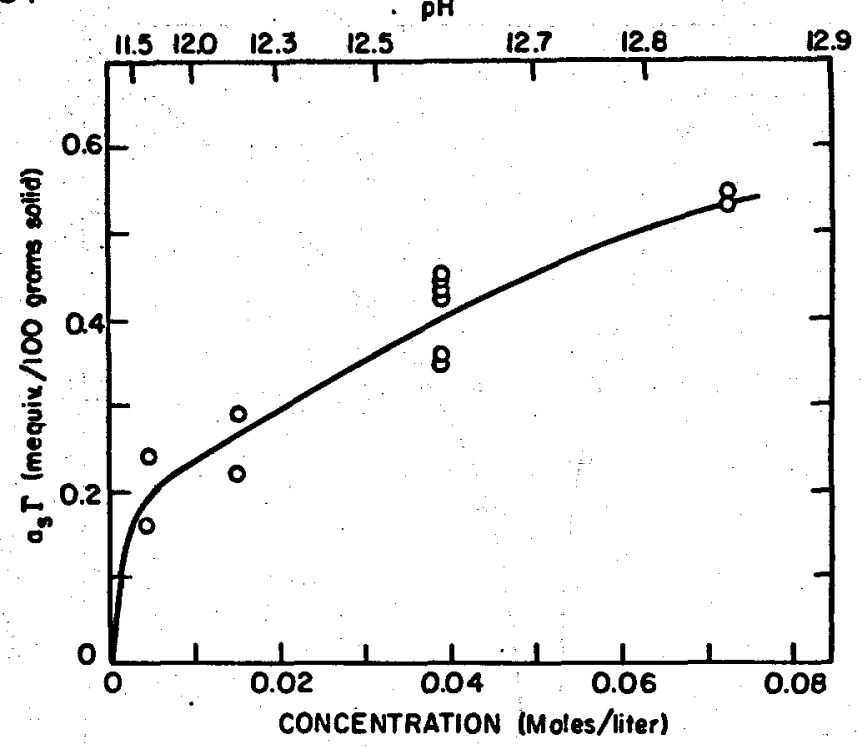

XEL 786-5284

Figure 8. Equilibrium caustic adsorption as a function of hydroxyl concentration on Rangerzone reservoir sand.

Henry law isotherm region, Thomas" analytical solution is applicable (Sherwood et al., 1975). Figure 9 compares the experimental caustic elution curve with the theoretical calculation, with the mass transfer coefficient estimated from the work of Newman and Tiedemann (1978). clearly, external mass transfer (and/or axial dispersion) cannot explain the observed spread, and additional resistances must be considered. The most likely, but unexpected, candidate is an internal-particle mass-transfer resistance suggesting porous solids in the Ranger-zone sand. This possibility is strengthened by the high specific surface area of this sand (about 7 $\mathrm{m}^{2} \mathrm{~g}^{-1}$ by nitrogen BET) with particle sizes between 10 and $100 \mu \mathrm{m}$.

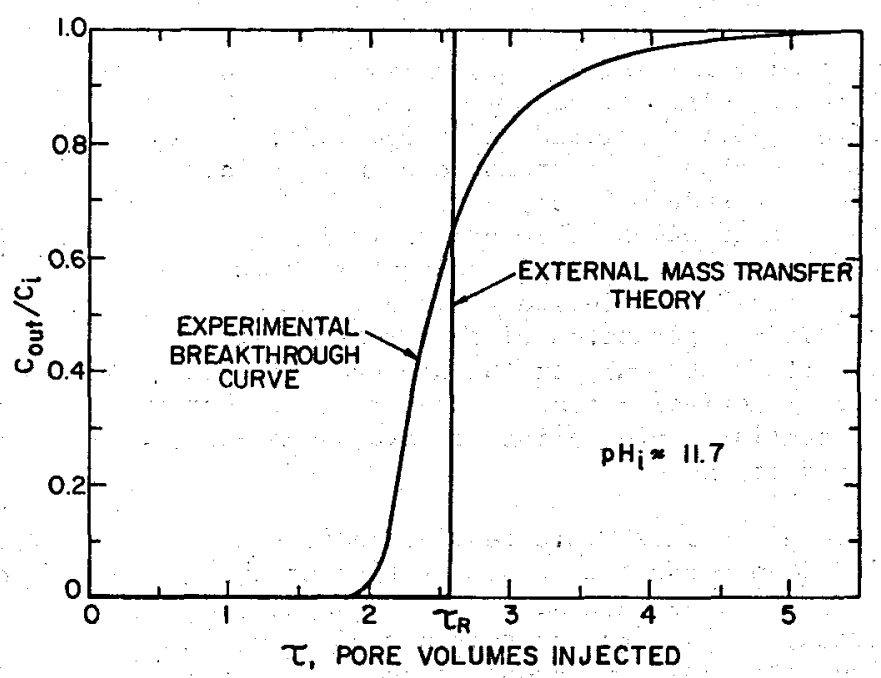

$X 8 L$ 786-5283

Figure 9. Experimental caustic elution curve compared to external mass transfer theory. 
Considerable evidence indicates that caustic $108 s$ increases dramatically os a function of temperature (Robinson et al., 1977). This work is pursuing both the kinetic and equilibrium aspects of the temperature dependence of alkali loss using frontal-analysis chromatography.

\section{PLANNED ACTIVITIES FOR FISCAL YEAR 1979}

In fiscal year 1979 , we will place more emphasis on alkaline tertiary flooding of Wilmington reservoir 8 ands, including studies on the effects of $\mathrm{pH}$ and salt content, use of buffers, flooding rate, mobility control, and cheap surfactant additives. The present flooding apparatus will be altered to permit continuous operation and, after rebuilding a second mercury injection pump, another complete flooding apparatus will be constructed. These modifications will reduce the long times that are presently required to obtain a recovery result.

Studies on the caustic-1oss problem will be expanded to include both batch and chromatographic test 8 in order to decide the importance of reservoir sand dissolution. We will also begin analysis of the clay content of the reservoir 8 and.

The emulsion studies of this coming year will be directed towards the use of dilute emulsions for mobility control. Secondary displacement tests of viscous oils in both homogeneous and heterogeneous cores will be used to ascertain the possible effectiveness of such emulsion mobility control.

\section{REFERENCES CITED}

Cayias, J. L., Schechter, R. S., and Wade, W. H., 1975. The reasurement of low interfacial tension via the spinning drop" technique in Adsorption at interfaces. A.C.S. Symposium Series 8 .

Claridge, E. L., and Bondor, P. L., 1974. A graphical method for calculating linear displacement with mass transfer and continuously changing mobilities. Soc. Pet. Eng. Jour , v. 14, pp. 609-618.

City of Long Beach, Dept. Oil Properties, 1977. Improved secondary oil recovery by controlled water flooding pilot demonstration. Technical proposal for ERDA.

England, D, C., and Berg, J, C, , 1971. Trans fer of surface activity agents across a liquidliquid interface, AIChE Jour, , v. 17, no. $2, p \cdot 313$.

Farmanion, P. A, Davis, N, , Kwan, K, T., Yen, T. F, and Weinbrandt, R. M, 1978, Isolation of native petroleum fractions for lowering Inter facial tensions in aqueousalkaline systems. Presented at Chemistry of

- Oil Recovery Symosium, American Chemical Society, Anaheim, California, March 1978 .

Fayers, F. J., and Perrine, R. L., 1959. Mathematical description of detergent flooding in oil reservoirs. Trans. AIME, v. 216, PP. 276-283.
Jenn ings, H. Y., Jr., Johnson, C. E., Jr., and McAuliffe, C. D., 1974. Acaustic waterflooding process for heavy oils. Jour. Pet. Tech., v. 126 , no. 12, pp. 1344-1352.

Jennings, H. Y., Jr., 1975. A study of caustic solution-crude oil interfacial tensions. Soc. Pet. Eng. Jour., v, 15, p. 197.

Johnson, C. E., Jr., 1976. Status of caustic and emulsion methods. Jour. Pet. Tech:; v. 28, Pp. 85-92.

Kremesec, V. J., and Treiber, L. J., 1976, Effect of system wettability on oil displacement by micellar flooding. Prepared for the $51 \mathrm{st}$ Annual Fall Technical Conference and Exhibition of the Soc. Pet. Eng. AIME, New Orleans, Oct. $3-6,1976$. Da1las, Soc. Pet. Eng. AIME, SPE 6001 .

Larson, R. G., and Hirasaki, G., 1976. Analysis of the physical mechanisms in surfactant flooding. 51 st Annual Fall Technical Conference and Exhibition, Soc. Pet. Eng. AIME, New Orleans, Oct. 3-6, 1976. Da1188, Soc. Pet. Eng. AIME, SPE 6003.

Mansfield, W. W., 1952. The spontaneous emulsification of mixtures of Oleic acid and paraffin oil in alkaline solutions, Australi an Jour. Sci. Res. Sec, A, Physical Sciences, v. 5, pp. 331-338.

McAuliffe, C. D., 1973a. Crude-oil-in-water emulsion to improve fluid flow in an oil reservoir. Jour. Pet. Tech,, v, 25, pp. 721-726.

1973b. 0il-in-water emulsions and their flow properties in porous media. Jour. Pet, Tech., v. 25, pp. 727-733.

McCaffery, F. G., 1976. Interfacial tensions and aging behavior of some crude oils against caustic solutions. Jour. Can. Pet. Tech., v. 15, pp. 1-4,

Newman, J., and Tiedemann, W., 1978. Flow-through process electrodes. Advances in Electrochemistry and Electrochemical Engineering, v. 11 , pp. 353-438.

Patton, J.T., Coats, K. H., and Colegrove, G. T., 1971. Prediction of polymer flood performance, Soc. Pet. Eng Jour., v. 11, Pp $72-84$.

Radke, C. J., and Somerton, H., 1977. Enhanced recovery with mobility and reactive tension agents, Third ERDA Symposium on Enhanced $O$ il and Gas Recovery and Improved Drilling Methods, Tulsa, Washington, D. C., U. S. Energy Research and Development Administration. $v$. 1, p. B-5.

Robinson, R. J, Burse 11, C, G, and Restine, J. L., 1977. Acaust ic steamflood Pilot-Kern River field. Prepared for 47th Annual California Regional Meeting of the SPE and AIME, Bakersfield, Californis, April 13-15, 1977. Dallas, Soc. Pet. Eng. AIME, SPE-6523.

Sherwood, T. K., Pigford, R. $L .$, and Wilke, C. R. 1975. Mass transfer. New York, McGrawHill, pP. 15-17.

Subkow, P., 1942. Process for the removal of bitumen from bituminous deposits. U. S. Patent No. 2288857 (July 7,1942 ).

Wang, H. L., Duda, J. L., and Radke, C. J., 1978. Solution adsorption from liquid chromatography. Jour. Colloid Int. Sci., v. $66, \mathrm{pp}, 153-165$. 
Wachmann, c., 1964. A mathematical theory for the displacement of oil and water by alcohol. Soc. Pet. Eng. Jour, v, Pp. 250-266.
We1ge, H. J., Johnson, E. F., Ewing, S. P., Jr., and Brinkman, F. H., 1961. The Iinear displacement of oll from porous media by enriched gas. Jour. Pet. Tech., v. 13, pp. 787-796.

URANIUM IN ALKALINE ROCKS

B. Strisower, H. A. Wollenberg, M. Murphy, H. Bowman, S. Flexser, and I. S. E. Carmichael

\section{INTRODUCTION}

Uranium ores mined in the United States to date have come primarily from sedimentary. deposits; crystalline rocks have yielded much of the uranium mined in the rest of the world. Among these crystalline rocks are the alkaline intrusive rocks, known to contain uranium as a result of exploration in Greenland and of mining in Brazil and Canada. A single alkaline intrusive occurrence in the United States, the RossAdams deposit in peralkaline granite at Bokan Mountain, Alaska, has been mined for uranium. Other alkaline intrusive occurrences in the United States might be expected to add to uranium resources. Within the category of alkaline igneous rocks are peralkaline nepheline syenites, alkaline-peralkaline granites, and carbonatites. Funded by Bendix Field Engineering Corp. for the U. S. Department of Energy, Lawrence Berkeley Laboratory completed a preliminary study of the potential for the occurrence of uranium in alkaline intrusive rocks. Results are detailed in a report by Murphy et al. (1978).

\section{ACTIVITIES IN FISCAL YEAR 1978}

The principal alkaline igneous occurrencès of known uranium resource potential were characterized by on-site visits. On-site inspections were made of uraniferous nepheline syenites at Ilímaussaq, Greenland, and Poços de Caldas, Brazil. These alkaline intrusive occurrences, together with the uraniferous peralkaline granite at Bokan Mountain, Alaska, and the niobium-uranium occurrence in carbonatites of the Ottawa Graben of southeastern Canada, were used as type-localities.

Information gained from on-site visits and published reports dealing with the four typelocalities was used to develop a set of criteria which were used for comparing other alkaline igneous occurrences in the United States.

The characteristics considered for comparison of alkaline intrusive areas included: petrology, mineralogy, tectanic setting, age of implacement, form of implacement, country rocks, late-stage hydrothermal activity, pathfinder elements, uranium mineralization, and radioactivity. Potential uranium resource areas in the alkaline rocks of the United States were identified by means of computer literature searches and review of relevant reports. These areas are Identifled in Table 1 and the accompanyling map on page 183 . of the 69 alkaline Intrusive occurrences shown on the map, only 40 had enough reported data to be judged using the type-locality criteria. Based on these criterla, nine areas showed the most promise for exploration. There are:

1. Alkaline-carbonatitic occurrences at Magnet Cove and Potash Sulphur Spring8, Arkansas

2. Carbonatite-pyroxenite nepheline syenitic Powderhorn intrusion near Gumisón, Colorado

3. Rocky Boy hydrothermally altered carbonatitic stock in the Bearpaw Mountains, Montana

4. Lujavritic stocks and sills of the Diablo Plateau, west Texas

5. Lujavritic-tinguaitic dike near Beemerville, New Jersey

6. Pegmatitic veins in riebeckite granite near Quincy, Massachusetts

7. Peralkaline pegmatites in the alkalic Quanah gramite of the Wichita Mountains, Oklahoma

8. Hydrothermally altered shear zones at the contact between alkalic granite and Precambrian granite near Jamestown, Colorado

9. Sheared and altered granite and pegmatites of Mt. Rosa, Colorado

Because of the presence of secondary hydrothermal alteration combined with deep lateritic weathering, attributes of the Poços de Caldas uranium occurrence, the Magnet Cove/Potash Sulphur Springs area is considered the toppriority exploration target of the nine areas. More detailed descriptions of the areas are presented by Murphy et al. (1978).

A second line of investigation was a study of potential pathfinder elements-those occurring with uranium in the minerals contained in alkaline intrusive rocks. The question was: If no radioelement data existed in the literature on a given occurrence, could one use data on other elements to indicate the presence of appreciable uranium?

Trace-element and radicelement data from reports on the alkaline intrusive occurrences were collected for several elements--Zr, $\mathrm{Nb}, \mathrm{Be}$, 
$F$, rare earths, $L_{i}, \mathrm{Zn}_{\mathrm{n}}$, and Mo-as well as for $U$ and $T h$ in the same rocks. The compilation included data from (a) peralkaline granites of Bokan Mountain, Alaska; (b) peralkaline intrusives at Magnet Cove, Arkansas; Illímaussaq, Greenland; and Lovozero, Soviet Union; and (c) calc-alkalic intrusives of New England and the Sierra Nevada batholith. Concentrations of each element were plotted against uranium or uraniumplus-thorium contents, using available data from the literature.

In the country rock surrounding the mineralized occurrences, $\mathrm{Zr}$ had the strongest relationship to U + Th. The log-log plot (Figure 1) 11lustrates this correlation. After $\mathrm{Zr}$, the next best correlation was $\mathrm{La}+\mathrm{Ce}$ with $\mathrm{U}+\mathrm{Th}$ as shown In Figure 2.

Relationships between other trace elements and radicelements were weaker, or data were too sparse to be useful. In many cases the anslyses of trace elements reported in the literature were semiquantitative, which may account for the lack of strong correlations.

Quantitative analyses were done at LBL on samples of country rock from collections from Poços de Caldas, Brazil; Ilímaussaq, Greenland; Nemegos, Ontario; and Magnet Cove, Arkansas. Mean concentrations and ranges for major and trace elements are given for several alkaline intrusive rocks from these sites (Table 2). The 11 nepheline syenite samples were collected from Poçós de Caldas, Brazil; Nemegos, Ontario; and Magnet Cove, Arkansas, For rock specimens collected from three different alkaline intrusives in widely separated geologic areas, the ranges are remarkably small.

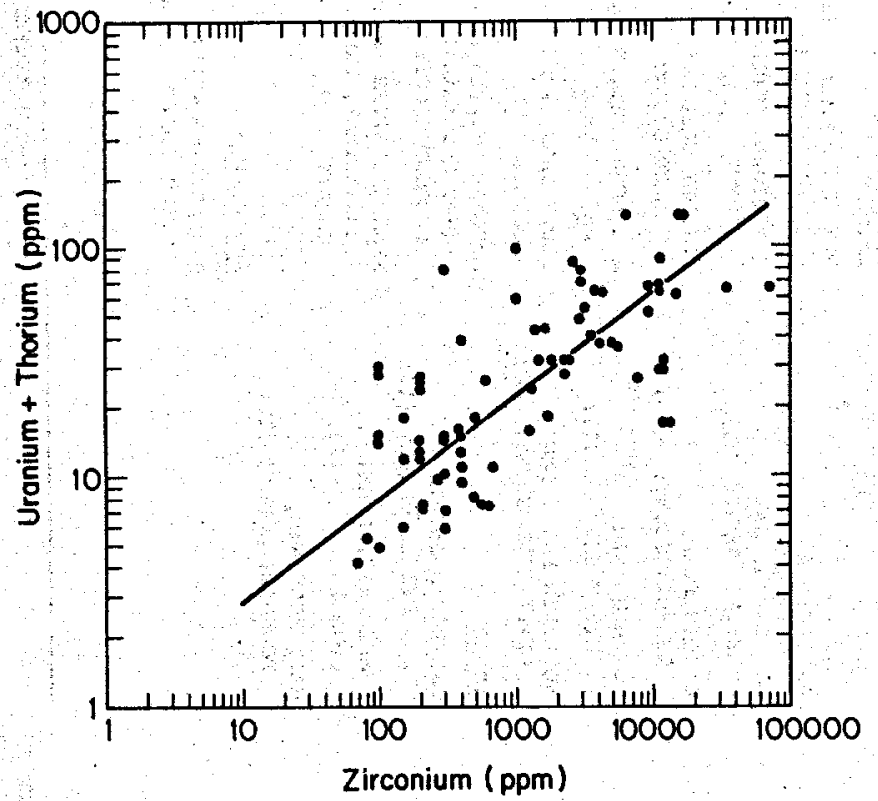

xoL. $781-184$

Figure 1. Zr vs. U + Th; data from the literature.

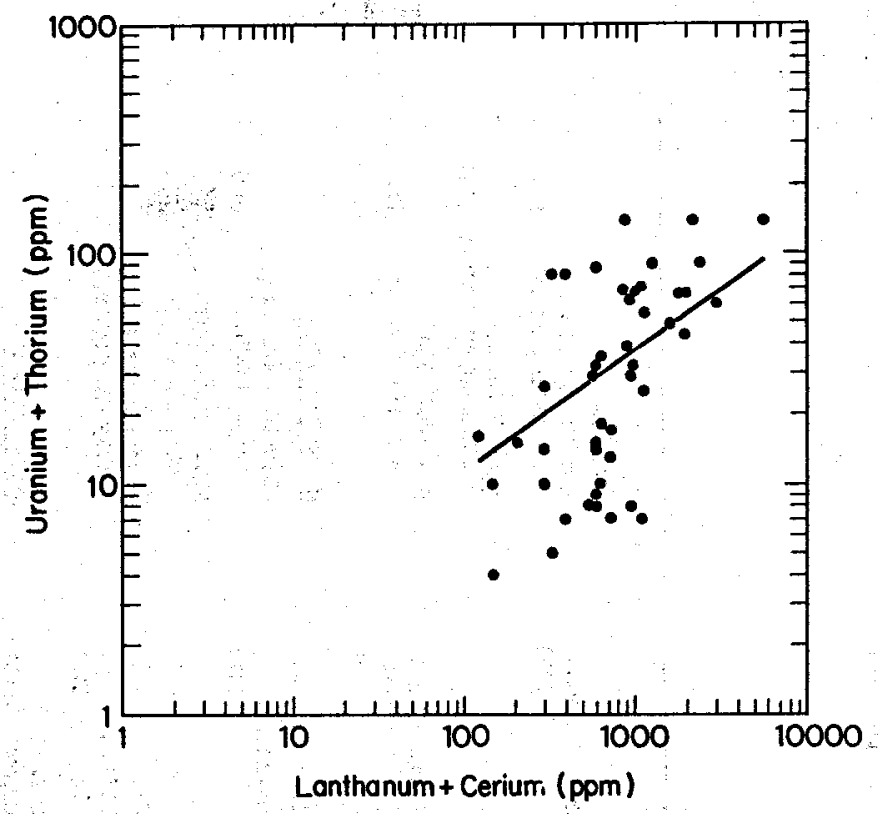

xEL Tra-123

Figure 2. La + Ce vs. U + Th; data from the literature.

In these data, a good correlation is evident between the radioelements $\mathrm{U}+$ Th and the rareearth elements $\mathrm{La}+\mathrm{Ce}$ (FIgure 3 ). Using the same data, there is essentially no correlation between $U+T h$ and $\mathrm{Zr}$. It is possible that in these rocks the minerals containing $\mathrm{Zr}$ are not necessarily those containing the radioand rareearth elements.

These relationships suggest that $\mathrm{Zr}$ and rare-earth elements may be used as qualitative pathfinders for radice lements. The usefulness of these and other elements as pathfinders can be confirmed by more petrologic and chemical analytic work on a more controlled group of samples.

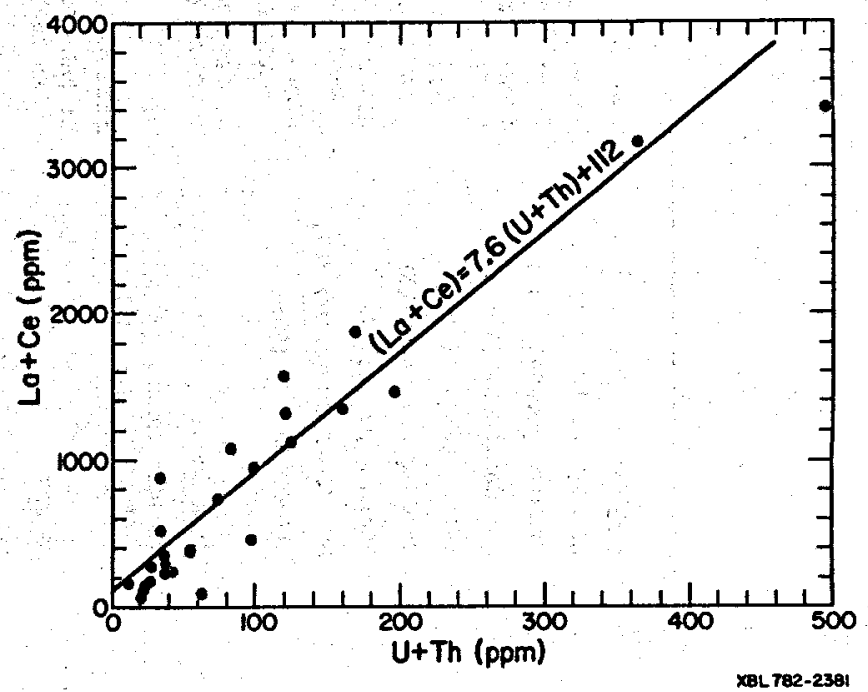

Figure 3. $\mathrm{La}+\mathrm{Ce}$ vs. U + Th; data from LBL analyses. 
TABLE 1

MASTER LIST OF U.S. ALKALINE OCCURRENCES

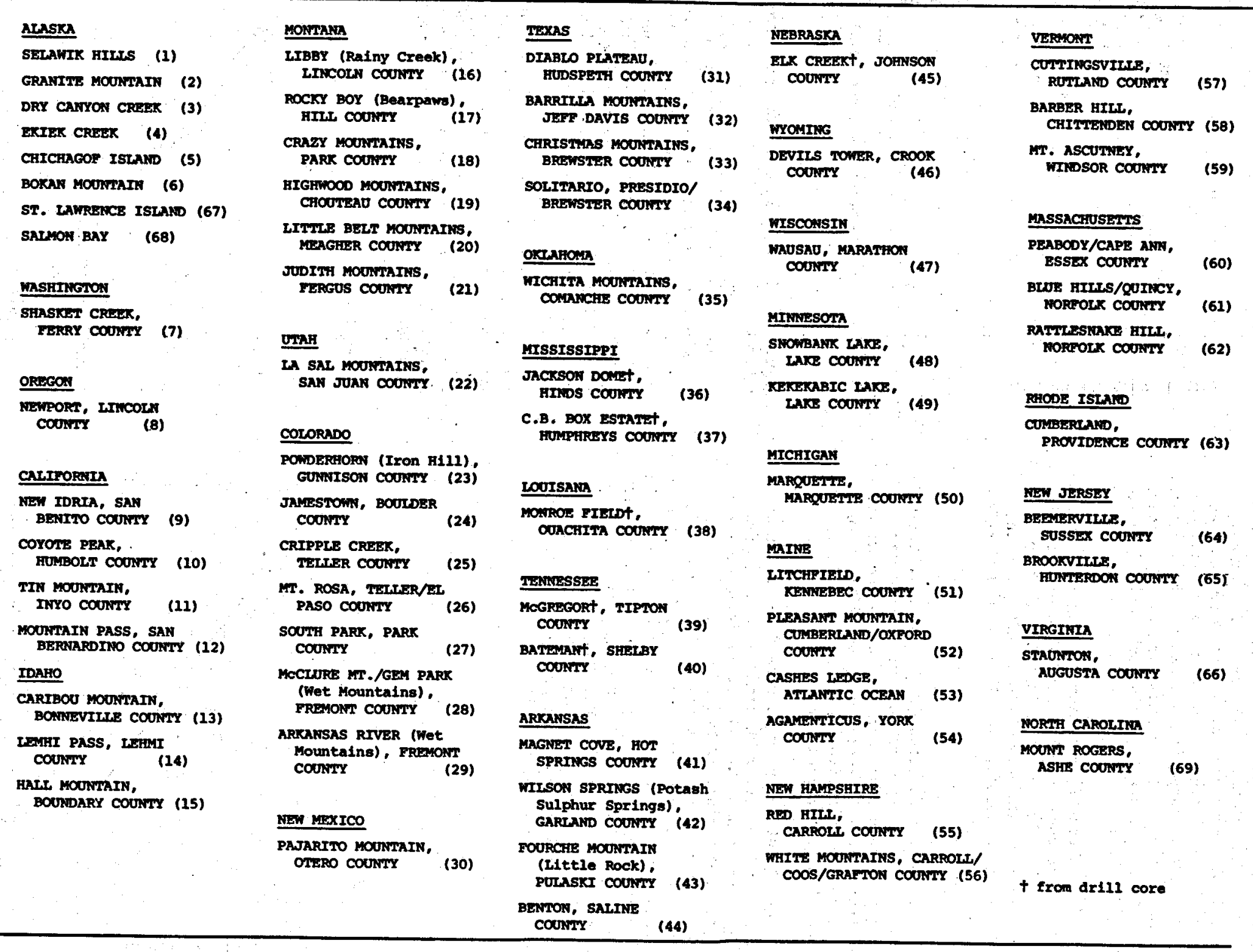




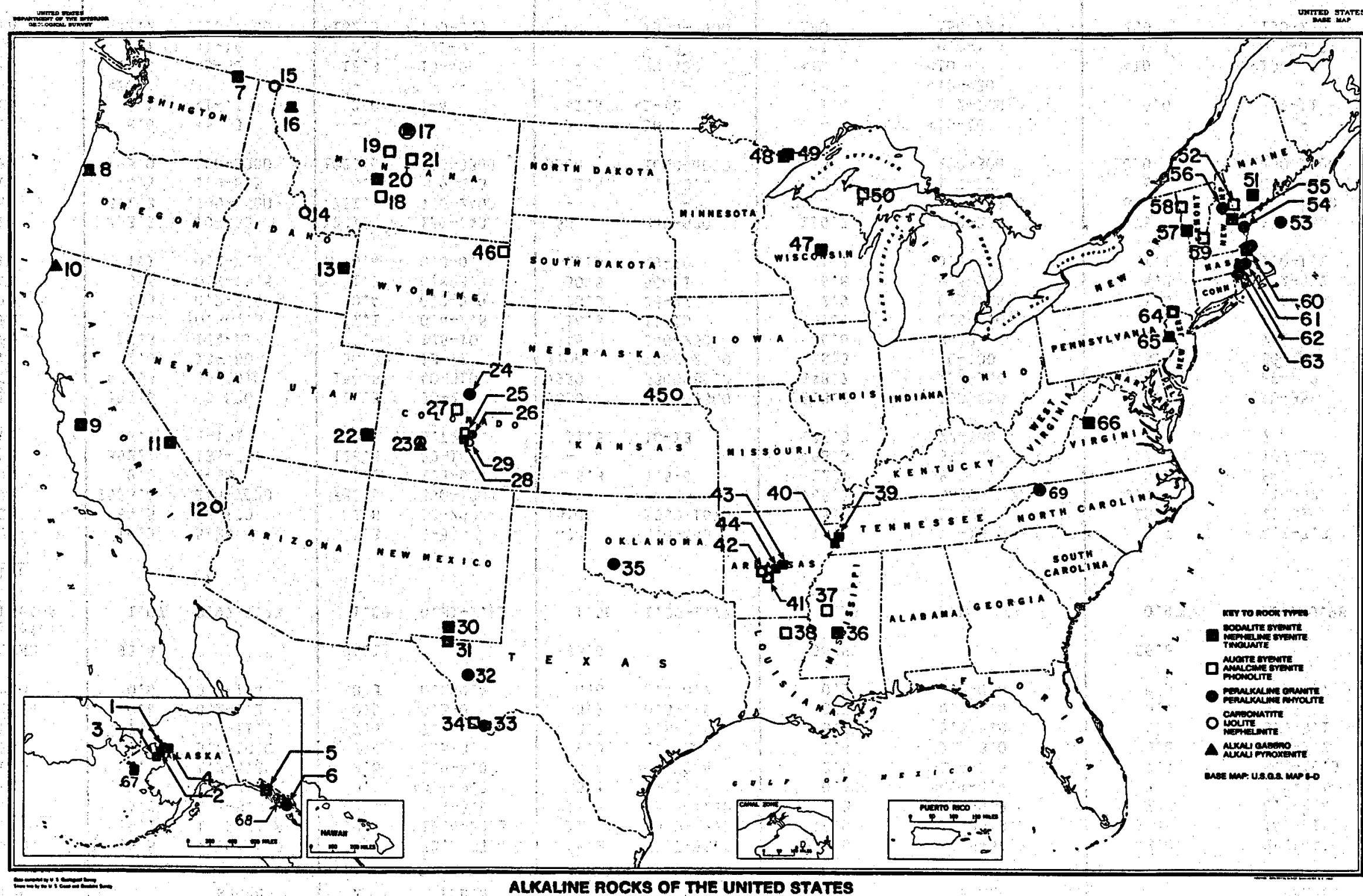


Table 2. Mean values and ranges of major and trace elements in rock types

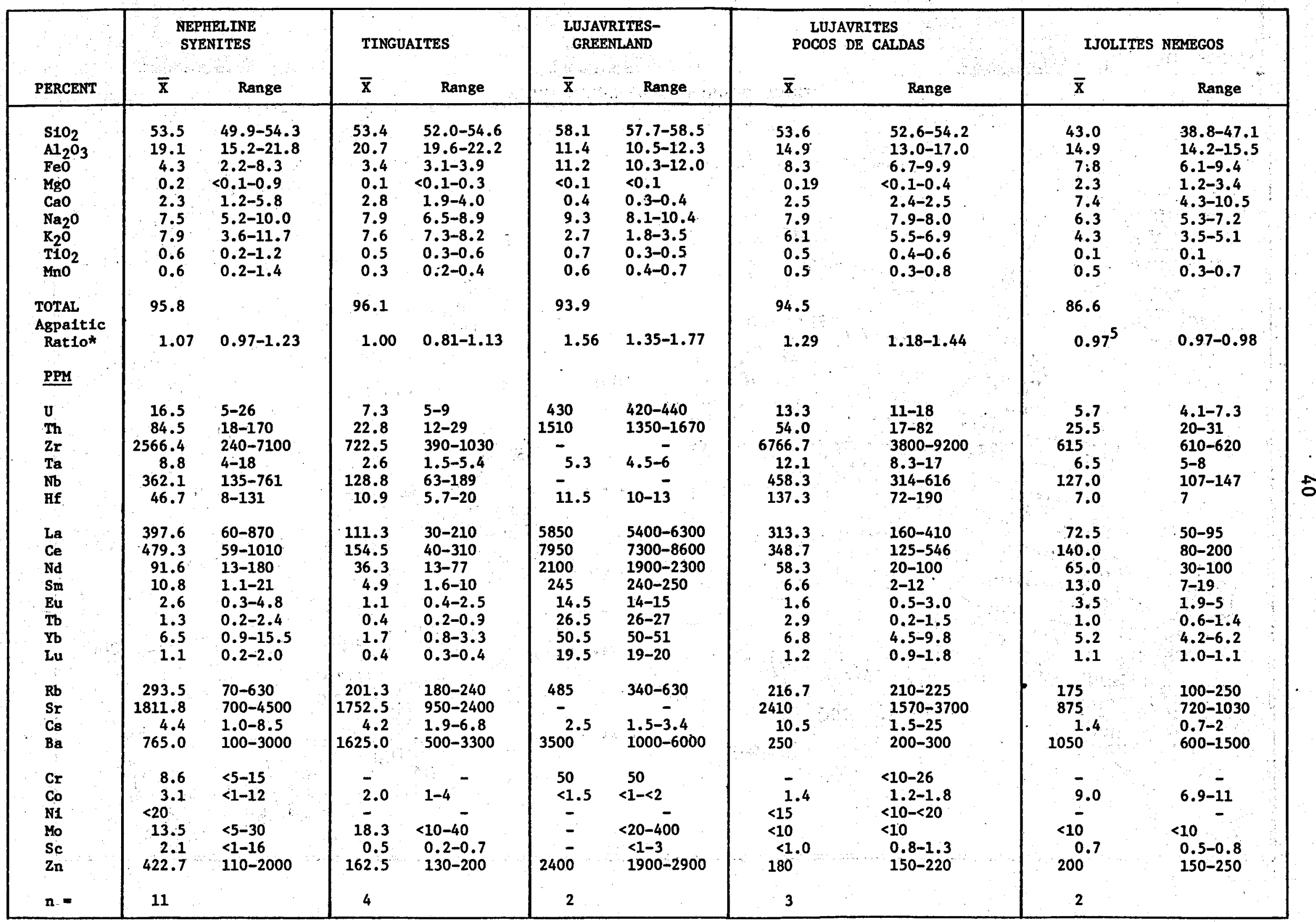

*Agpaitic ratio calculated from (Na+R)/Al) where $\mathrm{Na}, \mathrm{K}$, and Al are molecular abundances of sodium, potassium, and aluminum. 
PLANS FOR FISCAI YEAR 1979

The project was not funded in 1979.

\section{REFERENCES}

Murphy, M., Wollenberg, H., Strisower, B., Bowman, H., Flexser, $S$. and Carmichael, $I$.

\section{GEODOSE PROJECT}

\section{H. A. Wollenberg and B. Strisower}

\section{INTRODUCTION}

Under the auspices of EG\&G, Inc,, the geochemical literature was searched for data on the uranium, thorium, and potassium contents of the major rock types. The primary purpose of the project is to characterize rock and soil types by their natural gama-ray exposure rates. This information helps us predict and interpret the gamma-ray exposure rates measured on radiological surveys by aircraft of the DOE/EG\&G Aerial Measurements System.

\section{ACTIVITIES IN FISCAL YEAR 1978}

From radioelement contents, the computer program DOSECAL calculated gamma-ray exposure rates and radiogenic heat production. Exposure rates for an elevation of $1 \mathrm{~m}$ above the ground were calculated using the equations of Beck and de $P$ lanque (1968), relating the radiation field to distributed gamma-ray sources in the ground. Results of analyses of over 2,400 rocks are summarized in Table 1 . Histograms of exposure rates comprise Figures 1,2 , and 3 , of the igneous rocks, the alkali feldspathoidal rocks

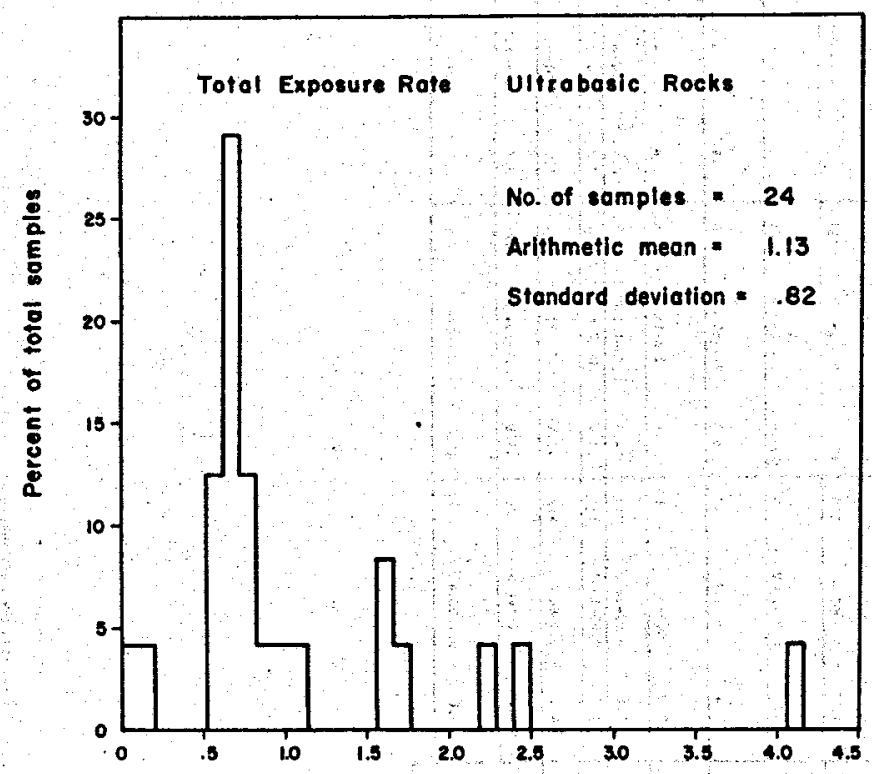

Micro $R$ per hour

Figure 1. Histogram showing the total exposure rate for ultrabasic rocks.
S. E. 1978. Uranium in alkaline rocks. Berkeley, Lawrence Berkeley Laboratory, LBL-7029.

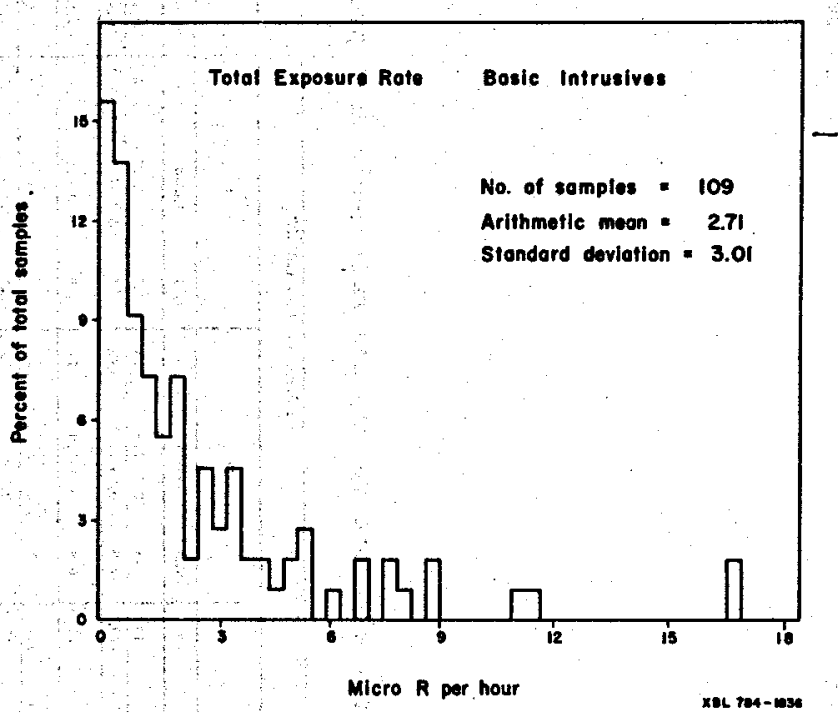

Figure 2. Histogram showing the total exposure rate for basic intrusive rocks.

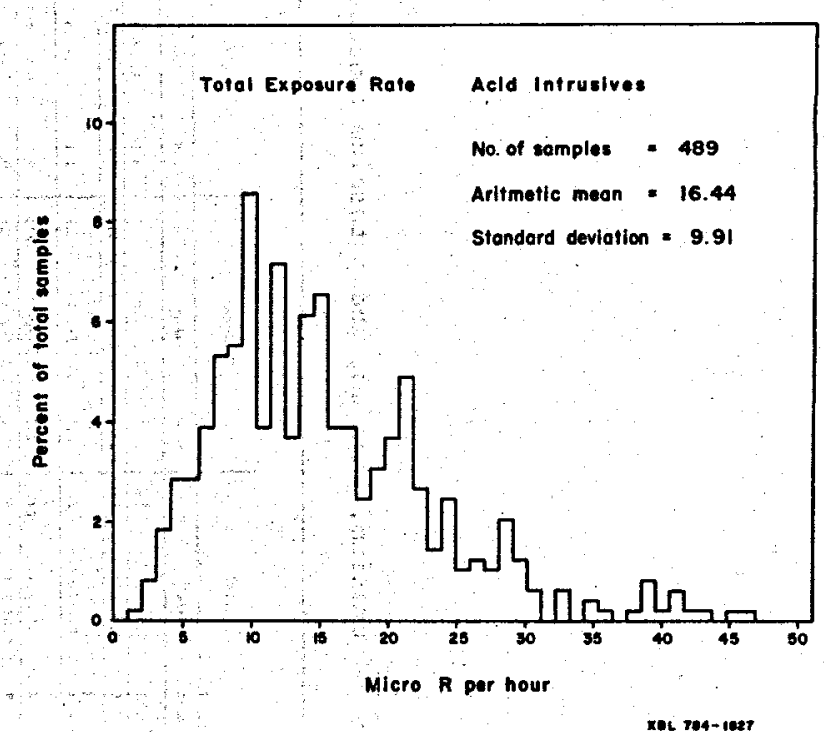

Figure 3. Histogram showing the total exposure rate for acid intrusive rocks. Note that the mean of total exposure rate for the acid intrusives is a factor of 10 higher than the mean for ultrabasic rocks. Basic intrusives have intermediate values. 


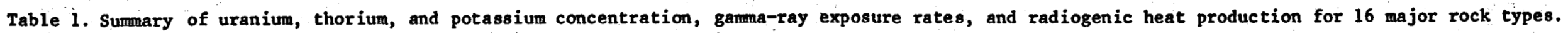

\begin{tabular}{|c|c|c|c|c|c|c|c|c|c|c|c|c|c|c|c|c|c|c|c|c|c|c|c|c|}
\hline \multirow{3}{*}{$\frac{1}{\operatorname{sox} a \operatorname{ses}}$} & \multirow{2}{*}{\multicolumn{3}{|c|}{$0(\mathrm{~ms})$}} & \multirow{2}{*}{\multicolumn{3}{|c|}{ In (ppe) }} & \multirow{2}{*}{\multicolumn{3}{|c|}{$x(x)$}} & \multicolumn{12}{|c|}{ 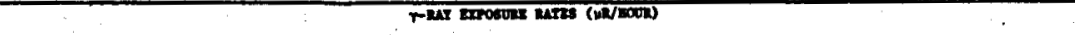 } & \multirow{2}{*}{\multicolumn{3}{|c|}{ 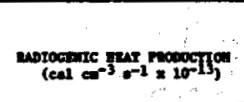 }} \\
\hline & & & & & & & & & & \multicolumn{3}{|c|}{ v } & \multicolumn{3}{|c|}{$\therefore \quad \therefore \mathbf{m}$} & \multicolumn{3}{|c|}{$x$} & \multicolumn{3}{|c|}{ rotel } & & & \\
\hline & min & wine & - & mex & entax & 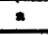 & $\operatorname{man}$ & $\operatorname{mex}$ & - & men & merex & - & mex & mans. & 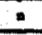 & $\max$ & mext & 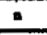 & $\operatorname{men}$ & nenger &. & $\mathrm{man}$ & tuan & - \\
\hline sesu betrene & 4.1 & $0.4-16.6$ & 13 & H.e & $1.1-1.0$ & 13 & 3.1 & $1.0-6.2$ & - & 2.7 & $0.5-10.7$ & ${ }^{23}$ & 3.6 & $0.3-12.6$ & 3 & 3.1 & $1.6-10.2$ & - & 20.2 & a.2-16.5 & - & 6.6 & $2.0-10.2$ & 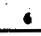 \\
\hline Lete Intruén & 4.5 & $0.1-30.0$ & 409 & 25.7 & $0.2-233.2$ & 693 & 3.4 & $0.1-7.6$ & 43 & 2.8 & $0.1-19.6$ & 40 & 7.9 & $0.03-77.7$ & 493 & 3.6 & $0.2-12.5$ & 493 & 26.4 & $2.1-98.3$ & 60 & 10.5 & $1.7-58.7$ & 40 \\
\hline Internodiate & 1.1 & $0.2-2.6$ & 21 & 2.4 & 0.46 .6 .4 & $2 x$ & 1.1 & $0.01-2.5$ & 6 & 0.1 & $0.2-2.7$ & 21 & 0.8 & $0.1-2.0$ & 21 & 1.9 & $0.9-4.1$ & 6 & 4.1 & $2.2-7.2$ & 1 & 2.0 & $2.5-4.7$ & - \\
\hline $\begin{array}{l}\text { Intortidince } \\
\text { Intrmatim }\end{array}$ & 3.2 & $0.1-23.4$ & 272 & 12.2 & $0.4-106.0$ & 273 & 2.1 & $0.1-6.2$ & 273 & 2.1 & $0.05-15.3$ & 271 & d.7. & $0.1-32.5$ & 273 & 3.3 & $0.2-10.2$ & 273 & 8.4 & $0.3-11.2$ & $m$ & 6.2 & $0.227,6$ & 272 \\
\hline 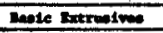 & 0.0 & $0.03-3.3$ & 53 & 2.2 & $0.05-8.6$ & 32 & 0.7 & $0.06-2.4$ & 33 & 0.5 & $0.02-2.2$ & 39 & 0.7 & $0.02-2.7$ & 55 & 1.1 & 0.16 .6 & 35 & 2.3 & $0.1-8.7$ & 53 & 1.5 & $0.1-5.6$ & 33 \\
\hline 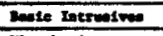 & 0.1 & $0.01-3.7$ & 119 & 2.3 & $0.05-15.0$ & 220 & 0.8 & $0.01-2.67$ & 129 & 0.5 & $0.01-3.7$ & 210 & 0.7 & $0.01-6.6$ & 1110 & 1.3 & $0.1-10.3$ & 120 & 2.7 & $0.2-16.6$ & 109 & 1.0 & $0.1-10.0$ & 109 \\
\hline Terrstente & 0.3 & $a-1.6$ & 31 & 1.4 & 0.7 .5 & 30 & 0.3 & $0-0.8$ & 28 & 0.2 & $0-1.1$ & 31 & 0.4 & $0-2.3$ & .30 & 0.4 & $0-1.1$ & 28 & 1.1 & $0.1-6.0$ & 24 & 0.7 & $0.1-2.7$ & 26 \\
\hline 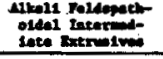 & 29.7 & $1.9-62.0$ & 230 & 233.9 & D.5-265.0 & 239 & 6.5 & $2.0-9.0$ & \$ & 19.4 & $1.2-60.1$ & 136 & 41.1 & $2.8-42.4$ & 13 & 10.1 & $3.4-14.9$ & 36 & 21.5 & $16.0-127.2$ & 33 & 68.4 & $21.1-\infty 0.7$ & 35 \\
\hline 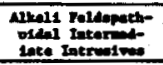 & 55.0 & $0.3-720.0$ & 73 & 132.6 & $0.4-280.0$ & 23 & 4.2 & 1.0-9.9 & 61 & 36.5 & $0.2-470.9$ & 75 & $\$ 0.7$ & $0.1-491.2$ & 5 & 6.9 & $1.7-16.4$ & 61 & 42.7 & 3.3-323.2 & 6 & 30.4 & $2.1-299.1$ & 6 \\
\hline 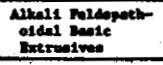 & 2.6 & $0.5-12.0$ & 20 & $\mathbf{0 . 2}$ & $2.1-60.0$ & 20 & 1.9 & 0.26 .9 & 20 & 1.3 & $0.3-7.9$ & 20 & 2.5 & $0.6-10.4$ & 20 & 3.2 & $0.5-11.4$ & 20 & 7.2 & $2.2-36.7$ & 20 & 4 & 2.0-23.9 & 20 \\
\hline 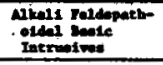 & 2.3 & $0.4-5.4$ & 3 & 8.4 & $2.8-19.6$ & - & 1.8 & $0.5-6.8$ & 1 & 1.3 & $0.3-3.5$ & - & 2.6 & $0.9-6.0$ & 8 & 3.0 & $0.9-7.9$ & 8 & 7.1 & $1.6-17.4$ & - & 4.7 & $1.0-11.4$ & 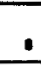 \\
\hline 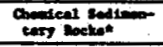 & 3.6 & $0.03-26.7$ & 243 & 14.9 & $0.03-132.0$ & 239 & 0.6 & $0.02-8.4$ & 42 & 2.4 & $0.02-17.5$ & 243 & 4.6 & $0.02-60.3$ & 239 & 0.9 & $0.03-13.9$ & 62 & 3.2 & $0.2-45.3$ & 30 & 3.5 & $0.1-27.8$ & $x$ \\
\hline corbontem & 2.0 & $0.03-11.0$ & 141 & 1.3 & $0-10.8$ & 131 & 0.3 & $0.01-3.5$ & 35 & 1.3 & $0.02-11.8$ & 141 & 0.6 & $0-3.3$ & 231 & 0.5 & $0,02-5.6$ & 35 & 1.9 & $0.2-6.4$ & 32 & 1.4 & $0.1+4.0$ & 32 \\
\hline $\begin{array}{l}\text { Dotriteal sodidum- } \\
\text { eary hooke }\end{array}$ & 6.1 & $0.1-80.0$ & 412 & 12.4 & $0.2-362.0$ & 411 & 1.5 & $0: 02-9.7$ & 298. & 3.1 & $0.05-52.3$ & 412 & 3.8 & $0.1-121.1$ & 411 & 2.5 & $0,02-16.1$ & 291 & ... & $0,4-146.6$ & 298 & 6.2 & $0.2-93.1$ & $2 n$ \\
\hline 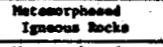 & 4.0 & $0.1-148.5$ & 128 & 14.0 & $0.1-104.2$ & 228 & 2.5 & $0.1-6.1$ & 124 & 2.6 & $0.1-91,1$ & 128 & 4.6 & $0.02-12.0$ & 128 & 4.2 & $0.2-10.0$ & 228 & 12.3 & $0.0-124.6$ & 128 & 1.5 & $0.0-100.7$ & 220 \\
\hline 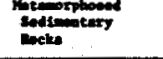 & 3:0 & $0.1-53.4$ & 207 & 12.0 & $0.1-91.4$ & 200 & 2.1 & $0.01-5.3$ & 206 & $2: 0$ & $0.05-34.9$ & 207 & 3.1 & $0.2-28.2$ & 208 & 3.4 & $0.02-6.7$ & 200 & 9.1 & $0.4-50.5$ & 207 & 6.0. & $0.2-62.3$ & 207 \\
\hline
\end{tabular}

- Inctiven cartionateo

XBL 791-7832 
(predom nant ly nepheline syenites) are highest in radioelement content, whereas basic to ultrabasic rocks (basalts, gabbro, periodotite) have exposure rates and heat production an order of magnitude lower.

Detrital sedimentary rocks (sandstone; shale, conglomerate) are relatively radioactive compared with chemical sedimentary rocks, especially the carbonates ( 1 imestone and dolomite). Within the metamorphic rocks, radioactivity depends primarily on the composition of the ir igneous or sedimentary predecessors, secondarily on the degree of metamorphism which the rocks have undergone.
PIANNED WORK IN FISCAL YEAR 1979 ,

Additional data are being included as new results are published. Histograms and tabular sumaries will be prepared and a final report written.

\section{REFERENCE}

Beck, H., and de Planque, G., 1968. The radiation field in air due to distributed gama-ray sources in the ground... USAEC Health and Safety Lab. Rept. HASL-195.

\section{THERMAL EFFECTS IN OVERLYING SEDIMENTARY ROCK FROM IN-SITU} COMBUSTION OF A COAL SEAM

D. C. Mangold, H. A. Wollenberg, and C. F. Tsang

\section{INTRODUCTION}

The purpose of this investigation was to determine the times at which significant differences in temperature would occur, at varying depths in overlying sedimentary rock, in response to combustion of a coal seam. The results may be important for interpretation of a irborne thermal infrared surveys, such as those flown by EG\&G, Inc., over the U. S. Department of Energy's Hanna, Wyoming, in-situ coal gasification experimental facility. A more detailed description of the study is presented by Mangold et a1. (1978).

The duration of the experimental "burns" (in excess of one-half year) associated with in-situ coal, oil-shale, or tar-sand combustion experiments raises the following questions. When might the surface temperature be affected due to the high temperatures at depth? Would surfacetemperature effects be detectable by highresolution aerial-survey equipment? The models in this preliminary investigation only considered thermal conduction as the heat-transfer mechanism. Heat transfer to the surface by convection within the overlying sedimentary rock or along fissures or cracks was not addressed.

\section{NUMERICAL SIMULATION: MODEL AND RESULTS}

The in-situ coal gasifcation was modeled by a thermal front, behind which the temperature was $1,200^{\circ} \mathrm{C}$, progressing at the rate of $0.3 \mathrm{~m} /$ day along a horizontal coal seam 5 m thick at an average depth of $62.5 \mathrm{~m}$.

The initial temperatures of the seam, rock, and surface were assumed to be $20^{\circ} \mathrm{C}$, and the surface temperature was maintained at $20^{\circ} \mathrm{C}$ as a boundary condition for the calculations. The movement of the thermal front was simulated by assuming a flow through the seam of a fluid whose temperature is maintained at $1,200^{\circ} \mathrm{C}$ and whose density is the same as the seam itself. Heat transfer to the overlying rock was assumed to be by conduction only.

The numerical model ccc (Lippmann et al.. 1977) was used to perform the calculations. Regults were tabulated for the initial column of elements, whose nodal centers are al1 located 0.5 m horizontally from a line directly above the starting point of the coal-seam "burn." Thheights of the nodal centers of the rock layers, are $0.5,2.5,7,22.5$, and $47.5 \mathrm{~m}$, respectively, above the top of the coal seam. The temperatures at the end of two-year intervals are shown in Figure 1. After eight years, the temperature in the layer, wich is in contact with the surface would reach on $190.2^{\circ} \mathrm{C}$ above the initial temperature of $20^{\circ} \mathrm{C}$ and after 10 years, it would reach $20.4^{\circ} \mathrm{C}$.

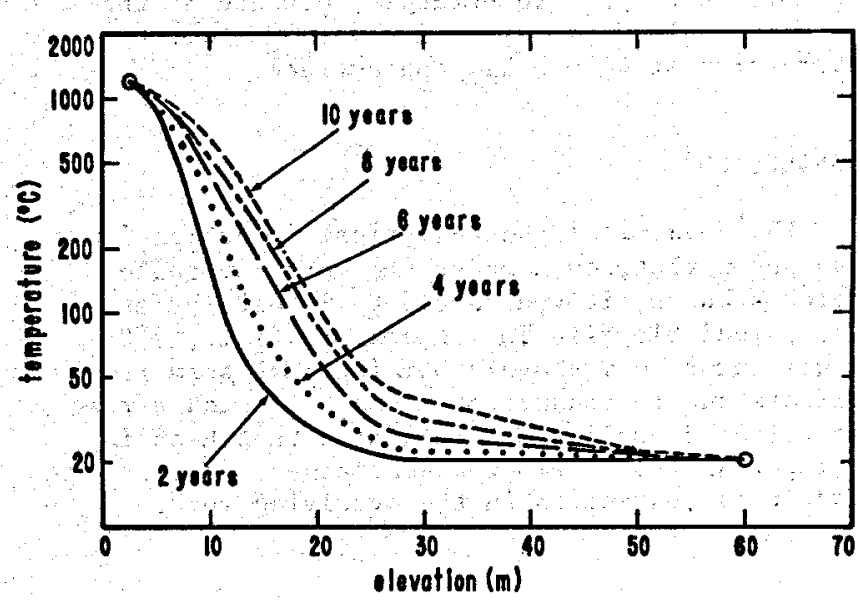

XELTE9- 2056

Figure 1. Temperature distribution in over lying rock at various elevations above a progressively heated seam, obtained by numerical model $\mathrm{CCC}$. 
Therefore, in the model of a progressive front, if appreciable thermal effects were observed at the surface ( $60 \mathrm{~m}$ above the seam) less than eight years after combustion begar, they would be due to leakage of heat along vents or cracks, or to convection within the overlying sedimentary rock.

Calculations were also made for the model with a closed boundary (no flow of heat) at the surface. The results were identical to the $20^{\circ} \mathrm{C}$-boundary case in the 10 -year period covered by both simulations.

\section{ANALYTICAL MODELS AND RESULTS}

To further check on the numerical calculaticns, an analytical model was used (Carslaw and Jaeger, 1959) assuming sudden, uniform heating of a rectangular $s$ lab of finite thickness, over an infinite length. Flow of heat is allowed at the upper boundary of the layered system. Under these conditions, of instantaneous uniform heating to $1,200^{\circ} \mathrm{C}$ and a boundary maintained at $20^{\circ} \mathrm{C}$, the time of arrival of the $2^{\circ} \mathrm{C}$ thermal transient was calculated for various levels above the top of the seam. The results are presented in Figure 2. A further re finement incorporating a denser mesh in CCC yielded numerical results Identical with those of the analytical calculations: (DIscrepancles were on the order of $0.1 \%$ or less.)

In addition, another calculation was made using a model that assumes no flow of heat at the boundary and a variable overburden thickness (Carslaw and Jaeger, 1959, pp. 308-310). For a 60-m-thick slab, it takes approximately 5.5 years to achieve at $2^{\circ} \mathrm{C}$ temperature rise at $47.5 \mathrm{~m}$ above the seam, and approximately 8 . years for a $2^{\circ} \mathrm{C}$ rise to reach the upper boundary (in contact with the surface). A similar model was used by Greene et al. (1969) to calculate thermal effects in strata overlying a coal-mine fire. They concluded that it may be two decades or more before the temperature increase at the surface could be observed for $a 100^{\circ} \mathrm{C}$ temperature rise at $60 \mathrm{~m}$ below the surface.

\section{CONCLUSION}

This numerical and analytical investigation has shown that, even under the most favorable circumstances, it would be 5 to 8 years before an appreciable rise in temperature (i.e., $\sim 2^{\circ} \mathrm{C}$ ) would occur $60 \mathrm{~m}$ above a burning coal seam from effects due to conduction alone. If such a rise is detected earlier, it indicates that heat is being transferred along cracks and joints, and/or by convection in the overlying rock.

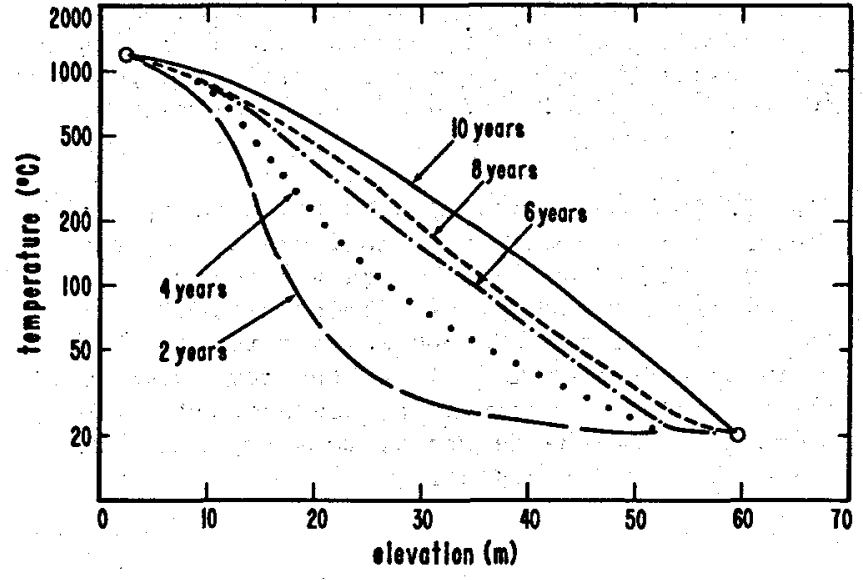

xat_788-2052

Figure 2. Temperature distriburion in overlying rock at various elevations above a uniformly heated seam, obtained from analytical calculations.

\section{PLANNED ACTIVITIES FOR FISCAL YEAR 1979}

On the basis of these results, a further investigation is planned, to examine heat transfer by convection as we 11 as by conduction. Further research may also be performed to study the effects of fissures and cracks in heat transfer in the overlying sedimentary rock.

\section{REEERENCES}

Cars law, H. S., and Jaeger, H. S., 1959. Conduction of heat in solids, Oxford, Oxford University Press, 2nd ed.

Greene, G. W., Moxham, R. M., and Harvey, H. H., 1970. Aerial infrared surveys and borehole temperature measurements of coal mine fires in Pennsylvania, in Proc. Sixth Internat. Symp. on Remote Sensing of the Environment, Will ow Run Laboratories, University of Michigan.

Lippmann, M. J., Tsang, C. F., and Witherspoon, P. A., 1977. Analysis of the response of geothermal reservoirs under injection and production procedures. Dallas, Soc. Pet. Eng. AIME, SPE-6537.

Mangold, D., Wollenberg, H., and Tsang, C. F., 1978. Thermal effects in overlying sedimentary rock from in-situ combustion of a coal seam. Berkeley, Lawrence Berkeley Laboratory, LBL-8172. 
FOUR-CHANNEL SIMULTANEOUS COLLECTION SYSTEM FOR HIGH-PRECISION

MASS SPECTROMETRY

M. C. Michel, D. F. Mosier, and W. R. Keyes

\section{INTRODUCTION}

Two years ago, we began a project to adapt our 5-ft-radius isotope separator to very high precision measurements of isotope ratios of interest to geochronology (for example, $\mathrm{Sr}$ and Nd). We felt that conventionsl techniques, involving sequential measurement of isotope beams, had been developed as much as possible and that exploiting the apparent advantages of collecting isotope beams simultaneously was a possible way of extending the precision. For practical reasons, this requires a relatively large-radius mass spectrometer.

Interest in higher precision has also developed among researchers in geochronological techniques as more sophisticated measurements are made with familiar systems such as Rb-Sr, and as the utility of new systems such as $\mathrm{Sm}$-Nd becomes apparent (Carter et al., 1978).

A previous report (Miche1, 1978) describes most of the preliminary work leading up to the first testing of the complete system during this year. As is often the case, the initial performance is somewhat below expectations, but it shows every evidence of responding to attempts at improvement. The present per formance is quite similar to some of the best work by conventional techniques.

\section{ACTIVITIES IN FISCAL YEAR 1978}

The primary accomplishment of this year's work has been the actual construction, debugging, and use of the four-channel data readout system shown in Figure 1. (At present only three of the channels are in use, corresponding to the strontium isotopes of mass 86,87 , and 88.)

To sumarize briefly, the ion beams corresponding to the three strontium isotopes above are incident on the ir respective Faraday cups, the collected current is amplified to a voltage proportional to the input current, periodically stored in corresponding channels of the sample and hold circuit, and then sequentially digitized by a single digitizing device.

Assuming that the Faraday cup currents are truly a measure of relative isotope abundances, we need only guarantee that the three amplifiers have the same (but not necessarily known) gain and are linear to the desired precision, in order to supply data to the sample and hold circuit (which is capable of giving the desired precision). If the sample and hold circuit does not introduce further discrimination, and if the digitizing device has the appropriate precision, the entire system should function as desired.

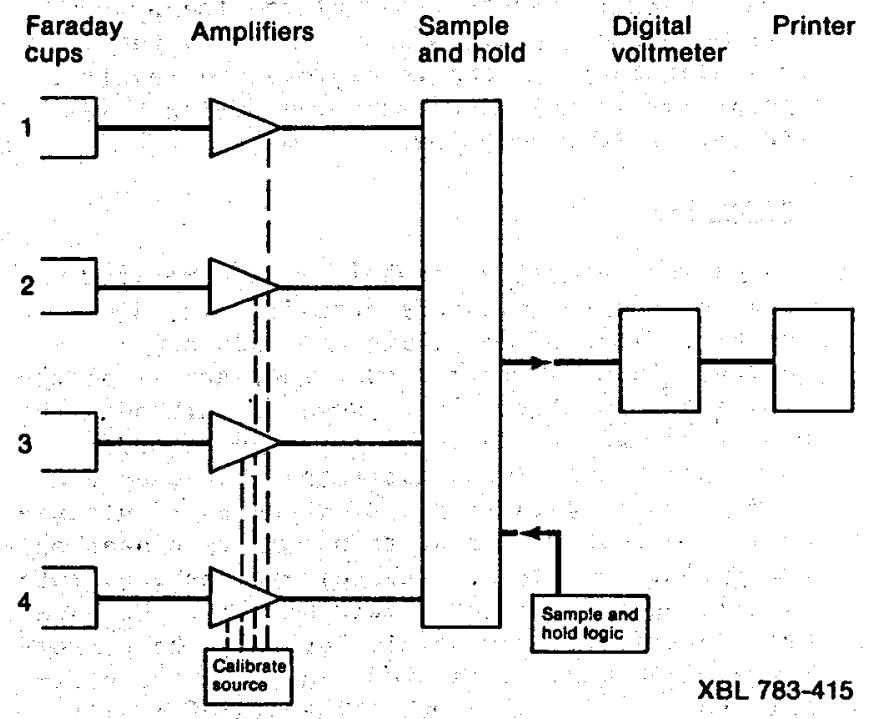

Figure 1. Block diagram of four-channe1 data system.

Calibration of the amplifier gains, made before each measurement, indicates stability of a few ppm for several days or longer, allowing one calibration per day to be sufficient. The limitation on calibration repeatability is the stability of the amplifier zero offset and averages about $\pm 4 \mu V$, almost independent of the calibration signal level. Table 1 shows the variation in the calibration of the threeamplifier system over a three-month period. As

Table 1. NBS strontium isotopic standard run on four different days.

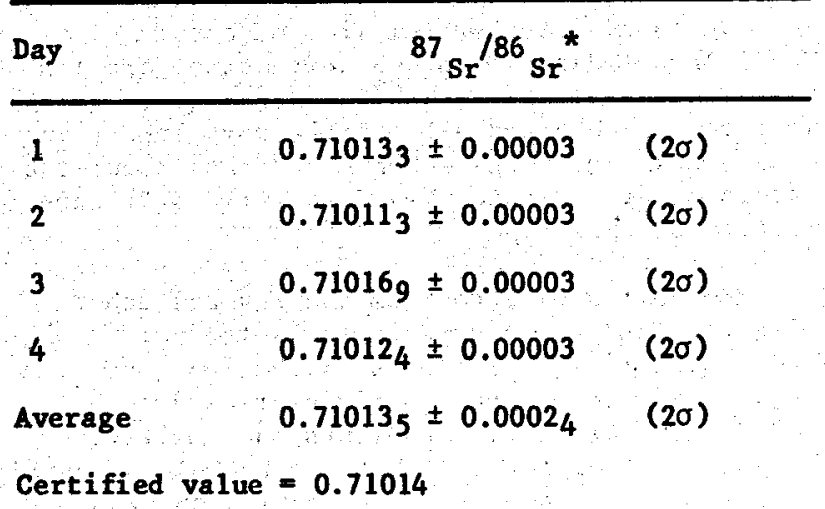

*Corrected for fractionation. 
shown in the table, the calibration will not limit the precision except to levels of one part in $10^{5}$ or less, and the use of higher calibration signals can improve this by at least a factor of three.

This three-amplifier system has been used to measure the National Bureau of Standards strontium isotopic standard to evaluate the system. Generally the results are satisfactory but much work can still be done to improve the results. The primary problems encountered during this work are discussed below.

\section{Ion Source}

As was generally recognized, thermal ion sources tend to emit ions nonuniformly, and bursts of ions of a few microseconds are comion. This is one reason simultaneous collection looks so attractive. However, although the D.C. response of the amplifiers can be made identical, there is no guarantee that they can be matched in gain at all frequencies simultaneously, so that different transient responses may and in fact do occur. Much effort has gone into minimizing this effect electronically. We have been moderately successful, but only the performance with standard samples can prove the ultimate success of this work. The use of a silica gel matrix (see below) has also helped moderate this problem.

\section{Ground Currents and Thermally Generated Voltages}

As in any system where signal levels of $\mu Y$ are significant, careful attention must be paid to eliminating these effects, mostly by painstaking trial-and-error procedures. The last remaining problem of unknown sire is a possible few- $\mu \nu$ effect on the amplifier zero offset; produced by the permanent in-vacuum wiring in the mass spectrometer vacuum probe, on which the simultaneous collector is mounted. Redesign of this part of the instrument could easily eliminate this problem, but would be moderately expensive and may not be necessary.

\section{Ion-Source Isotopic Fractionation}

A persistent problem has been the extreme range of isotopic fractionation exhibited by our ion source over the useful life of a sample. The internal-discrimination correction, applied to all data based on the ${ }^{86} \mathrm{Sr} /{ }^{88} \mathrm{Sr}$ ratio, will remove this and all other errors linear in mass. However, we have serious doubts about the precision of data that have had a $1 \%$ to $3 \%$ correction of this type.

Ionization of strontium and several other elements from a silica-gel matrix tends to reduce the time variability of the ion beam. In trying this technique sharply decreased to reduce the effect of transients on amplifier response, we discovered that the technique sharply decreased the range of fractionation observed during a sample lifetime. There are plausible explanations for such behavior, but we do not really understand it in detail. of course it is exciting to contemplate the reduction of fractionation to very low levels and the ability to make high-precision measurements on systems without an internal standard ratio.

Along with the reduction in fractionation, we observed a distinct improvement in the precision of the corrected isotopic ratios, indicating that as previously reported (Bentley et al., 1959) the fractionation may not be exactly linear in mass, and therefore not properly corrected by our linear internal standardization, unless the correction is kept quite small.

\section{Beam Focusing and Positioning}

Although our ion beams are very much narrower than the rectangular masks in front of the Faraday cups, we found a slight variation of isotope ratio with exact placement of the beam within the Faraday cup masks. This undoubtedly results from the long "tails" on the ion beams being intercepted partially and in different degrees for each isotope because of unavoidable mechanical dissimilarities of the masks. We anticipated this problem and found that 8 movable slit, much smaller than the mask (transmitting only $75 \%$ to $90 \%$ of the ion beam), allows quite reproducible focusing and positioning of the beam. In this way, only absolute differences in beam transmission (affecting absolute ratios but not precision) would be left. As might be expected, the effect of "tailing" is dependent on the effective ion-optical source in the mass spectrometer, For our system, this is the ion-source exit-hole diameter, nominally about $0.75 \mathrm{~mm}$. Decreasing the size of this hole does improve the performance of the system, but since the sample has to be introduced to the ion source through this hole, there is a practical limit to reducing the hole size much further.

\section{CONCLUSIONS}

As an example of the present precision of the system, Table 2 shows the analysis of the NBS strontium standard over the life of a single loading, measured on four different days. Each day's average is the result of many individual determinations of the isotopic ratios corrected for linear discrimination effects as discussed above. It, is clear that the precision within a day's run is quite reproducible at about four parts in $10^{5}$, but that differences of this order do occur from day to day. This run was somewhat atypical in that no trend is visible with time--the usual effect being a slight decrease of ratio with time. This may be the result of nonlinear fractionation or some other unknown effect.

With real samples, a certain amount of rubidium impurity is often present, leading to erroneously high $87 \mathrm{Sr} /{ }^{86} \mathrm{Sr}$ ratios early in the life of the sample. In principle, the fourth amplifier, reading the ${ }^{85} \mathrm{Rb}$ ion beam could be used to correct these data. However, 
Table 2. Calibration with D.C. voltage standard of all three amplifiers in data readout system. Ratios of outputs of amplifiers 1 and 2 to amplifier 3 for identical input currents.

\begin{tabular}{lll} 
Day Amp. 1/Amp. 3 & Amp. 2/Amp. 3 \\
\hline 1 & 0.999995 & 1.000011 \\
2 & 0.999977 & 0.999998 \\
3 & 0.999980 & 1.000003 \\
4 & 0.999975 & 0.999976 \\
5 & 0.999975 & 1.000011 \\
6 & 0.999996 & 1.000020 \\
7 & 0.999984 & 0.999974 \\
8 & 1.000018 & 1.000054 \\
9 & 1.000050 & 1.000009 \\
10 & 1.000007 & 0.999991 \\
11 & 1.000018 & 1.000028 \\
12 & 1.000030 & 1.000008 \\
13 & 1.000022 & 1.000027 \\
Avg & 1.000002 & 0.000013 \\
& & $1.000008 \pm 0.000012$
\end{tabular}

Note: all errors are $2 \sigma$.

because the ions result partly from diffusion from solid materials and are even more prone to sharp bursts, this is not very effective. In addition, the correct isotope ratio to be used for rubidium is unknown to at least 17 or $2 \pi$. This restricts the correction to very small amounts of rubidium indeed, and makes the rubidium content critical in determining the precision with which the ratios can be measured.
PLANNED WORK IN FISCAL YEAR 1979

The primary activity in fiscal year 1979 will be to determine the reliability and precision of the system with both standards and real samples. We will pay particular attention to eliminating the effects of rubidium contamination, beam tailing, and fractionation on the precision of the data. Work on further decreasing the total fractionation during sample life will also receive emphasis, especially the use of dispersing agents other than silica gel to reduce fractionation and smooth the ion output.

We are confident that significant improvements in precision will result from increased experience with the system, as is the case with many new techniques.

\section{REFERENCES CITED}

Bentley, P. G., Blshop, J., Davidson, D. F., and Evans, P. B. F., 1959, Isotople analysts of 11thium by mass spectrometry. Jour. Sc1. Inst., $v, 36, \mathrm{pp}, 32-34$.

Carter, S. R., Evensen, N. M., Hamilton, P. J., and o'Nlons, R. K., 1978. Neodymium strontium lsotope evidence for crystal contamination of continental volcanics. Sclence, v. 202, pp. 743-747.

Michel, M. C., 1978. High-precision mass spectrometry, in Earth Sciences Division annual report $\overline{1977}$. Berkeley, Lawrence Berkeley Laboratory, LBL-7028, pp. 34-36.

\title{
DETERMINATION OF THE PROPERTIES OF SOILS BY IN-SITU MEASUREMENTS
}

\author{
W. C. B. Villet and J. K. Mitchell
}

\section{INTRODUCTION}

Accurate identification and characterization of subsurface conditions are essential for successful geotechnical design and construction. Reliable information on geologic conditions in general, and specific geotechnical parameters in particular, is required for the design of foundations on and in the ground, for the design of safe slopes, and for the analysis of problems related to the use of underground space. These problems include storage and extraction of energy, as well as groundwater pollution that may be caused by either injection or removal of fluids.

Site investigation to determine the required geotechnical parameters in a completely unknown area consists of a number of steps. - The first step is developing a rough geologic model by mapping local geologic surface features as well as interpreting geologic maps (when available) and perhaps aerial photographs. Depending on the magnitude of the proposed project, it may be economically feasible to improve this initial mode 1 by preliminary drilling and/or indirect measurements such as, seismic-refraction surveying. A detailed investigation program can then be planned, including the number, type, size, location, and approximate depth of boreholes; the kinds and location of samples, and the types and locations of tests. It is always imperative that such a final program remain flexible enough to be tailored to unexpected geologic conditions. Economic constraints normally limit the detail with which such investigations may be carried out.

Geotechical investigation of soils is complicated by the fact that 8 and and clay properties have traditionally been evaluated in rather different ways: sands, by means of the socalled standard penetration test, and clays by laboratory testing of "undisturbed" samples. 
There exist severe limitations in both approaches. Standard penetration test results are very dependent on the exact equipment and testing procedures (which are not really "standard"). For clays, limitations are imposed by sample disturbance, changes in sample properties due to unloading and exposure, and the difficulties associated with retaining (or reestablishing) in the laboratory, the in-situ state of stress, temperature, and chemical and biological environments: Furthermore, if a 8011 layer of either type is drilled through, an additional borehole may be needed if tests are required in that layer. The above limitations have become particularly evident as the volume of offshore and underground construction has increased. The need for reliable techniques for the in-situ determination of the engineering properties of soils has, therefore, emerged as one of the most important geotechnical problems of the present time.

This research project, initiated in spring 1976, is concerned with the identification, development, and implementation of new and promising approaches for in-situ measurement of soil properties. A closely related objective has been the evaluation of presently available techniques.

\section{ACCOMPLISHMENTS IN IISCAL YEAR 1978}

Emphasis in the research project to date has been on evaluating existing techniques, and developing a new testing approach based on the analysis of acoustic emissions generated during the penetration of a soil layer by a rigid object.

Planned activities for 1978 were: (a) to publish a state-of-the-art report on in-situ measurement of soil properties by means of direct tests; (b) to study and evaluate the suitsbility and potential of remote sensing and geophysical techniques to provide data from which quantitative assessments of the mechanical properties of soils may be made; and (c) to study acoustical measurements during quasistatic cone penetration tests as a basis for determining soil types and properties. This latter study was separated from the LBL activity on March 1, 1978, when a substantial grant was received from the National Science Foundation for intensive research on the subject.

During fiscal year 1978, Mitchell et al. (1978) published a report entitled "The Measurement of Soil Properties In-Situ." This report presents: (a) a description of existing in-situ testing techniques and equipment; (b) their associated evaluation theories and correlations for obtaining geotechnical parameters; (c) an assessment of the current suitability of each method for determining specific geotechnical parameters; and (d) their potential for future development. The report is concerned with the following testing techniques:
1. Permeability tests by pump-in or -out methods, and by piezometer methods, employing both steady-state and transient techniques

2. The standard penetration test

3. Cone penetration tests of various kinds

4. The vane shear test

5. The Iowa borehole shear test

6. The pressure meter test

7. Plate bearing tests

8. Screw plate tests

9. Hydraulic fracturing tests

10. Down-hole and cross-hole seismic tests

The suitability of each test type is discussed in chapters dealing with permeability, shear strength, in-situ state of stress, and deformation constants. Extensive references are listed. The report should serve as a definitive starting point for anyone interested in the subject.

Several less direct techniques for determining soil properties and characterizing sites are still being studied. These predominantly. involve geophysical techniques, and include: seismic methods, including refraction, reflectlon, down-hole and cross-hole surveys; resistivity surveys, including focused probes; gravimetric, magnetic, nuclear, radar, electromagnetic, spontaneous potential, and thermometric methods; and remote-sensing techniques such as GEOSAT.

As a result of these studies, a report is being prepared that will present the theory of each technique briefly, describe testing methods and evaluation theory, assess the current suitability of each technique for determining geotechnical properties quantitatively, and assess their potential for future development. This report will serve as a guide to what is currently available and feasible, and should be a stimulus for future research.

The research project progressed much as planned for fiscal year 1978, except that the report dealing with remote-measuring techniques has not yet been completed. This delay is the result of the immense wealth of information that must be reviewed and evaluated. The report should, however, be completed in the coming year.

\section{PLANNED ACTIVITIES FOR FISCAL YEAR 1979}

Additional support for this project will not be available for fiscal year 1979. 
REFERENCE

Mitche11, J. K., Guzikowski, F. J., and Villet, W. C. B., 1978. The measurement of $80 \mathrm{il}$ properties in-situ, present methods - the ir applicability and potential. Berkeley, Lawrence Berkeley Laboratory, LBL-6363.

\section{STATISTICAL ANALYSIS OF THE CORRELATION OF EARTHQUAKES WITH RADON CONCENTRATION IN WATER FROM SHALLOW WELLS NEAR OROVILLE, CALIFORNIA B. Berlin}

\section{INTRODUCTION}

This report is an account of work performed from June 20 to September 25,1978 , funded by Lawrence Berkeley Laboratory Director's Development funds. This work is part of an investigation to determine whether a statistical relationship exists between varying radon concentration in well waters and the occurrence of nearby earthquakes. If such a dependence is verified, then certain patterns of changing radon activity may be useful for predicting earthquakes .

Radon concentration in two water we11s near Oroville, California, the Prosise and the Gilley we 118, were compared with periodic aftershocks of the August 1, 1975, Oroville earthquake for a pertod of about 600 days. The data are consistent with data being generated from a distribution of: (a) all nolse, or; (b) long-term selsmic fluctuations correlated with changes in the Prosise well, or short-term selsmic fluctuations with changes in the Gilley well, or both. In both cases, the dependence must be expressed with different equations in different directions from the we11s. A1so the data are inconsistent with data being generated from a distribution where the dependence between seismic activity and radon activity is very strong in all directions.

\section{DATA COLLECTION}

The collection of radon data started a few days after the August 1,1975 , Oroville (California) earthquake of magnitude 6 on the Richter scale, and so coincides with the series of aftershocks. Sampling consisted of filling a pair of 500-ml-capacity polyethylene bottles at the wellhead, sealing them immediately against gas 1088 , transporting them to LBL within a few days of collection time, and making direct measurement of the radon content of the water by low-level gamma-ray spectrometry at the LBL Low Backg round Counting Facility.

One sample per day was collected from each of six wells in the region of aftershock occurrence, including wells drilled into poorly consolidated sediments and into bedrock formations. The location of these we $11 \mathrm{~s}$ is given in Figure 1. Subsequent experience showed that only bedrock wells showed a significant radon variation. Sampling at other wells was then curtailed, and our efforts were concentrated on acquiring detailed data from three bedrock wells. The shallowest of these (the Norman we11, 65-ft deep) is belleved to have suffered occasiona1 Invaston of Irrigation water applied to nearby pasture land. Data from this well are therefore of questionable value. Data from the two remaining bedrock wells (the Gilley and Prosise wells, each about 200-ft deep and dedicated to domestic use only) cover the time from August 12, 1975, to April 6, 1977-a stretch of 604 days. For each of these wells, there are fewer than 10 days of missing observations. Values were simulated for the missing days by 11near or cubic interpolation from neighboring values. Typical data obtained from the Gilley and Prosise wells are illustrated in Figure 2.

The seismic data include earthquake time (to the second), epicenter coordinates, depth, and Richter magnitude. This information was obtained from lists compiled by the California State Department of Water Resources (SWR), Sacramento, California, and the United States Geological Survey National Center for Earthquake Research (USGS), Menlo Park, California.

\section{STATISTICAL ANALYSIS}

The objective is to measure the extent to which variations in the earthquake process (time, magnitude, distance from wells) are correlated with changes in radon activity. The technique used is described in detail by Brillinger (1975). A more elementary introduction to this topic is given by Kendall (1973).

\section{NOTATION AND MODEL}

Time is discretized in days. That is, both radon sampling times and earthquake event times are truncated to the nearest day. The days are numbered: $t=1,2,3, \ldots . . N=600$. The number of days studied, 600 , was chosen because computations involved in the analysis are much less time-consuming when $N$ can be factored in many small primes $\left(600=2^{3} .3 .5^{2}\right)$.

Earthquake data are thought of as the dependent variable where: $Y_{1}(t)=1$ if an earthquake occurs on day $t$, and where $Y_{1}(t)=0$, if not: It would have been very desirable to deal simultaneously with the epicenter-we 11 distance, thus: $Y_{2}(t)=$ $1 /$ distance, if the earthquake occurs on day $t$, 


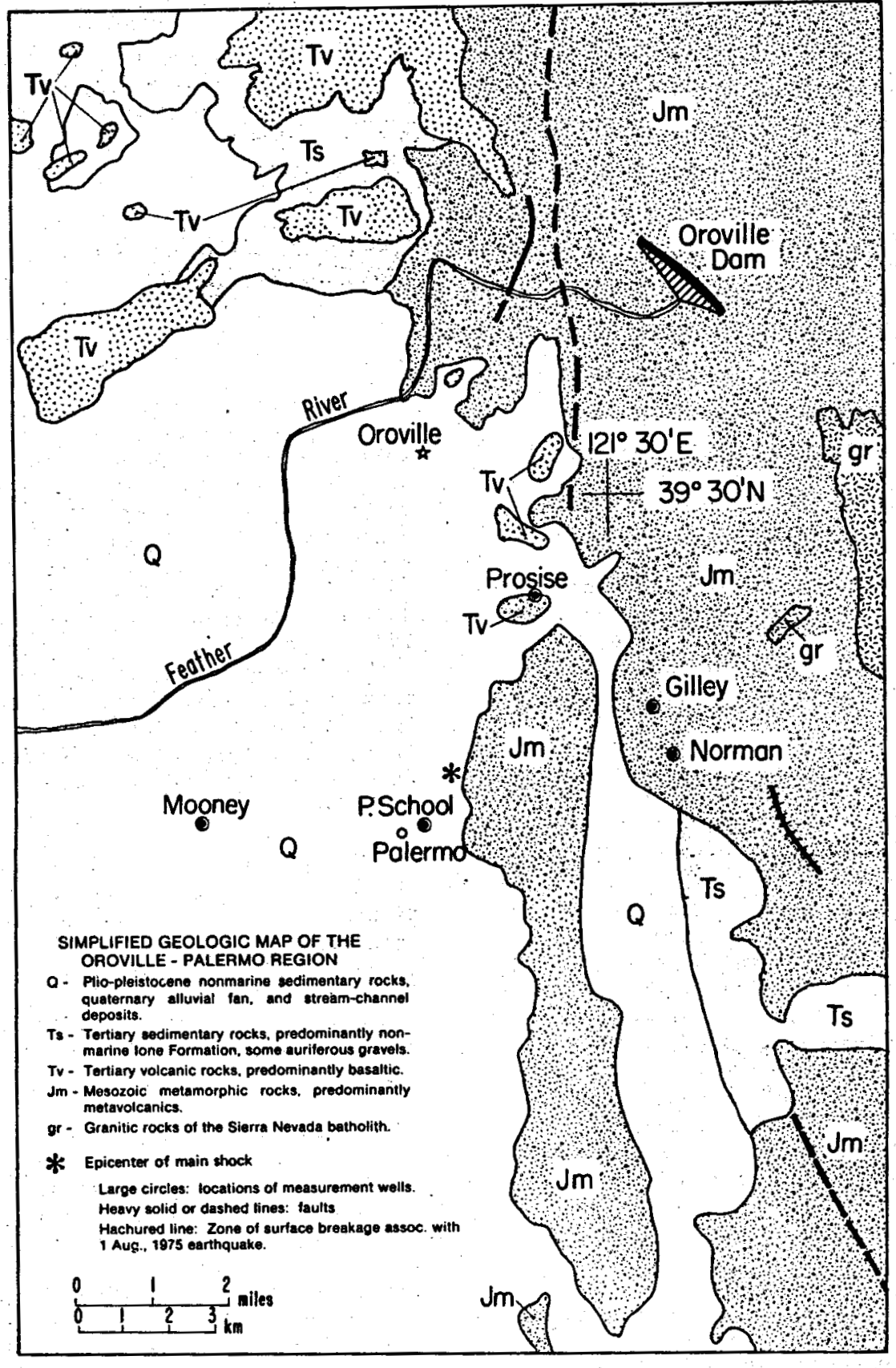

XBL $775-956$

Figure 1. Simplified map of the Oroville, California, area, showing surface geology and the locations of sampled wells in relation to the August 1, 1975, earthquake.

and $Y_{2}(t)=0$, if not. However, problem arises here because $Y_{2}=0$ usually means that there was no earthquake. In the sssumed model, $Y_{2}=0$ is confused with having a very distant earthquake; therefore, $Y_{2}$ is not used.

The appropriate model for simultaneous analysis of occurrence, location, and magnitude is a marked-point process in which the distribution of the location and magnitude is defined only when earthquake occurs.
Well data are the independent variable where:

$X_{1}(t)=$ radon activity in Prosise on day $t$

$X_{2}(t)=$ radon activity in Gilley on day $t$;

Many subsets of earthquakes have been fitted to models of the following type:

$Y(t)=Y_{1}(t)$, and $X(t)=\left[X_{1}(t), X_{2}(t)\right]$. 


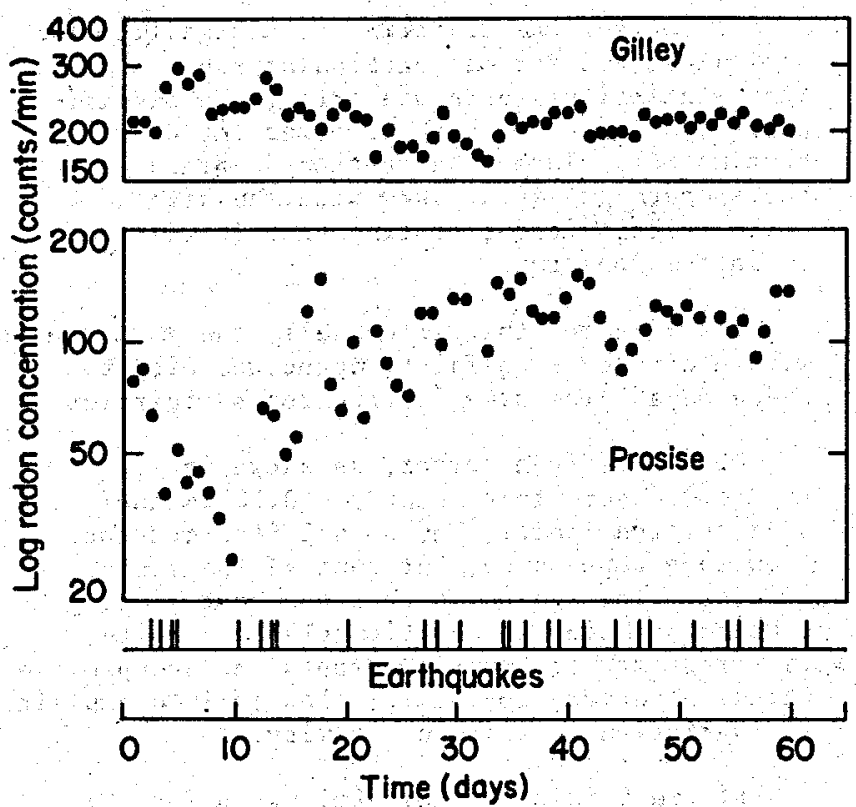

XBL $794-1239$

Figure 2. Typical data from the Gilley and Prosise wells for the period October to November 1975, showing daily radon activity and the occurrence times for all earthquakes with magnitudes greater than $\sim 2$ on the Richter scale.

These are assumed to be stationary time series. Therefore, we can conclude the following.

The expected values of $Y(t)$ and $X(t)$ remain constant in time, so that fluctuations are observed to occur about a fixed mean Ievel. This is, strictly speaking, false. Both the seismic activity and the radon measurements in the two we11s show trends. Linear components of all trends have been removed as a first step to treat the data. Although the rate of seismic events decreases, as during the time interval studied, radon activity in the Prosise well shows a positive trend and for the Gilley we 11 it is negative. The change in average radon level is considerable. The Prosise radon level is $40 \%$ higher toward the end of the 600-day period compared with the begining; for the Gilley well the decrease is also $40 \%$ over the same time period. The removal of such a trend is a concession that only changes can be analyzed, for which several cycles are observed in the 600 days available.

Any dependence within and between processes relates only to the length of time between the two points considered, rather than to the ir absolute location on the time scale. Thus, February and April of 1976 are assumed to be as strongly related as September and November of 1977 (two months apart in both cases).

These assumptions are expressed in terms of the covariances:

$\operatorname{Cov}\left[X_{i}(t), X_{j}(t+u)\right]=c x_{i}, X_{j}(u)$

for $a 11 t, i, j=1,2$

$$
\begin{aligned}
& \operatorname{Cov}[Y(t), Y(t+u)]=C_{Y Y}(u) \\
& \text { for all } t, 1, j=1,2 \\
& \operatorname{Cov}\left[Y(t), X_{j}(t+u)\right]=C_{X_{j} Y}(u) \\
& \quad \text { for all } t, i, j=1,2
\end{aligned}
$$
linear:

The model commonly used to relate $Y$ and $X$ is

$$
Y(t)=\mu+\sum_{\mu=-\infty}^{+\infty} \underline{a}(u) \underline{X}(t-u)+\varepsilon(t)
$$

meaning that the probability of an earthquake on day $t$, given a particular pattern of $\underline{X}$ around $t$, is:

$$
\mu+\sum_{\mu=-\infty}^{+\infty} a(u) \underline{x}(t-u)
$$

Here, $\mu$ is the long-term probability of an earthquake, and $a(u)$ is a function of the time lag $u$. For each $u=0, \pm 1, \pm 2, \ldots, a(u)$ is $a$ vector with two elements of unknown constants and $\varepsilon(t)$ is the error series, which also is stationary. If the variations in $Y$ are well accounted for by equation (1) for some values of $\mu$ and $g(u)$, then the variation in $\varepsilon(t)$ will be considerably less than in $Y(t)$. Note that when $u$ is allowed to assume values smaller than zero, the future of $X$ (beyond $t$ ) is involved, so a good fit for equation (1) does not necessarily imply that a prediction based on past $X$ only will be success ful.

Equation (1) is reminiscent of multiple linear regression, but here observations are correlated even when they are made at different times. This complicates the analysis quite a bit; statisticians prefer to work with Fourier transforms of the series and their covariance functions because it is much easier to derive criteria to check if any patterns in the data are statistically significant, that is, if they are unlikely to have arisen only from random noise. In the covariance functions given above, dependence is described for observations $u$ days apart. The Fourier transforms of these functions te 11 the same message, but the argument is a frequency $\lambda$, rather than the time $18 g \mathrm{u}$. In Fourier analysis, the time series is decomposed in a linear combination of many trigonometric functions (sines and cosines) of varying amplitudes. The different components have frequencies varying between 0 and $\pi$, where the highest. frequency corresponds to $u=1$, or cycles of 1 day. Here $u$ and $\lambda$ correspond to the same wave and are inversely proportional.

\section{DISCUSSION OF RESULTS}

Spectra for radon data alone reveal two things. First, the long-term variations (periods greater than 15 days) have much larger amplitude than components with periods of a few days. This phenomenon appears despite the fact that a linear trend has been removed. Second, 
the correlation between the two wells is negligible. This suggests that any effect that increased stress has on radon activity is very local. The wells are $3.7 \mathrm{~km}$ apart.

It is more difficult to find a consistent pattern in the earthquake spectra. Whereas each attempt to fit the data involves the complete set of well observations, the set of selected earthquakes changes. This is done by including al1 earthquakes within some distance of the well considered

Also, only earthquakes with a magnitude greater than 1.5 are included. For some selections, there is a tendency for the events to occur in cycles; in other cases the estimated dependence is weak, more like a Poisson process. This is a matter to which little attention has been given during this search for a relation between earthquakes and radon data. It is worth further investigation.

Finally, we considered the dependence between seismic events and radon activity. The extent to which the data fit the model (equation 1) is measured by the coherence $R_{f_{X}}(\lambda)$, a generalization of the usual correlation coefficient used in simple linear regression. For a particular $\lambda$, it measures the dependence of the trigonometric wave in earthquake occurrence (frequency) on the linear expression of radon data, $a$ in equation (1).

Looking first at the vicinity of the Prosise we 11, a 11 earthquakes were picked within radii of 2, 3 , and $4 \mathrm{~km}$. In each case, the estimated coherence was low enough to be consistent with no dependence at all. Thereafter, semicircles and quadrants were tried with $3-\mathrm{km}$ radii, or a total of eight different tests. In two cases the coherence assumed significant values. These are presented in Figure 3.

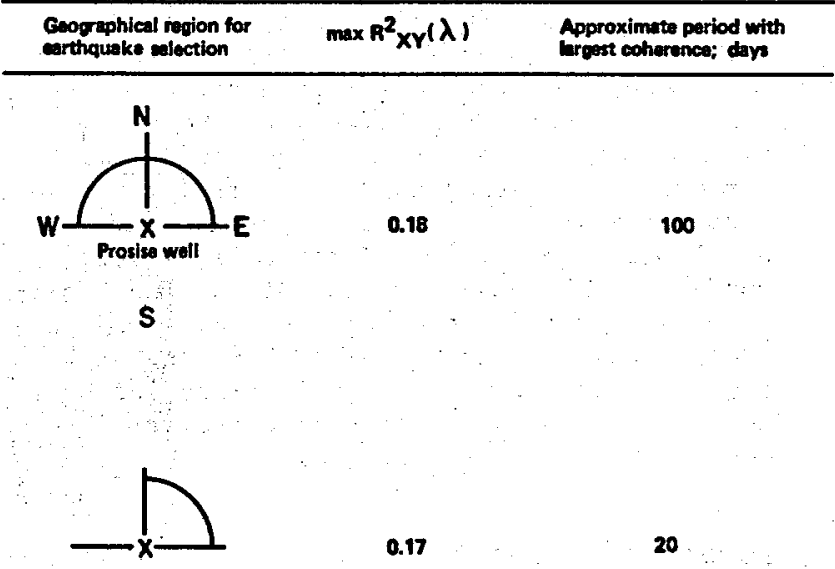

XBL $794-1240$

Figure 3. Geographical selections of selsmic events within a $3-\mathrm{km}$ radius of the Prosise well showing the correlation between seismlcity and radon activity. of course, the criteria for a significance are calculated for one particular run. Where many statistical tests are tried, the significance statements lose the ir power for drawing conclusions. Rather, attention is drawn here to the subsets of earthquakes with the highest correlation, without stating that it will hold up in the long run.

Likewise for the Gilley we11, the earthquakes within circles show faint dependence with the radon data. The same is true for semicircles.

Quadrants look better, as shown in Figure 4. Note that $R^{2} x y(\lambda)=0.16$ is the 57 rejection limit. Why do all four quadrants show some dependence, but none of the semicircles? The reason is that the best fitting constants [ $\mathrm{a}(\mathrm{u})$ in equation (1)] are quite different for the four quadrants, and compromise values necessary for semicircles fail to explain the variation in seismic activity.

Figure 5 is a plot of $a(u)$ vB. u for the four quadrant zones around the Gilley well that showed some promise with respect to coherence. The horizontal u-axis has been reversed, putting negative $u^{\prime} s$ to the right. The advantage is that the positive u's (corresponding to preceding days) will be to the left of the origin. The plots of $a(u)$ all show strong oscillations from high to low values. What does this mean? A first idea would be to reconstruct what pattern of radon changes makes the right-hand

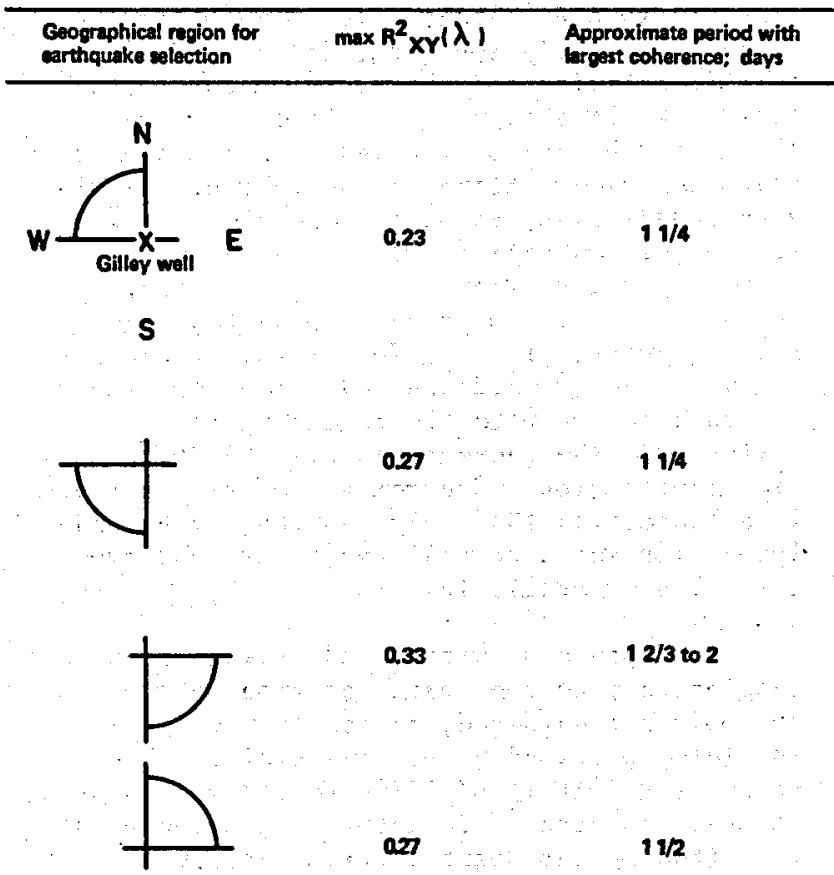

XBL 794 - 1241

Figure 4. Geographical selections of selsmic events within a $3-\mathrm{km}$ radius of the Gilley well showing the correlation between seismicity and radon activity. 


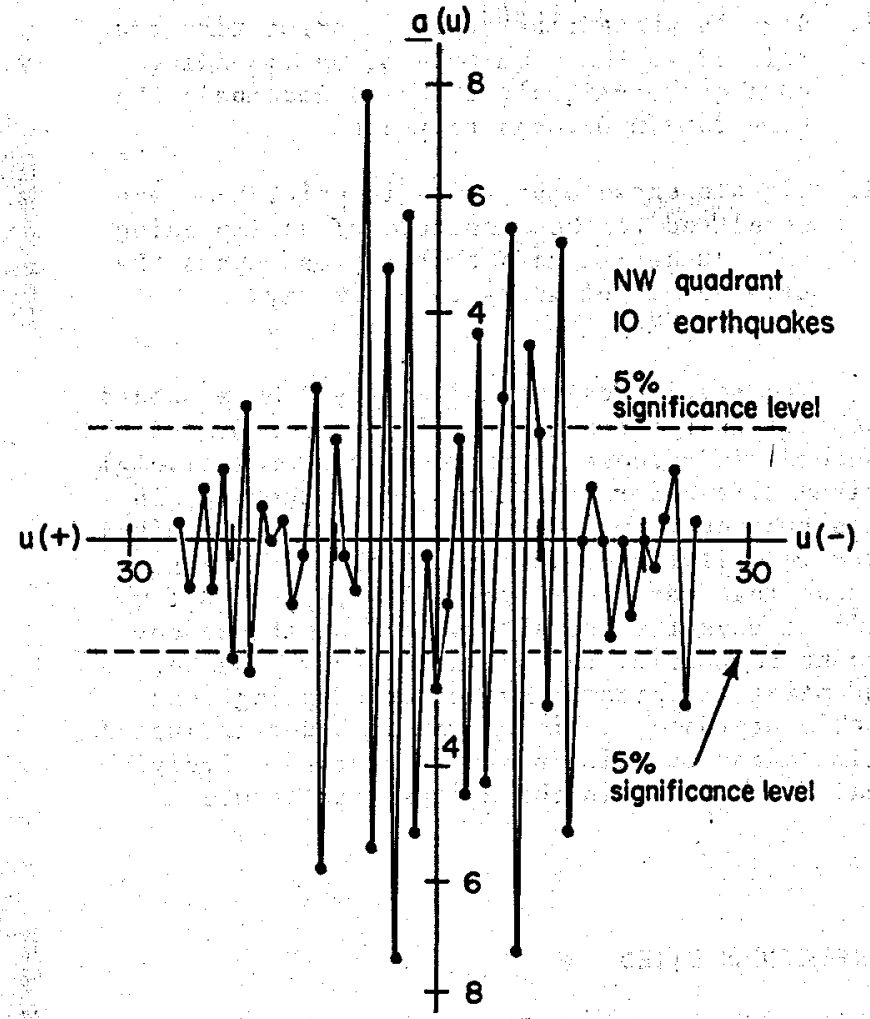

XEL $794-1243$

Figure 5. Profile of values for the constant a(u) in equation ( 1$)$, computed for the $3-\mathrm{km}-$ radius quadrant northwe st of the Gilley we 11. Previous days are plotted to the left of the origin; future days, to the right. The ordinate scale is in terms of the estimated standard deviation on $a(u)$ values.

side of equation (1) large for the given estimated $a(u)$. That is, what makes the chance for an earthquake large? Also, what pattern makes the chance small?

Obviously, a day with a large positive a(u) calls for a positive radon count to contribute to a large probability. If $a(u)$ has a large negative value, the radon count should be unusually small. Therefore, a strongly oscillating radon pattern would serve as a precursor. Further, an oscillating pattern out of phase with the former type would be an "antiprecursor" and make the chance small.

However, this idea is a dead end because the radon record simply does not have any such rapid oscillations. As mentioned earlier, the variation in radon activity is dominated by slow oscillations.

A more believable interpretation of the rapid fluctuations of $a(u)$ is that the predictive effect of radon changes is very short term, about 1 to 2 days.

From the point of view of earthquake prediction, the long-term variations with large amplitude are noise that must be filtered away by the coefficients $\underline{a}(u)$. This is actually achieved with high and 1 ow a(u) following each other.

An object for further investigation is to st udy the quickly varying radon signal that remains after filtering, which actually serves as a precursor.

The combined predictive ability for the two wells was also tried by selecting earthquakes within ellipses that had the wells as foci, as illustrated in Figure $6(\mathrm{a})$.

As expected from the weak dependence of the two radon series, it turned out that for these subsets, the Prosise well had negligible dependence with the earthquakes, while the largest coherence observed so far occurred between the

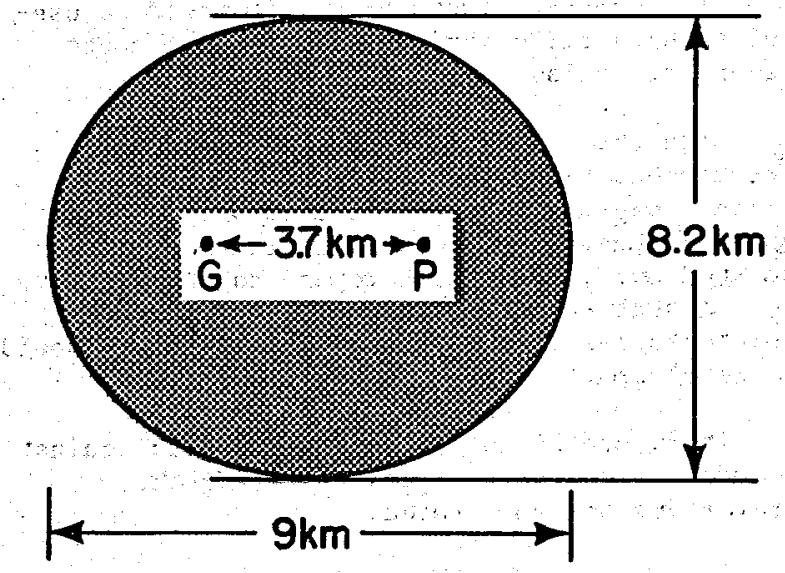

(a)

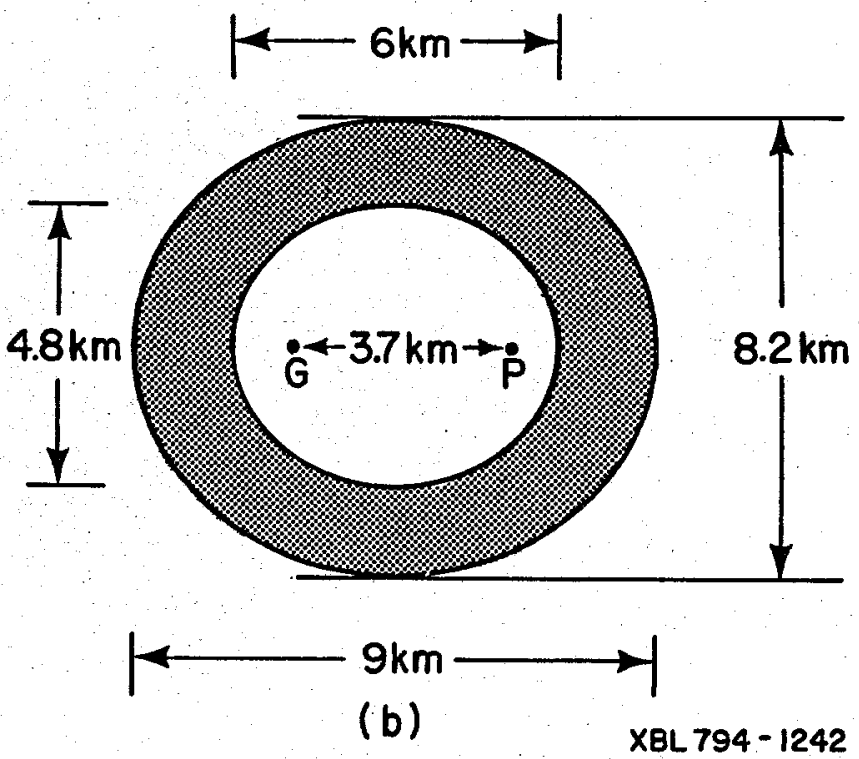

Figure 6. Configurations to test the combined predictive ability for Prosise and Gilley wells (shaded areas indicate regions in which earthquakes occurred). 
Gilley well and the earthquakes. Ellipses of different sizes were tried and the fit improves further if an inner ellipse is excluded, as shown in Figure $6(\mathrm{~b})$.

Further work should be done to identify a more reasonable looking zone where the Gilley we 11 is sensitive. The substantial coherence appeared at a frequency corresponding to a period of $2-1 / 2$ days.

\section{RECOMENDATIONS}

To put the above inconclusive findings to a test, we recommend the following.

More data are needed, particularly from the Gilley we11, which appears most promising. In the present data, the radon samples are not exactly 24 hours apart; they were taken at different times in the afternoon. To check the one- to four-day fluctuations, it would be useful to have radon activity recorded at exact 12-hr intervals.

With the statistical methods used here (cpntinuous time series) there is no satisfactory way to take epicenter-to-weil distance and magnitude into account simultaneously, as pointed out earlier with regard to the variable $\mathrm{Y}_{2}$. A statistical method relating a markedpoint process to a continuous time series should be developed.

It is useful to test the radon data against a model in which two types of earthquake precursors are postulated:
1. Signals whose appearance in prior-țime are related to the magnitude of an impending earthquake-signsis that may encompass the time domain of days to years

2. Signals whose appearance in prior-time are unrelated to the magnitude of an impending earthquake-signals that may encompass the time domain of hours to a few days (foreshocks)

The statistical method employed here should be well suited for identifying precursors of the second kind-those that occur at a (relatively) fixed time before an earthquake. However, in its present form, the method is not wel1 suited for identifying precursors of the first kindthose that may occur over a few days to a few $10 \mathrm{~s}$ of days for the aftershock magnitudes encountered during the Oroville study. Hence, adapting the present method or adopting some other approach, is important in order to include time/magnitude/distance parameters for individual earthquakes in the analysis procedure.

\section{REFERENCES CITED}

Brillinger, D. R., 1975. Time series, data analysis, and theory. New York, Holt, Rinehart and Winston.

Kenda 11, M. G., 1973. Time series. New York, Griffin. 